\title{
1 TRIM25 and ZAP target the Ebola virus ribonucleoprotein complex to mediate interferon-
}

2 induced restriction

3

4 Rui Pedro Galão ${ }^{1,5,6}$, Harry Wilson ${ }^{1,5}$, Kristina L Schierhorn ${ }^{1}$, Franka Debeljak ${ }^{1}$, Bianca S Bodmer ${ }^{2}$,

5 Daniel Goldhill ${ }^{3}$, Thomas Hoenen ${ }^{2}$, Sam J Wilson $^{4}$, Chad M Swanson ${ }^{1}$ and Stuart J D Neil ${ }^{1,6}$

6 1: Department of Infectious Diseases, School of Immunology and Microbial Sciences, King's College

7 London, UK

8 2: Institute for Molecular Virology and Cell Biology, Friedrich-Loeffler-Institut, Greifswald, Germany

9 3: Section of Virology, Department of Medicine, Imperial College London, London, UK.

10 4: MRC Centre for Virus Research, University of Glasgow, UK

115 : These authors contributed equally to this work

12 6: Corresponding authors: stuart.neil@kcl.ac.uk; rui pedro.galao@kcl.ac.uk

13

18 Running title: TRIM25 and ZAP target the EBOV vRNP

19 
bioRxiv preprint doi: https://doi.org/10.1101/2021.05.23.445113; this version posted May 24, 2021. The copyright holder for this preprint (which

was not certified by peer review) is the author/funder, who has granted bioRxiv a license to display the preprint in perpetuity. It is made available under aCC-BY-NC-ND 4.0 International license.

\section{Highlights}

- TRIM25 and ZAP play a major role on type I IFN-mediated inhibition of EBOV trVLP

23 replication

24 - TRIM25 interacts with the EBOV NP and is recruited to vRNPs in the cytoplasm after viral

25 entry

26 - TRIM25 ubiquitinates NP and displaces it from the viral genome, facilitating ZAP interaction

27 - ZAP targets CpGs in the EBOV genome to inhibit EBOV trVLP replication

28

29

30 


\section{Summary}

32 Ebola virus (EBOV) causes highly pathogenic disease in primates. Through screening a 33 library of human interferon-stimulated genes (ISGs), we identified TRIM25 as a potent 34 inhibitor of EBOV transcription-and-replication-competent virus-like particle (trVLP)

35 propagation. TRIM25 overexpression inhibited the accumulation of viral genomic and 36 messenger RNAs independently of the RNA sensor RIG-I or secondary proinflammatory

37 gene expression. Deletion of TRIM25 strongly attenuated the sensitivity of trVLPs to 38 inhibition by type-I interferon. The antiviral activity of TRIM25 required ZAP and the effect of 39 type-I interferon was modulated by the $\mathrm{CpG}$ dinucleotide content of the viral genome. We

40 find that TRIM25 interacts with the EBOV VRNP, resulting in its autoubiquitination and 41 ubiquitination of the viral nucleoprotein (NP). TRIM25 is recruited to incoming vRNPs shortly 42 after cell entry, and leads to dissociation of NP from the vRNA. We propose that TRIM25

43 targets the EBOV vRNP, exposing CpG-rich viral RNA species to restriction by ZAP.

46 Keywords: Ebola virus, type I interferon, TRIM25, ZAP 


\section{Introduction}

Type I interferons (IFN-I) are released as part of the innate immune response to viruses and induce the expression of an array of genes, many of which have direct antiviral activity (McNab et al., 2015; Schoggins et al., 2011). These proteins often target conserved structures or fundamental processes common to the replication of diverse viruses that cannot be avoided by simple point mutations in a given viral protein (Schneider et al., 2014). In turn, viruses encode mechanisms to inhibit either the detection of virally-expressed pathogen associated microbial patterns (PAMPs) by pattern recognition receptors (PRR), or the signalling through the IFN-I receptor complex (IFNAR1/2). These strategies are essential for efficient in vivo viral propagation and pathogenesis (Basler, 2015; Beachboard and Horner, 2016). However, viral evasion from innate immune responses is generally incomplete; acute viral infections are characterized by local and systemic IFN-I responses, and most viruses exhibit some degree of sensitivity to interferon treatment in their target cell types. Understanding the mechanisms by which IFN-I exerts its antiviral effects not only yields new understanding of how mammals have evolved to defend themselves against viral pathogens, but also reveals areas of vulnerability in virus replication that may be exploited therapeutically.

Ebola virus (EBOV, species Zaire ebolavirus) is the prototypic member of the ebolavirus genus of the Filoviridae, a family of filamentous enveloped non-segmented negative strand RNA viruses responsible for sporadic outbreaks in sub-Saharan Africa (Messaoudi et al., 2015). Ebola virus disease (EVD) is characterized by its high mortality rate (25\%-90\%), with symptoms including severe fever, vomiting, diarrhoea, that in some cases progress to haemorrhagic fever (Geisbert et al., 2003b). EBOV and other filoviruses are zoonotic infections in man, probably transmitted from bat species (Amman et al., 2014; Leroy et al., 2005), and are spread from person to person by close contact with bodily fluids (Vetter et al., 2016). Individuals that recover from EVD can harbour persistent virus, and men can shed infectious EBOV in the semen for many months after viremia becomes undetectable (Deen et al., 2017; Subissi et al., 2018; Thorson et al., 2021).

EBOV replicates in various tissues but is thought to primarily infect cells of the myeloid lineage (Geisbert et al., 2003a). After uptake by macropinocytosis, the virion membrane fuses with the host endosome following the interaction between a proteolytically processed form of its glycoprotein (GP) and the cellular receptor, NPC1 (Carette et al., 2011; Chandran et al., 2005; Cote et al., 2011). Fusion releases the viral genome into the cytoplasm, allowing the initiation of the replication cycle 
78 (Muhlberger, 2007). The viral genomic RNA (vRNA) exists as a helical ribonucleoprotein complex 79 (RNP) that contains the viral nucleoprotein (NP) and its cofactor VP35, as well as, at lower 80 concentrations, the transcriptional regulator VP30, and the viral RNA-dependent RNA polymerase L 81 (Noda et al., 2010). As with all negative-strand RNA viruses, the viral genome is first transcribed by L 82 to generate mRNAs for viral gene products. L-mediated transcription initiates only at the 3 ' leader 83 sequence of the vRNA. Viral genes are arrayed along the genome in an order correlating with their 84 abundance in the infected cell; at the intergenic boundaries between each viral gene, $L$ either 85 dissociates from the genome, or reinitiates transcription, a process regulated by VP30 (Biedenkopf et al., 2016; Muhlberger, 2007). VP30 also acts as the molecular switch to promote the synthesis of a full length positive sense copy of the RNA genome (cRNA) (Kruse et al., 2018; Biedenkopf et al., 2013). The cRNA acts as template for the production of new copies of vRNA, that are then assembled into new vRNPs within cytoplasmic inclusion bodies, which are themselves induced by vRNP components (Hoenen et al., 2012). New vRNPs are then targeted to the plasma membrane (PM) where they interact with VP40, and bud from the surface as new virions (Martin-Serrano et al., 2001; 92 Noda et al., 2002). EBOV encodes two major activities that counteract the innate immune responses. First, VP35 counteracts recognition of viral RNA species by the PRR retinoic acid induced gene I (RIG-I), as well as by playing an incompletely defined role in disabling proinflammatory signalling downstream of PRR activation (Basler et al., 2003; Cardenas et al., 2006; Chang et al., 2009; Luthra P et al., 2013; Prins et al., 2009). Second, VP24 inhibits signalling through IFNAR1/2 by blocking nucleocytoplasmic transport of phosphorylated STAT1 (Shabman et al., 2011; Zhang et al., 2012). Additionally, the virus may antagonize certain antiviral proteins directly; notably the activity of tetherin/BST2 is counteracted

100 by EBOV GP in some experimental systems (Kaletsky et al., 2009; Lopez et al., 2010). However, 101 EBOV replication can still be inhibited by pre-treatment of target cells with IFN-I, and a number of 102 ISGs have been proposed to have antiviral activities against EBOV (Huang et al., 2011; Kuroda et al., 103 2020; Okumura et al., 2008).

104 The requirement for high containment laboratories makes identifying host factors that 105 facilitate or inhibit the replication of filoviruses challenging. To identify novel EBOV antiviral proteins, 106 we used a well-established EBOV transcription- and replication-competent virus-like particle (trVLP) 107 system to screen a human ISG library (Kane et al., 2016; Watt et al., 2014). Amongst these, we 
108 identified tripartite-motif family member 25 (TRIM25) as a potent antiviral inhibitor of EBOV trVLP

109 replication. TRIM25, an E3 ubiquitin ligase, until recently widely accepted as being a positive regulator

110 of RIG-I-mediated pattern recognition of cytoplasmic viral RNA, has other emerging roles in innate

111 immunity (Gack et al., 2007; Li et al., 2017; Martin-Vicente et al., 2017). Of note, a recent study has

112 implicated nuclear forms of TRIM25 as having direct antiviral activity against the influenza A virus

113 vRNP (Meyerson et al., 2017). Furthermore, TRIM25 is an important cofactor of the zinc-finger

114 antiviral protein (ZAP, also known as ZC3HAV1 or PARP13), which broadly targets many RNA

115 viruses (Li et al., 2017; Zheng et al., 2017). Recent evidence has shown that ZAP binds to RNAs with

116 a high content of CpG dinucleotides (Chiu et al., 2018; Takata et al., 2017), targeting them for

117 degradation. How TRIM25 regulates ZAP is unknown. Although TRIM25 interacts with and

118 ubiquitinates ZAP, these events are not required for ZAP activity (Li et al., 2017; Zheng et al., 2017).

119 Here we show that TRIM25 interacts with the EBOV vRNP and induces the dissociation of NP from

120 the genomic RNA, thereby promoting CpG-dependent restriction by ZAP.

\section{Results}

123 EBOV trVLP replication is sensitive to type I interferon. The EBOV trVLP system is a reverse

124 genetics system that models the entire replication cycle of the virus without the need for high 125 containment laboratory facilities (Figure S1A)(Watt et al., 2014). trVLP stocks are produced in 126 HEK293T cells (called passage 0 (p0) cells), which are then used to infect HEK293T or U87-MG 127 target cells expressing the viral entry factor TIM-1 (passage 1 (p1) cells). Propagation of trVLPS 128 requires co-transfection of plasmids encoding the VRNP components NP, VP35, VP30 and L prior to 129 infection. trVLP replication can be measured by Renilla luciferase (Rluc) activity in lysates of target 130 cells $\mathrm{p} 1$, and by assessing infectivity of harvested $\mathrm{p} 1$ supernatants on new target TIM-1 expressing 131 HEK293T cells (passage 2 (p2) cells). p1 cells can also be used to assess the effects of exogenous 132 treatments, and over-expression or knockdown/knockout of candidate cellular factors.

133 In order to identify candidate ISGs that inhibit EBOV replication, we first tested the sensitivity 134 of trVLPs to IFN-I. HEK293T and U87-MG cells stably expressing TIM-1 were pre-treated overnight 135 with various doses of universal type-I IFN- $\alpha$ and then infected with equal doses of EBOV trVLPs. Rluc 136 activity was measured in $\mathrm{p} 1$ cells $24 \mathrm{~h}$ after infection, and trVLP yield was assessed in the 137 supernatants by infecting HEK293T-TIM1 p2 cells. IFN-I treatment of both cell types gave a robust 
138 dose-dependent inhibition of Rluc activity in $\mathrm{p} 1$ and $\mathrm{p} 2$, although trVLP replication was more sensitive

139 to IFN-I in U87-MG cells (Figure 1A). Given the distinct impact of IFN- $\alpha$ and IFN- $B$ on filoviruses

140 pathogenesis in animal models and humans (Escudero-Perez et al., 2019), we tested their

141 independent effect on EBOV trVLPs. As observed with the universal type-I IFN- $\alpha$, both IFN- $\alpha 2 a$ and

142 IFN-B1a produced a dose-dependent inhibition of EBOV trVLPs on U87-MG cells, with IFN-B1a being

143 slightly more antiviral (Figure S1B), reproducing a previously reported observation (McCarthy et al.,

144 2016). Using an EBOV VP40-Blam VLP-based entry assay, IFN-I pre-treatment of target cells

145 resulted in a minor reduction in entry of particles pseudotyped with EBOV-GP, indicating the majority

146 of the inhibition of trVLP replication was taking place post viral entry (Figure 1B). In keeping with this,

147 IFN-I treatment resulted in a dose-dependent reduction of VRNA and mRNA species in the infected

148 cells (Figure 1C), as well as concomitant reduction of new viral minigenomes in the supernatant that

149 mirrored the effects on Rluc activity (Figure 1D). Importantly, IFN-I treatment did not affect the levels

150 of the vRNP proteins expressed in trans (Figure S1C). Thus, human cells exposed to type I IFN

151 exhibit a robust inhibition of filoviral replication through the induction of one or more ISGs targeting

152 trVLP gene expression and minigenome replication.

153 A human arrayed ISG screen identifies TRIM25 as a potent inhibitor of EBOV trVLP replication

154 We then screened an expression library of 407 human ISGs individually cloned into mammalian 155 expression vectors, and measured the impact of each ISG on EBOV trVLP replication (Kane et al., 156 2016). Briefly, individual expression vectors encoding a human ISG were transfected into HEK293T-

157 TIM1 p1 cells alongside the vRNP components and a firefly luciferase (Fluc) transfection control. 24h

158 later the cells were infected with a fixed dose of trVLPs. Rluc activity was measured at the harvest of

159 supernatants $24 \mathrm{~h}$ later. Supernatant infectivity was then assessed on p2 cells as before. Negative

160 (GFP, empty vector) and positive (IRF1, BST2/tetherin) controls were included on each 96-well plate

161 and Rluc activity in both p1 and p2 cells was normalized to the activity of control Fluc within individual

162 wells and the effects of each individual gene was expressed as a percentage of the plate average

163 (Figure 1E, Table S1). Both p1 and p2 outputs of the screen were normally distributed (Figure S1D),

164 however we reasoned that outlier ISGs that directly inhibited EBOV replication should always display

165 a phenotype in p2 as well as potentially in p1, reflecting likely effects on early and/or late viral 166 replication stages. We focussed on ISGs that gave at least a 5-fold reduction of trVLP infectivity in p2, 167 and discarded any hit in $\mathrm{p} 1$ that did not carry over. The top 50 hits were validated in three 
168 independent experiments and ranked (Figure 1F). We then selected 20 of the top p2 hits from the 169 validation for further characterization. First, we examined their effects on trVLP RNA using a primers170 probe set in the VP40 gene (that detects VRNA, cRNA and VP40 mRNA) and another set in the trVLP 171 5'-trailer region (that detects vRNA and cRNA) in p1 cell lysates, as well as measuring viral RNA 172 levels in the supernatants as an indicator of released trVLP virions (Figure 1G). The majority of these 173 ISGs, with the exception of TNK2, CTCFL, HERC5 and OAS2 affected the levels of cell-associated 174 viral RNA. In addition to these, a few other ISGs had no significant impact on the viral RNA levels in 175 the supernatants (ARHGEF3, SLFN12, P2RY6 and PABPC4). Several (FFAR2, UNC93B1, APOL6, 176 SLC15A3, IFIH1 (MDA5), BST2, SLFN12 and PIM3) also reduced the expression of one or more of 177 the viral RNP components expressed in trans (Figure S1E), potentially a confounding factor. 178 Moreover, we noticed significant toxicity effects of FFAR2, C5ORF39, APOL6 and UNC93B1 179 consistent with previous reports of their proapoptotic activities (Figure S1F). Lastly, it is well known 180 that many ISGs, and particularly pattern recognition receptors, can activate proinflammatory signalling 181 pathways, indicating that antiviral activities measured could be mediated secondarily through 182 upregulation of other ISGs or interferons. We therefore screened the selected 20 hits for their abilities 183 to activate Fluc reporter genes driven by NFkB, IRF3 (ISG56/IFIT1) or IFN-induced ISGF3 (ISRE) 184 dependent promoters (Figure S1G). As expected, expression of both IFIH1 (MDA5) and IRF1 185 activated ISG56 and ISRE promoters, indicating both an IRF3 and a secondary IFN-I-dependent 186 response. IFIH1 (MDA5), FFAR2, P2YR6 and BST2 also triggered NFkB-dependent responses at 187 both $24 \mathrm{~h}$ and $48 \mathrm{~h}$. In contrast, TRIM25 only gave a detectable NFkB-dependent signal at $48 \mathrm{~h}$ (i.e. $24 \mathrm{~h}$ 188 after p1 viral harvest). Importantly, TRIM25 overexpression robustly inhibited the accumulation of 189 trVLP RNA species in p1 cells without affecting expression of vRNP components or demonstrating 190 overt toxicity (Figures 1F, S1E and S1F). Moreover, recent evidence suggests that TRIM25 inhibits 191 influenza virus independent of RIG-I (Meyerson et al., 2017). Thus, TRIM25 was one of the candidate 192 EBOV antiviral factors taken forward for further analysis.

193 TRIM25 plays a major role in IFN-I-mediated inhibition of EBOV trVLP replication and reduces

194 the abundance of viral RNA species. To further characterize the antiviral activity of TRIM25 we first 195 showed that its ectopic expression in HEK293T-based p1 cells significantly blocked trVLP Rluc 196 activity, both in these cells and subsequent carry over to p2 at increasing trVLP inputs (Figure 2A), 197 without affecting entry of EBOV-GP pseudotyped lentiviral vectors (Figure 2B). The block to trVLP 
198 replication correlated with reduced intracellular levels of viral mRNA, cRNA and vRNA, as well as

199 vRNA levels in the supernatant (Figure 2C). We then used lentiviral-based CRISPR/Cas9 vectors to

200 knockout TRIM25 in U87-MG and HEK293T cells (Figure 2D). In both cell types, TRIM25 is

201 expressed at readily detectable levels and this expression is further augmented upon IFN-I treatment.

202 Significantly, whereas IFN-I pre-treatment of control U87-MG cells carrying an irrelevant sgRNA

203 targeting E.coli LacZ gene resulted in a 20-30 fold inhibition of trVLP infectivity in p1 target cells,

204 knockout of TRIM25 significantly attenuated this block to trVLP production (Figure 2E), correlating

205 with a rescue of viral RNA species in the corresponding cell lysates and supernatants (Figure 2F).

206 Similarly, the antiviral effects of IFN- $\alpha 2 a$ or IFN-B1a on EBOV trVLPs were also attenuated on U87-

207 MG TRIM25 knockout cells (Figure 2G). Importantly, this effect of TRIM25 knockout was specific to

208 the EBOV trVLPS, as IFN-I reduced the infectivity of VSV-G-pseudotyped HIV-1-based vectors

209 equally in control sgRNA (LacZ) and knockout U87-MG cell lines (Figure 2H). Furthermore, in the

210 absence of IFN treatment, TRIM25 knockout HEK293T cells gave significantly higher Rluc activity in

211 p0 producer cells and yielded significant higher levels of virus (p1 infectivity) (Figure 2l). Thus,

212 TRIM25 restricts trVLP production, and is an important component for the IFN-induced antiviral

213 restriction of EBOV.

214 TRIM25-mediated restriction of EBOV requires components of the cytoplasmic RNA pattern

215 recognition machinery, but not proinflammatory signal transduction. The best characterized role

216 of TRIM25 is as a cofactor of the cytoplasmic RNA sensor RIG-I (Gack et al., 2007). TRIM25 and/or

217 Riplet mediate Lys63-linked polyubiquitination of RIG-I and promote the binding of this PRR to viral

218 RNAs and its interaction with the full-length (FL) mitochondrial antiviral protein (MAVS) isoform. This

219 is essential for the propagation of proinflammatory signalling downstream of RIG-I and its related 220 helicases (Loo and Gale, 2011). We therefore used CRISPR/Cas9 to delete both RIG-I and MAVS in 221 HEK293T and U87-MG cells (Figure 3A and B). Whilst RIG-I expression is only detectable after IFN222 treatment of the control sgRNA cells (LacZ), FL-MAVS and a shorter isoform known as miniMAVS 223 (Brubaker et al., 2014) are readily detected in both cell lines at steady state. Both isoforms are 224 expressed as alternative translation products from the same mRNA. miniMAVS localizes and interacts 225 with FL-MAVS, but having no CARD domains, cannot interact with RIG-like helicases and activate 226 antiviral signal. Moreover, its interference with FL-MAVS activity has suggested it as a negative 227 regulator of RNA sensing (Brubaker et al., 2014). We designed sgRNA guides that would target exons 
228 upstream or downstream of the miniMAVS start codon and thus generated FL-MAVS knockout, or FL-

229 MAVS and miniMAVS double-knockout cells (DKO). We then examined the effects of these

230 knockouts on the antiviral activity of ectopically expressed TRIM25. Whilst TRIM25 retained antiviral

231 activity when overexpressed in RIG-I knockout cells it lost this activity in FL-MAVS/miniMAVS double-

232 knockout cells (Figure 3C). Furthermore, there was no effect of RIG-I knock-out on the sensitivity of

233 trVLPs to IFN-I in U87-MG cells (Figure 3D). By contrast, trVLP replication was significantly rescued

234 from IFN-I antiviral effect in FL-MAVS/miniMAVS DKO cells, with FL-MAVS alone KO presenting only

235 a partial rescue (Figure 3E). To clarify the potential requirement of each MAVS isoform for the

236 antiviral activity of ectopically expressed TRIM25, we performed rescue experiments in which the

237 expression of miniMAVS and/or FL-MAVS was stably reconstituted in HEK293T MAVS DKO cells

238 (Figure 3F). The antiviral effect of TRIM25 against EBOV trVLP was rescued by the simultaneous

239 reintroduction of CRISPR-resistant forms of miniMAVS and FL-MAVS (MAVS ${ }^{\mathrm{CR}}$ ), whilst still

240 significantly attenuated when FL-MAVS $\left(M 142 A^{C R}\right)$ or miniMAVS $\left(M 1 A^{C R}\right)$ were expressed separately

241 (Figure 3G). Thus, the TRIM25 and IFN-I antiviral activities against EBOV trVLPs required both

242 signalling active and inactive MAVS isoforms, but not RIG-I, suggesting a mechanism distinct from

243 classical RLR signalling. To further rule out classical RNA sensing as the mechanism, we knocked out

244 TBK1, which is the essential kinase downstream of MAVS for IFN and ISG induction (Figure 3H). As

245 with RIG-I knockout, depletion of TBK1 did not affect TRIM25- or IFN-I-mediated inhibition of trVLP

246 replication (Figures 3I and 3J). Moreover, TRIM25 overexpression in all knockout cell lines induced

247 indistinguishable NFKB-dependent reporter activity at $48 \mathrm{~h}$ irrespective of its antiviral effect, arguing

248 against an indirect role of TRIM25-mediated signalling (Figure 3K). Taken together, these data

249 indicate that the TRIM25/IFN-I-dependent antiviral restriction of EBOV trVLP replication requires both

250 MAVS isoforms, but is independent of the proinflammatory signal generated by classical cytoplasmic

251 RLR sensing.

252 Potent IFN-mediated inhibition of EBOV trVLP propagation requires ZAP and is modulated by

253 CpG content of the viral genome. TRIM25 has been implicated in the regulation of ZAP, which has

254 antiviral activity against numerous mammalian RNA viruses (Bick et al., 2003; Gao et al., 2002; Li et

255 al., 2017; Zheng et al., 2017). ZAP is expressed as long (L) and short (S) splice variants, the latter

256 lacking the catalytically inactive PARP-like domain (Kerns et al., 2008). ZAP-L has more potent

257 antiviral activities against some viruses and has a stronger interaction with TRIM25 than ZAP-S 
258 (Charron et al., 2013; Goodier et al., 2015; Kerns et al., 2008; Li et al., 2017). Whilst ZAP-S is the 259 major IFN-regulated isoform (Goodier et al., 2015; Hayakawa et al., 2011) and was included in our 260 ISG screen, it did not score as a hit. By contrast, however, overexpression of ZAP-L had a potent 261 antiviral activity against EBOV trVLP replication in HEK293T-TIM1 p1 and p2 cells, which manifested 262 as significant reductions in viral mRNA, vRNA and cRNA species (Figures 4A and S2A). We then 263 generated HEK293T and U87-MG ZAP CRISPR knockout cells (Figure 4B), and found that like 264 TRIM25 knockout cells, they exhibited a significantly reduced restriction of trVLP replication and viral 265 RNA accumulation after pre-treatment with IFN-I (Figures 4C and 4D). We also observed an 266 attenuated effect of IFN- $\alpha 2 a$ and IFN-B1b on trVLP propagation (Figure S2B) and increased viral 267 yields from p0 cells (Figure S2C). Furthermore, ZAP and TRIM25 interdependence was confirmed by 268 showing that the antiviral effect conferred by their individual overexpression was abolished in cells lacking the other gene (Figure 4E). In contrast, while we could confirm the report (Meyerson et al.,

270 2017) that overexpression of TRIM25 targets the influenza vRNP, the magnitude of this activity was unaffected by ZAP knockout (Figure S2D).

272 ZAP has previously been shown to inhibit the expression of EBOV proteins (Muller et al., 273 2007), particularly the RdRp L which we supply here in trans. However, whilst we could demonstrate 274 significant reductions in L mRNA and protein levels in $\mathrm{p} 1$ cells transfected with ZAP-L (Figure 4F and 275 S2E), the same reductions were observed in TRIM25 KO cells where ZAP overexpression had limited 276 impact in reducing the levels of EBOV genomic RNA or antiviral activity (Figure S2F and 4E). 277 Moreover, our earlier observations that IFN-I treatment did not affect the expression levels of vRNP 278 components (Figure S1C) further argued against the reduction in $\mathrm{L}$ expression as the major 279 contributor to the TRIM25/ZAP-mediated restriction of EBOV trVLPs under these experimental 280 conditions.

281 Most mammalian viral RNA genomes exhibit marked suppression of CpG dinucleotides (Fros 282 et al., 2017; Takata et al., 2017). In the case of HIV-1, artificial increase in CpG concentration in the 283 viral genome impairs replication through ZAP-mediated inhibition, with evidence that ZAP binds 284 directly to the CpGs themselves and induces RNA degradation or translational repression (Takata et 285 al., 2017). The EBOV genome contains just over half of the number of CpGs expected by chance for 286 its nucleotide composition (Figure S2G). These CpGs are widely distributed across the genome, both 287 in the protein coding genes and intergenic regions with the notable exception of the intergenic region 
288 between GP and VP30 (Figure S2H). The trVLP CpG content is moderately higher, with 61 CpGs in 289 the Rluc reporter gene that replaces NP as first ORF. Since the RLuc coding sequence does not 290 contain any necessary viral cis-acting regulatory elements, this gave us the opportunity to test 291 whether CpG content could impact upon IFN-sensitivity of the virus. We generated a trVLP in genome 292 in which all the CpGs in Rluc were silently mutated, reducing the observed vs expected CpG content 293 of the trVLP to 0.45 (CpG low, Figures S2G and S2H). This modification had no detectable effect on 294 trVLP yield or replication (Figure 4G). However, the CpG-low containing trVLP exhibited partial rescue 295 from ZAP-L restriction (Figure 4G), which correlated with increased intracellular levels of viral mRNA, 296 cRNA and vRNA on these cells, as well as vRNA levels in the supernatant (Figure 4H). Furthermore, 297 the CpG-low containing trVLP was also less sensitive than the parental trVLP to IFN-I (Figure 4I). 298 Since Renilla expression is not required for trVLP replication and both of these phenotypes were 299 measured in p2 cells, these data imply that a major target of ZAP-mediated restriction is the CpG 300 dinucleotides in the trVLP. These data further suggest that $\mathrm{CpG}$ content of the genomes of RNA virus 301 can sensitize them to type I IFNs in a ZAP-dependent manner. Finally, ZAP-mediated targeting of 302 CpG-containing retroviral RNA for degradation was shown to depend not only on TRIM25, but also on 303 the cytoplasmic protein KHNYN, which predictably confers the nuclease activity that is lacking in both 304 ZAP isoforms (Ficarelli et al., 2019). However, in contrast to ZAP-mediated restriction of retroviruses, 305 this does not seem to be dependent on KHNYN, as depletion of this protein in U87-MG cells did not 306 attenuate the antiviral effect of IFN-I on EBOV trVLPs replication (Figure S4I and S4J).

\section{TRIM25 interacts with the EBOV vRNP and promotes ubiquitination of NP.}

308 While the role of TRIM25 as a ZAP cofactor is established, how it facilitates ZAP targeting of viral

309 RNAs is not understood. However, given the previously reported interaction between TRIM25 and 310 influenza virus (Meyerson et al., 2017), we hypothesized that it could act directly on EBOV vRNP 311 components to promote ZAP-mediated restriction. We noted that overexpression of TRIM25 induced 312 a smear of higher molecular weight species above NP in western blots of transfected HEK293T cell 313 lysates during the screen (Figure S1E), so we therefore first examined whether TRIM25 could interact 314 with the EBOV NP and its cofactor VP35. NP co-immunoprecipitated with TRIM25, whereas VP35 315 only pulled-down with TRIM25 in the presence of NP (Figure 5A). Furthermore, reciprocal 316 immunoprecipitation of NP from p1 cells brought down both VP35 and TRIM25, indicating that 317 TRIM25 could interact with the vRNP in an NP-dependent manner (Figure S3A). This interaction was 
318 resistant to RNAse treatment, suggesting that the vRNA was not bridging the interaction between

319 TRIM25 and NP (Figure S3B). Endogenous ZAP-L, but not ZAP-S, could also be detected in

320 TRIM25/NP coprecipitates. However, in cells lacking ZAP, TRIM25 could still interact with NP (Figure

321 S3C). To determine if TRIM25 localized to viral replication compartments, we analysed endogenous

322 TRIM25 expression by immunofluorescence. TRIM25 re-localized to NP-containing viral inclusion

323 bodies in cells transfected with the vRNP proteins (Figure 5B). NP expression was sufficient for this

324 re-localization, but it was markedly enhanced in the presence of VP35 which is known to regulate the

325 conformational dynamics of NP in the vRNP (Kirchdoerfer et al., 2015).

326 Like many TRIM family members, TRIM25 consists of a N-terminal RING domain containing

327 E3-ubiquitin ligase activity, two B-Box domains, a coiled-coil domain that allows it to form antiparallel

328 dimers, and a C-terminal PRYSPRY substrate recognition domain (D'Cruz et al., 2013; Gack et al.,

329 2007; Sanchez et al., 2014) (Figure 5C). Using deletion mutants of TRIM25, we found that the

330 mutants lacking the PRYSPRY domain, but not the RING domain, lost their ability to interact with NP

331 in co-immunoprecipitations (Figure 5C). However, both PRYSPRY and RING domains were essential

332 for antiviral activity against EBOV trVLPs when overexpressed in HEK293T-TIM1 p1 cells (Figure

333 5D). When activated by their cognate ligands, many TRIM proteins undergo autoubiquitination as well

334 as inducing ubiquitination of target proteins (Tomar and Singh, 2015). Consistent with this, in the

335 presence of HA-tagged ubiquitin, co-expression of TRIM25 and NP induced the appearance of higher

336 molecular weight species of both proteins, that could be precipitated with anti-HA and NP antibodies,

337 indicating the presence of ubiquitin molecules (Figure 5E). Ubiquitinated species of NP and TRIM25

338 could not be detected in cells transfected with the RING-deleted TRIM25 mutant, indicating the RING

339 E3 ligase activity was essential (Figure S3D). However, in HEK293T cells lacking either ZAP or FL-

340 MAVS and miniMAVS where TRIM25 antiviral activity is curtailed, TRIM25 and NP co-expression

341 could still lead to ubiquitination of both proteins (Figures S3E and S3F). To exclude the possibility that

342 our observations are product of an artefact associated with overexpressing HA-tagged ubiquitin, we

343 pulled-down EBOV NP following its co-expression with YFP or TRIM25 under endogenous levels of

344 ubiquitin, and treated this fraction with Ubiquitin Specific Peptidase 2 (USP2). The typical smear of

345 higher molecular weight observed above NP when TRIM25 is ectopically expressed disappeared

346 upon treatment with USP2, reinforcing our initial finding that TRIM25 promotes the ubiquitination of

347 NP (Figure 5F). Of note, we did not detect evidence of a differential NP degradation in the absence of 
348 TRIM25 (Figure S3G). Thus, the ubiquitin ligase activity of TRIM25, and specifically the ubiquitination

349 of NP and auto-ubiquitination of TRIM25, are necessary but not sufficient to explain its antiviral 350 activity against EBOV.

351 Recent evidence has suggested that activation of TRIM25 E3 ligase activity requires its 352 binding to RNA, with two distinct RNA interaction domains being described - a basic patch with 7

353 lysine residues in the linker between the coiled-coil and the PRYSPRY domain, and an RNA-binding 354 domain (RBD) in the N-terminal region of the PRYSPRY itself. Activation is also strictly dependent on 355 the multimerization of TRIM25 dimers through dimerization of N-terminal RING domains (Sanchez et 356 al., 2018). In order to further probe the determinants of TRIM25-mediated antiviral activity, we made a 357 series of mutations in these functional domains (Figure 6A). Compared to the wildtype protein, some 358 of the targeted mutations in the RING dimerization interface, the catalytic site itself, or the PRYSPRY 359 domain significantly impaired antiviral activity (Figure 6A). Of these RING dimerization mutants N66A, 360 L69A and V72A lost all antiviral activity (Figure 6A). Similarly, deletion of the RBD or mutation of the 361 linker region basic patch (7KA) led to lost activity. Targeted mutations predicted to disrupt the coiled362 coil (Sanchez et al., 2014) were not significantly defective in restricting trVLP replication. Western blot 363 analyses indicated that antiviral potency appeared to correlate well with NP ubiquitination under 364 endogenous levels of ubiquitin (Figure 6B). While most RING dimerization mutants blocked 365 ubiquitination of NP, individual mutations in the catalytic site reduced, but did not completely, abolish 366 it. Furthermore, the effectively antiviral coiled-coil mutants Y254A and Y252A, together with the 367 BBox2 RHK mutant, were still capable to induce NP ubiquitination. Interestingly the putative RNA368 binding activity mutants, particularly the RBD, were also impaired in NP ubiquitination. Unlike the full 369 deletion of the PRYSPRY domain, all functional RING mutants of TRIM25 tested retained the ability to 370 interact with NP in coimmunoprecipitations as did the RBD deletion (Figure 6C). Surprisingly, the 7K 371 mutant lost NP interaction, suggesting that it may affect PRYSPRY-mediated NP interaction.

372 TRIM25 is recruited to incoming vRNPs and reduces NP association with trVLP vRNA and 373 promotes its interaction with ZAP.

374 The data presented above support the hypothesis that TRIM25 and ZAP target the EBOV vRNP to 375 block its transcription and/or replication. To examine this in detail we first tested whether incoming 376 vRNPs alone were capable of re-localizing endogenous TRIM25. HEK293T LacZ CRISPR-TIM1 cells 377 were infected with concentrated trVLP supernatants in the absence of transfection of vRNP 
378 components, then fixed and stained for NP and TRIM25 3 to 6 hours post-infection. In approximately

$3795 \%$ of cells, distinct NP positive foci were detected in the cytoplasm, associated with an aggregation

380 of endogenous TRIM25 (Figure 7A, left panel). To ensure this re-localisation was specific for cells in

381 which trVLPs had entered, we made use of HEK293T-TIM1 cells in which the endosomal EBOV

382 fusion receptor NPC1 had been deleted by CRISPR, thus rendering them uninfectable by VLPS

383 pseudotyped with EBOV GP (Figure S4A-S4C). By contrast, in these cells we saw no evidence of

384 cytoplasmic NP structures or TRIM25 re-localization (Figure 7A, right panel), suggesting that TRIM25

385 can only associate with incoming EBOV vRNPs after fusion of the viral membrane and release of the

386 vRNPs into the cytoplasm.

387 We then asked whether TRIM25 or ZAP could affect the integrity of the vRNP. As a control

388 we could show that neither overexpression of TRIM25, nor ZAP, affected total cell-associated trVLP

389 genomes 3 hours post-infection (Figure S4D). mRNA abundance is very low at this timepoint,

390 showing that any primary transcription is below the limit of detection. Thus, under conditions in which

391 no vRNP components were ectopically expressed, we performed RNA-IPs of NP-associated genomic

392 trVLP vRNA after UV-crosslinking of cells overexpressing GFP, TRIM25 or ZAP. Immunoprecipitation

393 of NP under these conditions consistently brought down 5-to-10\% of the input genomes. Interestingly,

394 overexpression of TRIM25 or ZAP significantly reduced the levels of trVLP genome associated with

395 incoming NP (Figure 7B), independently of using WT or CpG low EBOV trVLPs (Figure S4E).

396 Importantly, TRIM25 and ZAP did not dissociate EBOV trVLP RNA from NP in NPC1 CRISPR

397 knockout cells where cell associated virions will remain unfused in endosomal compartments (Figure

398 7B). Furthermore, whilst TRIM25 overexpression in ZAP KO cells could still reduce NP/genome

399 association, ZAP overexpression could not mediate the same effect in TRIM25 KO cells (Figure 7C),

400 indicating that TRIM25, not ZAP, was essential for this effect, while the CpG content of the viral

401 genome does not influence the targeting of the RNP by TRIM25 (Figure S4F). Furthermore, neither

402 RING nor PRYSPRY-deletion mutants of TRIM25 could promote NP/genome dissociation (Figure

403 7D), neither could the RNA-binding or RING mutants (Figure 7E), consistent with their lack of antiviral 404 activity.

405 Since transcription of viral genes by the vRNP-associated RdRp is the one of the first events 406 in EBOV replication after cellular entry, we performed the experiment in Figure 7B in the presence of $407250 \mu \mathrm{M}$ of the $\mathrm{L}$ inhibitor T705, which is sufficient to inhibit trVLP RLuc expression by $90 \%$ (Figure 
408 S4G and S4H). Importantly, we found that T705 did not prevent TRIM25 overexpression from 409 dissociating NP from the genome of incoming viruses (Figure 7F). Together these data indicate vRNP 410 interaction, RNA-binding and activation of E3 ligase activity are required for TRIM25 to dissociate NP 411 from the viral genome of incoming EBOV vRNPs, and thus facilitate interaction with ZAP.

412 We then performed a similar crosslinking-IP in cells, this time precipitating overexpressed 413 ZAP. This markedly enriched for the trVLP viral genome at the same timepoint that NP/genome 414 association was reduced (Figure 7G). However, immunoprecipitation from TRIM25 KO cells under the 415 same experimental conditions showed no evidence of ZAP association with the trVLP genome, 416 indicating that this correlated with TRIM25-mediated NP/genome dissociation. To further address the 417 importance of the CpG content for ZAP association, we used a monocistronic genome containing the 418 Rluc gene flanked by the leader and trailer regions of EBOV, from which we generated a low CpG 419 variant in which all the CpGs in Rluc were silently mutated (Figure S4I). As expected, ZAP 420 overexpression impacts in the replication of the WT monocistronic genome, whilst its effect is 421 attenuated upon reduction of the CpG content (Figure S4J). This correlated with the significant 422 impairment of ZAP association with the CpG low monocistronic genome when compared with the 423 wild-type (Figure S4K), thus highlighting the important role of the viral genome CpG content for ZAP424 mediated antiviral effect.

425 Finally, we asked if the NP/genome dissociation could be recapitulated following an IFN-I 426 treatment. HEK293T LacZ-TIM1 cells, or those lacking TRIM25 or ZAP were treated overnight with 427 IFN-I and then infected for 3h with trVLPs and similarly subjected to UV-crosslinked RNA-IP of NP. In 428 HEK293T LacZ-TIM1 cells, IFN-I pre-treatment reduced the NP/genome association to a similar 429 extent to the ectopic overexpression of TRIM25, without affecting total cell-associated trVLP vRNA. 430 However, in TRIM25 knockout cells, there was no significant reduction in NP/genome association. In 431 ZAP knockout cells, whilst NP/genome interactions were largely restored, there remained a small 432 reduction in trVLP vRNA recovered after NP immunoprecipitation (Figure $7 \mathrm{H}$ ). Thus, the TRIM25 433 dependent dissociation of NP from the trVLP genome can be demonstrated in cells after IFN-I 434 stimulation, implying the relevance of these observations to the antiviral mechanism.

435 In order to further investigate whether we could observe the antiviral effect of TRIM25 and 436 ZAP in an alternative model of the trVLP system based only in infection, we created an EBOV 437 minigenome that expressed a nanoluciferase in place of the Renilla, resulting in a more sensitive 
438 reporter capable of reliably detecting at low enough quantities to observe primary transcription. The

439 observed primary transcription could be quantified specifically as luciferase signal was not observed

440 with either $\triangle \mathrm{GP}$ trVLPs or in NPC1 CRISPR knockout cells (Figure S4L). We then investigated the

441 effect of TRIM25 and ZAP and observed that the antiviral activity of IFN-I treatment on primary

442 transcription was attenuated in either TRIM25 or ZAP knockout cells at lower concentrations (Figure

443 7I). Furthermore, we also observed that TRIM25 overexpression was also antiviral in this system

444 (Figure S4M). These observations indicate that both TRIM25 and ZAP are important for the cellular

445 defence against EBOV in an infection only based model.

\section{Discussion}

448 Through screening of a human ISG library we provide evidence that TRIM25 and ZAP are major 449 effectors of interferon-induced antiviral restriction of EBOV trVLP. The data presented herein lead us 450 to propose the following model for the mechanism of this restriction (Figure 7J). TRIM25 interacts with 451 the viral NP and is recruited to the incoming vRNP shortly after fusion of the virion with the cellular 452 endosomal membrane. This results in the ubiquitination of both NP and TRIM25, and the apparent 453 displacement of NP from the viral genome, facilitating ZAP binding to the vRNA. The antiviral 454 inhibition of the subsequent transcription and replication of the virus is dependent on this interaction, 455 and the overall sensitivity of the virus to both ZAP and IFN-I can be modulated by the CpG content of 456 the viral genomic RNA. This activity of TRIM25 is completely independent of RIG-I-mediated sensing 457 of viral RNA and proinflammatory signalling but requires both isoforms of MAVS. As such we propose 458 this as a direct antiviral restriction mechanism associated with, but independent of, classical 459 cytoplasmic RNA pattern recognition.

460 Until recently, TRIM25 was thought to be an essential cofactor for the RIG-I helicase to 461 recognise viral RNA species, particularly those with exposed 5' triphosphates (Gack et al., 2007; 462 Okamoto et al., 2017). However, new data implicates Riplet as the essential E3 ligase in RIG-I 463 activation (Cadena et al. 2019). Upon activation, RIG-I and MAVS undergo a prion-like polymerization 464 into extended filaments that directly activate the kinase TBK1, and thus promote proinflammatory 465 signalling (Cai et al., 2014), and it is still unclear whether TRIM25 plays further roles in the pathway. 466 However, neither RIG-I nor TBK1 are necessary for TRIM25 to inhibit EBOV trVLP replication, 467 implying a role distinct from classical RNA sensing. 
The PRYSPRY domain of TRIM25 binds to and activates ZAP (Li et al., 2017; Zheng et al.,

469 2017), which has long been known as an antiviral effector targeting various RNA viruses (Bick et al.,

470 2003; Gao et al., 2002; Takata et al., 2017). For a number of positive sense RNA viruses, ZAP binds

471 to the RNA genome and restricts replication by blocking its translation and/or targets viral RNA for

472 degradation by the 3'-5' exosome (Bick et al., 2003; Li et al., 2017; Zheng et al., 2017). ZAP exists as

473 two isoforms, ZAP-L and ZAP-S, the latter being a splice variant lacking the C-terminal catalytically

474 inactive poly-ADP ribosyl polymerase (PARP) domain (Kerns et al., 2008). Whilst antiviral activity has

475 been ascribed to both isoforms, ZAP-L is more active against some viruses (Bick et al., 2003; Gao et

476 al., 2002; Li et al., 2017; Zheng et al., 2017). Upon overexpression, ZAP-L restricts EBOV trVLP more

477 potently than ZAP-S, and we find that only ZAP-L coprecipitates with TRIM25 and NP.

478 Overexpression of a rat ZAP has been previously shown to have an antiviral activity against EBOV,

479 by blocking the translation of the $L$ mRNA (Muller et al., 2007). While we also see an effect on both $L$

480 mRNA and protein expression upon ZAP overexpression in our assays, this is also observable in

481 TRIM25 KO cells where ZAP has no antiviral activity, in contrast with the impact of ZAP

482 overexpression on EBOV genomic RNA levels which occurs in a TRIM25-dependent manner.

483 Moreover, the TRIM25/ZAP-mediated block induced by IFN-I does not affect the expression of any

484 viral protein expressed in trans and ZAP activity is modulated by the CpG content in Renilla,

485 suggesting that ZAP is targeting the viral genome rather than just blocking the synthesis of $\mathrm{L}$.

486 ZAP has been implicated in driving the evolution of RNA viruses towards suppression of their 487 genomic CpG content (Fros et al., 2017; Takata et al., 2017). Most RNA viruses have a lower 488 abundance of CpGs than would be expected by chance, and in the case of HIV-1, artificially 489 increasing the CpG content in parts of the genome renders the virus sensitive to ZAP (Ficarelli et al, 490 2019; Odon et al., 2019; Takata et al., 2017). Evidence suggests ZAP directly binds to viral RNAs with 491 high CpG content and promotes their degradation (Chiu et al., 2018; Takata et al., 2017). EBOV 492 exhibits less CpG suppression than HIV (observed vs expected ratio of 0.5 compared to 0.2). 493 However, if we change this CpG content in either the trVLP or monocistronic systems we modulate 494 the viral sensitivity to ZAP, and in the case of the latter, enrich ZAP/RNA interactions. Since RLuc 495 expression is not required for the trVLP propagation, this result implies that ZAP can target CpGs in 496 the EBOV genome itself. 
How TRIM25 activates ZAP remains unclear. TRIM25 interacts with and ubiquitinates ZAP,

498 but the latter activity is not required for its cofactor activity (Li et al., 2017; Zheng et al., 2017). Our

499 data showing that TRIM25 displaces NP from the genome shortly after entry and that ZAP binds the

500 vRNA in a TRIM25-dependent manner raises the possibility that its role is to expose viral RNA rather

501 than acting directly on ZAP itself. Importantly, through this TRIM25/ZAP axis, we show that the CpGs

502 in the genome render EBOV sensitive to IFN-I. While both TRIM25 and ZAP are IFN-inducible, they

503 are constitutively expressed in most cells and only increase modestly at the protein level upon IFN

504 stimulation. Therefore, despite being essential effectors targeting EBOV trVLP replication, whether

505 this increase in their expression fully explains the IFN-regulated antiviral activity, or whether other

506 IFN-inducible components are required needs further study (Kuroda et al. 2020).

507 Our results indicate that TRIM25 may target the structure of the EBOV (and perhaps other

508 negative strand RNA virus) vRNP in a manner analogous to antiviral restriction by other mammalian

509 proteins. While we see no evidence of TRIM25-dependent NP degradation, TRIM25 does appear to

510 displace it from the viral RNA, which would likely dysregulate viral transcription and RNA replication.

511 Similar to rhesus TRIM5 and HIV CA, as well as TRIM21 and its antibody opsonised targets (Fletcher

512 et al., 2015; James, 2014), we see evidence of NP ubiquitination. While this correlates with antiviral

513 activity, we do not yet know whether that is itself essential. TRIM25 forms an antiparallel dimer

514 through its coiled-coil domain (Sanchez et al., 2014) and can then further assemble into multimers

515 through RING domain dimerization. This positions the RING moieties at either end of the dimer, with

516 the ligand-binding PRYSPRY located more centrally, either side of the coiled-coil. To act as an E3

517 ligase the TRIM25 RING domain must also dimerize, which can only happen through association with

518 another TRIM25 dimer. This has been demonstrated to be facilitated by the binding of the PRYSPRY

519 domain to one of its cognate ligands, the RIG-I 2CARD, generating the catalytically active domain that

520 can interact with E2 ligases (Sanchez et al., 2016). Thus, TRIM25 is only active as a multimer of

521 dimers when bound to its target. Two possibilities exist for the conformation of these multimers from

522 the current structural studies of TRIM25; either two TRIM25 dimers multimerize into a closed dimer of

523 dimers, or end-to-end multimerization of RING domains could lead to extended polymers of TRIM25

524 (Sanchez et al., 2016). We find evidence that TRIM25 interaction with NP depends on its PRYSPRY

525 domain. Antiviral activity, however, was blocked by mutations that impair RING dimerization as well

526 as catalytic activity, suggesting that multimerization of TRIM25 on the EBOV vRNP is also essential. 
527 Since this is a helical ribonucleoprotein complex, it is possible that end-to-end multimers of TRIM25

528 could form over such a structure, driving its disassembly, and thus recruit other RNA-directed antiviral

529 factors and sensors.

530 Several studies have suggested that TRIM25 is an RNA-binding protein itself and that this is 531 important for the activation of the E3 ligase activity. Two RNA binding sites have been identified. A 532 tyrosine-rich segment of loops 2 and 3 of the PRYSPRY domain has been shown to bind the Let7 533 miRNA both in vitro and in cellulo, and CLIP analyses has revealed many cellular TRIM25-associated 534 RNAs with a preference for G-rich regions (Choudhury et al., 2017). A second domain, a basic patch 535 in the unstructured region that links the coiled coil to the PRYSPRY, had also been shown to bind 536 RNA in vitro (Sanchez et al., 2018). In both cases, RNA-binding has been shown to promote E3 537 ligase activity in vitro, and mutation of these sites has been shown to block the substrate 538 ubiquitination. It is unknown whether both domains are functionally independent, or whether their 539 mutation have effects other than RNA-binding on TRIM25 substrate recognition. Interestingly, in the 540 case of EBOV restriction we find distinct phenotypes for either site. Mutation of the PRYSPRY RBD 541 loses antiviral activity and NP ubiquitination, but retains NP interaction consistent with this being 542 RNAse insensitive. Mutation of the basic patch (7KA) similarly loses antiviral activity, but unlike the 543 RBD deletion, also loses NP interaction similar to a full PRYSPRY deletion. Given that the basic patch 544 lies within a linker between the coiled-coil and the PRYSPRY, it is possible that such a change may 545 affect the spacing and positioning of the PRYSPRY relative to the coiled-coil for multimeric substrate 546 engagement, as is well-known for other TRIM-family members. The implication of RNA-binding in 547 TRIM25's antiviral mechanism is attractive in the light of our data that shows that it can dissociate NP 548 from the genome even when transcription is inhibited. Cryo-EM structures of the EBOV vRNP show 549 RNA tightly wound around helical NP assemblies, with each protomer engaging 6bp of RNA (Su et 550 al., 2018; Wan et al., 2017). The RNA is clamped into a cleft, reducing its accessibility to cellular 551 factors. In such a configuration, TRIM25 would have to interact with NP to access the vRNA, which is 552 consistent with our mutagenesis data. Recent studies have shown that nuclear TRIM25 associates 553 with influenza virus vRNPs to block transcriptional elongation (Meyerson et al., 2017). While there are 554 differences in these studies taken together, these observations raise the possibility that TRIM25 may 555 have a broad direct antiviral activity against negative-strand RNA viruses with helical vRNPs. More 
556 widely, these data also suggest that TRIM25 can act as a ZAP cofactor by disassembling RNA/protein 557 structures to expose CpG-rich RNAs.

$558 \quad$ Further to their direct antiviral restriction, several TRIMs ligand-induced synthesis of K63 559 polyubiquitin chains act as platforms for the activation of TAK1 and subsequently NFkB-dependent 560 proinflammatory gene expression (Fletcher et al., 2015; Pertel et al., 2011). TRIM5 acts effectively as 561 a pattern recognition receptor for the hexameric array of retroviral capsids, and TRIM21 for antibody562 bound microbes entering the cytoplasm. This therefore raises the question of whether the "classical" 563 cytoplasmic sensing mechanisms themselves are linked to a direct virus restriction. The requirement 564 for MAVS in TRIM25/ZAP-mediated restriction of EBOV replication would suggest that this may be 565 the case for the cytoplasmic RNA sensing pathway. Intriguingly, we find that both isoforms of MAVS 566 are required. Since signalling through MAVS is not required for the direct antiviral activity, we suggest 567 that it may act as a regulatory part of the complex. MAVS localizes primarily to mitochondrial 568 associated membranes and peroxisomes, and as such forms a platform for RNA sensing via RIG-I 569 and MDA5, and we suggest that this platform may also allow the recruitment of directly acting antiviral 570 factors, as well as a link to the ultimate disposal of viral components by the cell. Various studies have 571 linked MAVS, and its functional paralogue in DNA sensing, STING, to autophagic degradation upon 572 activation (Liu et al., 2018; Zhao et al., 2012).

573 TRIM25 is a common target for antagonism by RNA viruses. Influenza A virus NS1 blocks 574 TRIM25 activity to disable RIG-I in infected cells (Gack et al., 2009), whereas dengue virus encodes a 575 subgenomic RNA that functions analogously (Manokaran et al., 2015). We see no evidence of a direct 576 counteractivity for human TRIM25 encoded by EBOV. VP24, which blocks signalling from IFNAR1/2, 577 prevents the upregulation of ISGs after IFN-I exposure. In cells already exposed to IFN-I at the time of 578 infection, VP24 would not be expected to have any effect, and in any case is encoded by the trVLP. 579 VP35, is expressed in trans in the trVLP system and counteracts RIG-I and protein kinase R (PKR) 580 but has no known activity to inhibit TRIM25 (Basler, 2015). However, humans are not the virus' 581 natural host, and it is possible that filoviruses do have a countermeasure/resistance mechanism to 582 TRIM25/ZAP in other mammals, particularly putative bat reservoir species. Interestingly, adaptation of 583 EBOV to infection of both mice and guinea pigs is associated with amino acid changes in NP. 584 Furthermore, lethality of mouse adapted EBOV in C57BL/6 mice requires the knockout of mavs (Dutta 585 et al., 2017). Whilst this has been interpreted to be due to enhanced RNA sensing, given our 
586 observations that both MAVS isoforms are required for TRIM25/ZAP-mediated antiviral activity, it is

587 also possible that differences in direct restriction of the vRNP underlie this species-specific tropism.

588 Both ZAP and TRIM25 are under high levels of positive selection in mammals, suggesting a 589 continuous adaptation to new viral pathogens (Kerns et al., 2008).

590 In summary, our studies have revealed that TRIM25 and ZAP are major contributors to an

591 IFN-induced restriction of EBOV replication. We provide evidence that TRIM25 directly associates

592 with the incoming vRNP and dissociates NP from the genome. These data further suggest TRIM25 as

593 a key restriction factor for EBOV, and that its role is to expose $\mathrm{CpG}$ rich areas of the viral genome to

594 ZAP, which could then degrade or inhibit translation of the viral RNAs.

598 Material and Methods

\section{$600 \quad$ Cell lines}

601 HEK293T and U87-MG cells were obtained from ATCC. HEK293T-TIM1 and U87-MG-TIM1 cells

602 were produced by transduction of the parental cell lines with a MLV-based lentiviral vector packaging

603 a pCMS28 vector genome (Gallois-Montbrun et al., 2007) encoding the TIM1 construct, and selecting

604 the cells in puromycin. Alternatively, some of the CRISPR KO cell lines (described below) were

605 derived to stably express TIM1 by transduction with a MLV-based retroviral vector packaging a

606 pLHCX (Clontech) vector genome encoding TIM1, and selecting in hygromycin. All cells used on this

607 study were maintained in high glucose DMEM supplemented with GlutaMAX, 10\% fetal bovine serum

608 (FBS), $20 \mu \mathrm{g} / \mathrm{mL}$ gentamicin, and incubated at $37^{\circ} \mathrm{C}$ with $5 \% \mathrm{CO}_{2}$.

609

\section{Generation of CRISPR Knock-Out cell lines}

611 CRISPR guides targeting E.coli LacZ gene, or human TRIM25, ZAP, RIG-I, FL-MAVS, FL-MAVS/

612 miniMAVS, TBK1 and KHNYN genes were cloned into $B s m B I$ restriction enzyme sites in the lentiviral

613 CRISPR plasmid lentiCRISPRv2 (Addgene). LentiCRISPR VLPs were produced on HEK293T cells

614 seeded on a $10 \mathrm{~cm}$ dish, and transfected with $8 \mu \mathrm{g}$ of lentiCRISPRv2-Guide, $8 \mu \mathrm{g}$ of pCRV1-HIV-Gag

615 Pol (Neil et al., 2008) and $4 \mu$ g of pCMV-VSV-G (Neil et al., 2008). Supernatants were harvested 48 
616 hours later and used to transduce HEK293T or U87-MG cells, followed by selection in puromycin.

617 Furthermore, MAVS isoforms expression were rescued on HEK293T FL-MAVS \& miniMAVS CRISPR

618 DKO by transduction with a MLV-based lentiviral vector packaging a pCMS28 vector genome 619 encoding CRISR-resistant MAVS (MAVS ${ }^{\mathrm{CR}}$ ), miniMAVS (MAVS M1A ${ }^{\mathrm{CR}}$ ) or FL-MAVS (MAVS $620 \mathrm{M} 142 \mathrm{~A}^{\mathrm{CR}}$ ) constructs, and selecting cells in Blasticidin.

621 Additionally, the CRISPR guide targeting NPC1 gene was cloned into lentiCRISPR_v2_GFP as above 622 (Addgene). The generated plasmid was transfected into HEK293T-TIM1 cells, which were 623 subsequently sorted by flow cytometry, on a BD FACSCantoll, on the basis of their GFP expression.

624 Finally, NPC1 expression was rescued on these HEK293T NPC1 CRISPR KO-TIM1 cells by 625 transduction with a MLV-based lentiviral vector packaging a pCMS28 vector genome encoding NPC1 626 construct, and selecting the cells in Blasticidin to generate the HEK293T NPC1 CRISPR KO-TIM1 + $627 \quad$ NPC1 cell line.

628 All CRISPR guides sequences are in Table S2.

\section{Generated Plasmids}

631 TRIM25wt, TRIM25 $\triangle$ RING and TRIM25 $\triangle$ SPRY were PCR amplified from the ISG library plasmid 632 pcDNA-DEST40-TRIM25 (Kane et al., 2016) using forward and reverse primers encoding 5' 633 overhangs with, respectively, EcoRI and Xhol restriction sites. Purified amplification products were 634 then inserted into the corresponding sites on a pcDNA3.1 backbone. pcDNA3.1-TRIM25

$635 \Delta R I N G \triangle S P R Y$ was generated by PCR amplification using pcDNA3.1-TRIM25 $\triangle$ RING as template and 636 sub-cloning the PCR product into pcDNA3.1 backbone as above.

637 pcDNA3.1-TRIM25wt CR (CRISPR-resistant) was generated by overlapping PCR from pcDNA3.1638 TRIM25wt, using internal primers that inserted silent mutations on the CRISPR-guides target 639 sequence and the above mentioned TRIM25 ORF flanking forward and reverse primers with EcoRI 640 and $\mathrm{Xhol}$ restriction sites as 5' overhangs. pcDNA3.1-TRIM25wt CR was used as template for all 641 CRISPR-resistant TRIM25 mutants used on this study. These mutants were generated, unless 642 otherwise mentioned, by overlapping PCR using internal primers that inserted silent mutations, and 643 the above mentioned forward and reverse primers encoding 5' overhangs with EcoRl and Xhol 644 restriction sites. TRIM25 L7A CR was generated by PCR amplification of TRIM25wt CR with 645 L7A_CR_Fwd primer with a 5' EcoRI overhang and the above mentioned TRIM25_Xhol Rev primers. 
646 Purified amplification products were then inserted into the corresponding sites on a pcDNA3.1 647 backbone. pCMS28-Blast-MAVS ${ }^{\mathrm{CR}}$ was constructed by overlapping PCR from pCR3.1-MAVS (Pertel et al. 650 2011), using internal primers that inserted a silent mutation in the NGG PAM of the CRISPR guide 651 target sequence alongside forward and reverse primers encoding 5' overhangs with Notl and Xhol 652 restriction sites respectively. $\mathrm{pCMS28-Blast-MAVS}{ }^{\mathrm{CR}}$ was then used as a template and backbone for 653 the MAVS CRISPR resistant plasmids used in this study. pCMS28-Blast-M142A ${ }^{\mathrm{CR}}$, expressing only 654 the FL-MAVS isoform, was created by overlapping PCR from pCMS28-Blast-MAVS ${ }^{\mathrm{CR}}$ using internal 655 primers substituting the methionine for an alanine at position 142, in conjunction with the above 656 mentioned forward and reverse primers with Notl and Xhol 5' overhangs. Furthermore, pCMS28657 Blast-M1 $\mathrm{A}^{\mathrm{CR}}$ was created by $\mathrm{PCR}$ amplification using forward and reverse primers encoding $5^{\prime}$ 658 overhangs with $\mathrm{Notl}$ and $\mathrm{Xhol}$ restriction sites respectively, where the forward primer also encoded for 659 a mutation in the first methionine thus disrupting the expression of the FL-MAVS isoform. Amplified 660 DNA fragments were then inserted into the pCMS28-Blast backbone digested with Notl and Xhol.

662 pCMS28-TIM1 was generated by sub-cloning the product of pCAGGS-TIM1 digestion with EcoRI and 663 Notl enzymes into the corresponding sites in pCMS28 backbone. Additionally, pCAGGS-TIM1 served 664 also as template for the PCR amplification of TIM1, and the product inserted into Xhol and Not/ sites 665 on pLHCX backbone to generate pLHCX-TIM1.

666 Finally, pBABE-NPC1 (Carette et al., 2011) served as template for the PCR amplification of NPC1, 667 and the PCR product was digested with EcoRI/Xhol and inserted into the corresponding restriction 668 sites in pCMS28-Blasticidin to generate pCMS28-Blast-NPC1.

669 All primers used for cloning are described on Table S3.

671 To generate p4cis-vRNA-CpG low RLuc we have synthesised a 2141nt-long DNA fragment 672 (sequence available upon request), with 61 silent mutations that removed all CpG dinucleotides 673 present in the Renilla luciferase gene of the p4cis-vRNA-RLuc sequence. This DNA fragment was 674 digested with $A p a l$ and $B / p /$ and inserted into the corresponding sites in the original p4cis-vRNA-RLuc 675 minigenome plasmid. On the other hand, the monocistronic plasmid pT7-1cis-vRNA-CpG low-EBOV- 
676 hrluc expressing a Renilla luciferase with no CpG's was constructed by overlapping PCR using p4cis-

677 vRNA-CpG low as template. Briefly, two fragments were amplified by PCR with the primers P4 cis

678 Low Cpg TRAIL F and P4 cis vRNA Xmal R (size 793bp) and P4 cis Low CpG TRAIL R and P4 cis

679 vRNA Blpl F (size 1626bp). These DNA fragments were joined together by PCR using the outer

680 primers with the $B / p l$ and $X m a l$ restriction sites in their 5' overhangs, digested with these enzymes

681 and cloned into the pT7-1cis-vRNA-EBOV-hrluc plasmid to create a low CpG renilla monocistronic

682 EBOV plasmid.

683

684 Ebola transcription- and replication-competent virus-like particle (trVLP) assays

685 Unless otherwise stated, EBOV trVLPs (Watt et al., 2014) were produced in HEK293T producer cells

686 (also called p0 cells) seeded in a $10 \mathrm{~cm}$ dish, and transfected with 625ng of pCAGGS-NP, 625ng of

687 pCAGGS-VP35, 375ng of pCAGGS-VP30, 5 $\mathrm{gg}$ of pCAGGS-L, 400ng of p4cis-vRNA-Rluc (or

688 corresponding CpG low variant of this minigenome), and 250ng of pCAGGS-T7, using TransIT-LT1

689 transfection reagent. Medium was exchanged 4-6 hours post-transfection, and trVLP-containing

690 supernatants were harvested $48-72$ hours later and cleared by centrifugation for 5 minutes at 300xg.

691 Typically, 5 to $50 \mu$ l of cleared supernatants were transferred to $p 1$ target cells that had been seeded

692 on 24-well plates, and transfected 24 hours previously with $31.25 \mathrm{ng}$ of pCAGGS-NP, 31.25ng of

693 pCAGGS-VP35, 18.75ng of pCAGGS-VP30, 250ng of pCAGGS-L (or pCAGGS-L-HA where

694 mentioned) and 5ng of pFluc per well. In specific experiments, cells were also co-transfected at this

695 stage with $125 \mathrm{ng}$ of the ISG of interest. Furthermore, if p1 target cells were not stably expressing

696 TIM1, they were additionally co-transfected with 62.5ng of pCAGGS-TIM1 per well. Medium was

697 changed 4-6 hours post-transfection and, in experiments performed either with interferons or T705

698 (Favipiravir), increasing amounts of universal IFN-I, IFN alpha 2a, IFN beta 1a (PBL Interferon

699 Source) or T705 (AdooQ) were added to the cells at this stage. Cells were infected the following day

700 and medium was again changed 4-6 hours after infection of p1 target cells, and 24 hours later cells

701 were lysed with Passive Lysis 1x and reporter activities measured with Dual Luciferase Reporter Kit

702 (Promega). At the same time supernatants from $\mathrm{p} 1$ cells were cleared by centrifugation and passaged

703 onto fresh HEK293T-TIM1 p2 target cells, seeded in 24-well plates and transfected 24 hours earlier

704 exclusively with the EBOV RNP components and pFluc (same quantities as above). These cells were

705 lysed 24 hours post infection and reporter activities measured as already described. 
707 Specific experiments required the use of concentrated EBOV trVLPs. For that purpose trVLPs were

708 produced as above, and treated for 2 hours with 10U/mI DNase-I (Roche) before being concentrated

709 by ultracentrifugation through a $20 \%$ sucrose/PBS cushion $(28,000 \mathrm{rpm}$ on a Sorvall Surespin rotor,

710 for 90 min at $4^{\circ} \mathrm{C}$ ), and resuspended overnight in serum-free DMEM medium.

711

\section{ISG Screen}

713 ISG screen was conducted on HEK293T-TIM1 cells in a 96-well plate format, using a library of human

714 ISGs encoded by pcDNA-DEST40 (Kane et al., 2016). 50ng of individual ISG-expressing plasmids

715 were co-transfected onto $\mathrm{p} 1$ target cells together with EBOV RNP expressing plasmids and pFluc, as

716 described above in the trVLP assay. p1 target cells were infected with EBOV trVLPs 24 hours post-

717 transfection and medium changed 4 hours later. 24 hours post-infection the cells were lysed with

718 Passive Lysis $1 \mathrm{x}$ and reporter activities measured with Dual Luciferase Reporter Kit. At the same time

719 supernatants from $\mathrm{p} 1$ cells were used to infect fresh HEK293T-TIM1 p2 target cells, seeded in 96-well

720 plates and transfected 24 hours earlier exclusively with the EBOV RNP components (as described

721 above). These cells were lysed 24 hours post infection and reporter activities measured as already

722 previously described. For each ISG, the yield of infectious virions was expressed as a percentage of

723 the mean value across each library plate.

\section{Ebola monocistronic genome assays}

726 VLPs carrying the monocistronic EBOV genomes were produced in HEK293T cells seeded in $10 \mathrm{~cm}$ 727 dishes, and transfected with 625ng of pCAGGS-NP, 625ng of pCAGGS-VP35, 375ng of pCAGGS-

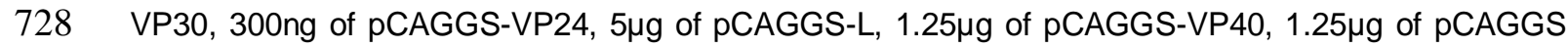

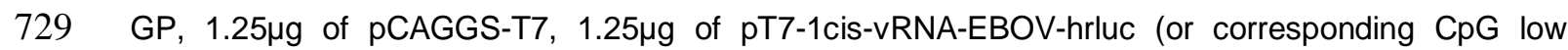
730 variant) and 125ng of pFLuc, using TransIT-LT1 transfection reagent. Medium was exchanged 4-6 731 hours post-transfection and supernatants harvested 72 hours later as described before. Experiments 732 with these monocistronic VLPs were performed following the same proceeding described above for 733 the EBOV trVLPs. 
736 EBOV trVLPs were produced containing a minigenome that encoded Nanoluciferase rather than

737 Renilla luciferase using the protocol previously described for EBOV trVLP production under section

738 heading Ebola transcription- and replication-competent virus-like particle (trVLP) assays. Target cells

739 were plated in a 96 well format and spinfected with $200 \mu$ l of cleared p0 supernatant the next day.

740 Cells were then washed three times in medium 6 hours after infection. Cells were lysed with passive

741 lysis buffer 48 hours after infection and reporter activity was then measured with a Nano-Glo

742 luciferase assay system (Promega). For IFN-I based experiments increasing amounts of IFN-I were

743 added 16 hours before infection and for TRIM25 overexpression experiments cells were reverse

744 transfected with either TRIM25 or YFP as well as TIM1 24 hours before infection.

745

746 Reporter Gene Assays

747 For transient reporter gene assays, HEK293T cells were seeded on 24-well plates and transfected 748 with 100ng of control pcDNA-DEST40-GFP or pcDNA-DEST40 expressing individual ISG of interest 749 in combination with 10ng of 3xkB-pCONA-Fluc (Mankouri et al., 2010), or pTK-ISG56-Luc (kindly 750 provided by Greg Towers, UCL), or pNL(NlucP/ISRE/Hygro) (Promega) luciferase reporters and 10ng 751 of pCMV-RLuc (Mankouri et al., 2010). Cells were lysed with 1x Passive Lysis buffer 24 or 48 hours 752 post-transfection, and Firefly and Renilla luciferase activities in the lysates were measured using a 753 dual luciferase kit (Promega).

\section{Influenza A Minigenome Assay}

756 Influenza A polymerase activity was determined using a minigenome reporter containing the Firefly 757 luciferase gene in a negative sense, flanked by the non-coding regions of the influenza NS gene 758 segment transcribed from a species-specific pol I plasmid with a mouse terminator sequence 759 (Moncorge et al., 2010; Pleschka et al., 1996). Each viral polymerase component was expressed from 760 separate pCAGGS plasmids encoding A/H1N1/Eng/195 NP, PA, PB1 and PB2 (Moncorge et al., 761 2013). To analyse polymerase activity, HEK293T LacZ, HEK293T RIG-I CRISPR and HEK293T ZAP 762 CRISPR cells were seeded in 24-well plates 24 hours prior transfection with 10ng PB1, 10ng PB2, 763 5ng PA, 15ng NP, 10ng pHPMO1-Firefly, 2.5ng pCAGGS-Renilla (transfection control, (Cauldwell et 764 al., 2013) and increasing amounts of pcDNA3.1-TRIM25 using Trans-IT LT1. Cells were lysed 24 
765 hours post-transfection with $1 \times$ Passive Lysis and reporter activities measured using a dual luciferase

766 kit (Promega).

767

768 Lentiviral Assay

769 HIV-based lentiviral VLPs expressing GFP were produced on HEK293T cells seeded on a 10cm dish, 770 and transfected with $6 \mu \mathrm{g}$ of pHR' Sin CSGW (Demaison et al., 2002), $4 \mu \mathrm{g}$ of pCRV-HIV Gag Pol and

$7712 \mu \mathrm{g}$ of pCMV-VSV-G using TransIT-LT1. Medium was changed 4-6 hours post transfection and VLP772 containing supernatants harvested 48 hours later and cleared by centrifugation (5 minutes, 1200rpm).

773 U87-MG LacZ CRISPR control and U87-MG TRIM25 CRISPR KO cells were treated overnight with 774 increasing amounts of IFN-I and then transduced with a fixed amount of pCSGW-HIV GP-VSVG 775 VLPs prepared as above. 48 hours post-transduction cells were harvested and analysed for GFP 776 expression by flow cytometry.

Blam Assay

780 Ebola BlamVP40-Ebola GP and Ebola BlaVP40-VSVg VLPs were produced on HEK293T cells. For that purpose, cells were plated in $10 \mathrm{~cm}$ dishes and transfected with $6 \mu \mathrm{g}$ of pcDNA3.1-EBOV BlaVP40

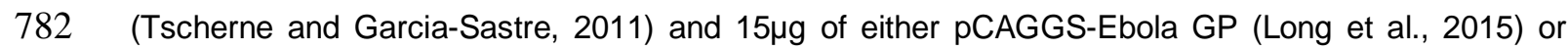
783 pCMV-VSVG using PEI max, and media was changed to OptiMEM 4-6 hours post-transfection.

784 Supernatants were harvested past 48 hours and cleared by centrifugation (5 minutes, 1500rpm) 785 before storage.

786 HEK293TIM-1 cells pre-treated with IFN-I, or transfected with either GFP or TRIM25, were 24 hours 787 later transduced with Blam VLPs prepared as above, and incubated for 3-5 hours. After incubation 788 cells were washed once with RPMI 1640 (no phenol red) medium (RPMI), and incubated in 1x loading 789 solution of LiveBLAzer FRET-B/G Loading Kit (Life Technologies) with CCF2-AM for 1 hour (dark, 790 room temperature). Following, cells were washed with $2.5 \mathrm{mM}$ Probenecid (Sigma) in RPMI and 791 incubated in the same medium overnight (dark, room temperature). Next day, cells were analyzed by 792 flow cytometry using BD FACSCanto II. Cells were gated on live cells and analyzed for CCF2 793 cleavage as readout for Blam VLP entry with Pacific Blue (cleaved) and FITC (not cleaved) laser 794 channels, and using FlowJo 10.4.2 software for analysis. 
796 Production and Purification of anti-EBOV antibodies

797 Rabbit antibodies against Ebola virus proteins NP, VP35 and VP30 were produced by Lampire

798 Biological Laboratories using their standard protocol. In brief, two rabbits per each viral peptide were

799 immunized with $0.50 \mathrm{mg}$ of antigen mixed with $0.5 \mathrm{ml}$ of Complete Freund's adjuvant. Two further

800 boosts were performed in the same conditions at days 21 and 42 . Serums used in this manuscript

801 were collected by day 50. The sequences of the viral protein peptides used in the immunizations are

802 as follow:

803 NP: DEDDEDTKPVPNRSTKGGQ

804 VP35: EAYWAEHGQPPPGPSLYEE

805 VP30: QLNITAPKDSRLANPTADD

807 For microscopy staining of the Ebola NP protein (see below), we have purified a fraction of the serum

808 collected from rabbits immunized with the viral NP peptide. For that purpose, protein A beads 809 (Invitrogen) were equilibrated by washing them with PBS, and then incubated with the serum for 2 810 hours at room temperature. Following, the beads were added into a column cartridge and washed 3 811 times with $10 \mathrm{ml}$ of PBS. IgGs were then eluted with $0.1 \mathrm{M}$ Glycine pH 3.5 in 5 batches of $1 \mathrm{ml}$. IgG 812 eluates were adjusted to $\mathrm{pH} 7.0$ with $2 \mathrm{M}$ Tris Base, $\mathrm{pH} 9.0$, and concentrated on Amicon Ultra 813 centrifugal filter units (MWCO 10kDa) (SIGMA) with buffer exchanged to PBS. Approximate 814 concentration of purified antibodies was determined by spectrometry $(280 \mathrm{~nm})$ and fragments 815 analyzed on SDS-PAGE.

\section{Analysis of cellular and viral proteins expression}

818 Cells used in this study were seeded on 24-well plates, and transfected the following day with EBOV

819 RNP-expressing plasmids as described above, either in combination with 150ng of individual ISG820 expressing plasmids per well or followed by the addition 4 hours post-transfection of increasing 821 amounts of type-I interferon. 24 hours later cellular lysates were subjected to SDS-PAGE and western 822 blots performed using mouse monoclonal antibodies anti-HSP90 (Santa Cruz), anti-HA (Covance) or 823 anti-TRIM25 (Abcam), or rabbit antibodies anti-EBOV NP, anti-EBOV VP35, anti-EBOV VP30, anti824 TRIM25 (Abcam), anti-RIG-I (Enzo), anti-MAVS/VISA (Bethyl), anti-TBK1 (Abcam), anti-ZCCHV/ZAP 
825 (Abcam) or anti-NPC1 (Thermo Fisher). Visualizations were done by Image-Quant using either HRP-

826 linked anti-mouse or anti-rabbit secondary antibodies (Cell Signaling).

\section{Immunoprecipitations}

829 To address the interaction of TRIM25 with EBOV-NP proteins cells were seeded in 6-well plates and 830 transfected with 500ng of either pcDNA3.1-GFP or pcDNA3.1-TRIM25wt, or mutants thereof, in 831 combination with $125 \mathrm{ng}$ of pCAGGS-NP and/or 125ng of pCAGGS-VP35. At 24 hours post832 transfection cells were lysed with a RIPA buffer containing $50 \mathrm{mM}$ Tris- $\mathrm{HCl}(\mathrm{pH} 7.4), 150 \mathrm{mM} \mathrm{NaCl}$, $8330.1 \%$ SDS, $0.5 \%$ sodium deoxycholate, $1 \%$ NP-40 and protease inhibitors (Roche). Following 834 sonication, lysates were immunoprecipitated overnight with either rabbit anti-TRIM25 (Abcam) or 835 rabbit anti-EBOV NP antibodies and protein $\mathrm{G}$ beads at $4^{\circ} \mathrm{C}$ on a tube rotator. On specific 836 experiments, cellular lysates were treated prior immunoprecipitation with $10 \mu \mathrm{g} / \mathrm{ml}$ of RNAseA 837 (SIGMA) for 2 hours at $37^{\circ} \mathrm{C}$.

838 For ubiquitination-related pull-downs cells were plated similarly in 6-well plates and transfected with $839500 \mathrm{ng}$ of either pcDNA3.1-GFP or pcDNA3.1-TRIM25wt, in combination with 125ng of pCAGGS-

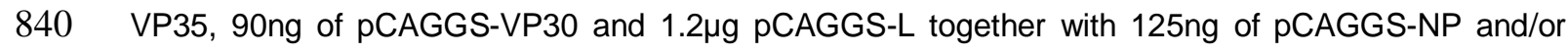
841 100ng of pMT123-HA-Ub (Treier et al., 1994). At 24 hours post-transfection cells were lysed with a 842 buffer containing 50mM Tris- $\mathrm{HCl}(\mathrm{pH} 7.4), 150 \mathrm{mM} \mathrm{NaCl}, 5 \mathrm{mM}$ EDTA, 5\% Glycerol, 1\% Triton-X 100, $84310 \mathrm{mM} \mathrm{N}$-Ethylmaleimide (NEM) and protease inhibitors. Lysates were treated as above and 844 immunoprecipitated overnight either with rabbit anti-EBOV-NP or mouse anti-HA (Covance).

845 Cell lysates and pull-down samples were subjected to SDS-PAGE and Western blots performed using 846 antibodies against HSP90 (Santa Cruz), TRIM25 (Abcam), EBOV-NP, EBOV-VP35, HA-tag 847 (Rockland) and ZAP (Abcam). Blots were visualized by ImageQuant using anti-mouse or anti-rabbit 848 HRP-linked antibodies (Cell Signaling).

\section{RNA Immunoprecipitation}

851 Cells were plated on $10 \mathrm{~cm}$ dishes and transfected in the absence of EBOV RNP expressing plasmids 852 with 2.5 $\mathrm{gg}$ of pcDNA3.1-GFP, pcDNA3.1-TRIM25wt (or mutants thereof), or pcDNA4-ZAP-L (Kerns et 853 al., 2008) and medium changed 4-6 hours later. Alternatively, cells were treated overnight with $8541000 \mathrm{U} / \mathrm{ml}$ of IFN-I or $250 \mu \mathrm{M}$ of T705. The following day cells were infected for 3 hours with $3 \mathrm{ml}$ of 
855 wild-type- or CpG low-EBOV trVLPs, or alternatively with the same volume of EBOV monocistronic

856 VLPs, and then gently washed in PBS prior to 'on dish' irradiation with $400 \mathrm{~mJ} / \mathrm{cm} 2$ using a UV

857 Stralinker 2400. Cells were subsequently lysed in $1 \mathrm{ml}$ of RIPA buffer (see above for composition) and

858 sonicated. Cleared lysates were immunoprecipitated overnight at $4^{\circ} \mathrm{C}$ with rabbit anti-EBOV NP or

859 rabbit anti-ZAP antibodies and protein G beads. Following 3 washes with RIPA buffer, the beads were

860 resuspended in $200 \mu \mathrm{l}$ of RIPA and boiled for $10 \mathrm{~min}$ to decouple protein/RNA complexes from the

861 beads. Finally, input and pulldown samples were incubated with proteinase $\mathrm{K}$ (Thermo Fisher,

$8622 \mathrm{mg} / \mathrm{ml}$ ) for $1 \mathrm{hr}$ at $37^{\circ} \mathrm{C}$, and then boiled for 10 minutes to inactivate the enzyme. Samples were

863 stored at $-20^{\circ} \mathrm{C}$ for downstream processing.

865 RNA Purification and Quantitative RT-PCR

866 Total RNA was isolated and purified from EBOV trVLP infected cells using a QIAGEN RNAeasy kit, 867 while viral RNA was extracted from supernatants using a QIAGEN QIAmp Viral mini kit, both 868 accordingly with the manufacture instructions. Unless otherwise stated, 50ng of purified RNA was 869 reverse transcribed by random hexamer primers using a High Capacity cDNA Reverse Transcription 870 kit (Applied Biosystems). Alternatively, strand-specific reverse transcription primers were used to 871 generate cDNAs for viral genomic RNA (-vRNA, EBOV -vRNA RT primer), complementary RNA 872 (+cRNA, EBOV +cRNA RT primer), or viral mRNA (oligo dT). Of the reaction, $5 \mu$ l were subjected to 873 quantitative PCR using primer/probe sets for human Gapdh (Applied Biosystems), and EBOV trVLP 874 5'-trailer region, L-Pol RNA or VP40 RNA (primer/probe sequences in Table S4). Quantitative PCRs 875 were performed on a QuantStudio 5 System (Thermo Fischer) and absolute quantification data 876 analyzed using Thermo Fisher's Cloud Connect online software.

877 Input and pulldown samples from RNA immunoprecipitations were first resuspended in QIAzol 878 (QIAGEN), and passed through QIAshredder columns (QIAGEN) for homogenization, and then 879 passed to phase lock gel tubes (VWR) prior to addition of chloroform (SIGMA). After manually 880 shaking the tubes, samples were centrifuged full-speed, for $15 \mathrm{~min}$ at $4^{\circ} \mathrm{C}$. The aqueous phase was 881 passed to a new tube, and isopropanol added. After 10 minutes at room temperature, tubes were 882 centrifuged as before and supernatants removed. RNA pellets were subsequently washed with $75 \%$ 883 Ethanol, and span at $7500 \mathrm{xg}$, for 5 minutes at $4^{\circ} \mathrm{C}$. Following aspiration of the supernatants, RNA 
884 pellets were left to dry and then resuspended in RNAse-free water. Downstream processing for reverse transcription and quantitative RT-PCR was done as detailed above.

\section{Deubiquitinase Assays}

888 Prior to the deubiquitinase reactions, immunoprecipitations were performed using similar conditions to 889 the ones described above for ubiquitination-related pull-downs. Briefly, HEK293T TRIM25 CRISPR 890 KO cells were plated in 6 well plates and transfected with 500ng of either pcDNA3.1-YFP or 891 pcDNA3.1-TRIM25 ${ }^{\mathrm{CR}}$ in combination with $125 \mathrm{ng}$ of pCAGGS-VP35, 90ng of pCAGGS-VP30, $1.2 \mu \mathrm{g}$ of 892 pCAGGS-L and 125ng of pCAGGS-NP, in the absence of ectopically expressed ubiquitin. Cells were 893 lysed 48 hours post-transfection and lysates immunoprecipitated overnight with rabbit anti-EBOV-NP 894 antibody using protein $\mathrm{G}$ agarose beads. Following immunoprecipitation, beads were treated with 895 UbiCREST Deubiquitinase Enzyme Kit (BostonBiochem) following manufacturer's instructions. Briefly, 896 beads were washed several times before being equally split into separate tubes and treated with 897 either USP2 or left untreated (NTC, non-treated control), for 30 minutes at $37^{\circ} \mathrm{C}$. Input lysates and 898 pull-down beads were subjected to SDS-PAGE and Western blots performed using antibodies against 899 HSP90 (Santa Cruz), TRIM25 (Abcam) and EBOV-NP. Blots were visualized by ImageQuant using 900 anti-mouse or anti-rabbit HRP-linked antibodies (Cell Signaling).

\section{Microscopy}

903 Cells were seeded on 24-well plates on top of coverslips pre-treated with poly-L-lysine to improve

904 their adherence. For transient assays, cells were transfected with different combinations of EBOV

905 RNP plasmids using the amounts described previously. Alternatively, cells were infected with $30 \mu \mathrm{l}$ of

906 concentrated EBOV trVLPs in the absence of ectopically expressed EBOV RNP components.

907 Cells were fixed 24 hours post-transfection, or 3 hours post-infection, with $4 \%$ paraformaldehyde for

90815 minutes at room temperature, and then washed first with PBS, followed by a second wash with $90910 \mathrm{mM}$ Glycine. Next, cells were permeabilized for 15 minutes with a PBS solution complemented with $9101 \%$ BSA and $0.1 \%$ Triton-X. Subsequently, cells were stained with mouse anti-TRIM25 911 (Abcam,10 $\mathrm{g} / \mathrm{ml})$ and purified rabbit anti-EBOV NP (1:50) antibodies diluted in PBS/0.01\% Triton-X 912 for an hour at room temperature. Cells were washed 3 times in PBS/0.01\% Triton-X, followed by an 913 incubation with Alexa Fluor 594 anti-mouse and Alexa Fluor 488 anti-rabbit antibodies (Molecular 
914 Probes, 1:500 in PBS/0.01\% Triton-X) for 45 minutes in the dark. Finally, coverslips were washed

915 once again 3 times with PBS/0,01\% Triton- $X$ and then mounted on slides with Prolong Diamond

916 Antifade Mountant with DAPI (Invitrogen). Imaging was performed on a Nikon Eclipse Ti Inverted

917 Microscope, equipped with a Yokogawa CSU/X1-spinning disk unit, under 60-100x objectives and

918 Laser wavelengths of $405 \mathrm{~nm}, 488 \mathrm{~nm}$ and $561 \mathrm{~nm}$. Image processing and co-localization analysis was

919 performed with NIS Elements Viewer and Image J (Fiji) software.

921 Statistical Analysis

922 Statistical significance was determined using paired two-tailed $t$ tests calculated using the Prism

923 software. Significance was ascribed to $p$ values as follows: ${ }^{*} p>0.05,{ }^{* *} p>0.01$, and ${ }^{* * *} p>0.001$.

924 Data relative to viral based assays, signalling reporter assay and Blam assays were performed in

925 duplicate in at least 3 independent experiments, and error bars represent +/-SEM.

926 For RNA IP experiments each data point is represented as average of three independent experiments

$927+$ +-SD.

\section{Contact for Reagents and Resources Sharing}

932 Further information and requests for resources and reagents should be directed to and will be fulfilled

933 by the Lead Contact, Stuart J.D. Neil (stuart.neil@kcl.ac.uk). Distribution of the CRISPR cell lines,

934 antibodies, EBOV p4cis-CpG low-vRNA-Rluc and pT7-1cis-vRNA CpG low-EBOV-hrluc minigenomes

935 generated in the course of this work will require signing of Material Transfer Agreements (MTA) in

936 accordance with policies of King's College London. All requests for other trVLP components should

937 be directed to Thomas Hoenen (thomas.hoenen@fli.de).

938

\section{Author Contributions}

940 Conceptualization: RPG, HW, SJW, CMS, SJDN ; Methodology: RPG, HW, KLS, FD, BSB, DG, TH,

941 SJW, CMS, SJDN; Investigation: RPG, HW, KLS, FD, BSB; Visualisation: RPG, HW, KLS, FD, CMS,

942 SJDN; Supervision: SJDN; Project Administration: SJDN; Funding Acquisition: SJDN; Writing - 
943 Original Draft: RPG, HW, SJDN; Writing - Review and Editing: RPG, HW, KLS, FD, TH, SJW, CMS,

944 SJDN

945

\section{Acknowledgments}

947 We thank other members of the Neil and Swanson laboratories for helpful discussions and Wendy S

948 Barclay (Imperial College London) for materials. We are grateful to Stefan Becker and his group for

949 advice. These studies were funded by an MRC Discovery Award MC/PC/15068 and a Wellcome Trust

950 Senior Research Fellowship (WT098049AIA) to SJDN, a Guy's and St Thomas's Charity Challenge

951 Fund grant to CMS and SJDN and MRC research grant MR/M019756/1 to CMS. This project has

952 received funding from the European Union's Horizon 2020 research and innovation programme under

953 the Marie Skłodowska-Curie grant agreement No. 750621 (KLS).

954

955 Conflict of interests

956 All authors declare no conflict of interests. 


\section{References}

959 Amman, B.R., Nyakarahuka, L., McElroy, A.K., Dodd, K.A., Sealy, T.K., Schuh, A.J., Shoemaker, 960 T.R., Balinandi, S., Atimnedi, P., Kaboyo, W., et al. (2014). Marburgvirus resurgence in Kitaka 961 Mine bat population after extermination attempts, Uganda. Emerg Infect Dis 20, 1761-1764.

962

Basler, C.F. (2015). Innate immune evasion by filoviruses. Virology 479-480, 122-130.

964

Basler, C.F., Mikulasova, A., Martinez-Sobrido, L., Paragas, J., Muhlberger, E., Bray, M., Klenk, H.D., Palese, P., and Garcia-Sastre, A. (2003). The Ebola virus VP35 protein inhibits activation of interferon regulatory factor 3 . J Virol 77, 7945-7956.

Beachboard, D.C., and Horner, S.M. (2016). Innate immune evasion strategies of DNA and

Bick, M.J., Carroll, J.W., Gao, G., Goff, S.P., Rice, C.M., and MacDonald, M.R. (2003). Expression of the zinc-finger antiviral protein inhibits alphavirus replication. J Virol 77, $11555-11562$.

975

Biedenkopf, N., Hartlieb, B., Hoenen, T., and Becker, S. (2013). Phosphorylation of Ebola virus VP30 influences the composition of the viral nucleocapsid complex: impact on viral transcription and replication. J Biol Chem 288, 11165-11174.

979 7496. 811.

988 Cadena, C., Ahmad, S., Xavier, A., Willemsen, J., Park, S., Park, J.W., Oh, S-W., Fujita, T., Hou, 989 F., Binder, M., Hur, S. (2019). Ubiquitin-Dependent and -Independent Roles of E3 Ligase RIPLET in Innate Immunity. Cell 16;177(5):1187-1200.e16.

Cai, X., Chen, J., Xu, H., Liu, S., Jiang, Q.X., Halfmann, R., and Chen, Z.J. (2014). Prion-like polymerization underlies signal transduction in antiviral immune defense and inflammasome activation. Cell 156, 1207-1222. Saphire, E.O., and Basler, C.F. (2006). Ebola virus VP35 protein binds double-stranded RNA and inhibits alpha/beta interferon production induced by RIG-I signaling. J Virol 80, 51685178. 
1004 Cauldwell, A.V., Moncorge, O., and Barclay, W.S. (2013). Unstable polymerase1005 nucleoprotein interaction is not responsible for avian influenza virus polymerase restriction 1006 in human cells. J Virol 87, 1278-1284.

1008 Chandran, K., Sullivan, N.J., Felbor, U., Whelan, S.P., and Cunningham, J.M. (2005). Endosomal proteolysis of the Ebola virus glycoprotein is necessary for infection. Science $308,1643-1645$.

1011

Chang, T-H., Kubota, T., Matsuoka, M., Jones, S., Bradfute, S.B., Bray, M., Ozato, K. (2009). Ebola Zaire virus blocks type I interferon production by exploiting the host SUMOS modification machinery. PLoS Pathog. Jun;5(6):e1000493. S-farnesylation is crucial for membrane targeting and antiviral activity of ZAP long-isoform. Proc Natl Acad Sci U S A 110, 11085-11090. Inhibition of Japanese encephalitis virus infection by the host zinc-finger antiviral protein. PLoS Pathog 14, e1007166.

Choudhury, N.R., Heikel, G., Trubitsyna, M., Kubik, P., Nowak, J.S., Webb, S., Granneman, S., Spanos, C., Rappsilber, J., Castello, A., et al. (2017). RNA-binding activity of TRIM25 is mediated by its PRY/SPRY domain and is required for ubiquitination. BMC Biol 15, 105.

Cote, M., Misasi, J., Ren, T., Bruchez, A., Lee, K., Filone, C.M., Hensley, L., Li, Q., Ory, D., Chandran, K., et al. (2011). Small molecule inhibitors reveal Niemann-Pick C1 is essential for Ebola virus infection. Nature 477, 344-348.

1031

D'Cruz, A.A., Kershaw, N.J., Chiang, J.J., Wang, M.K., Nicola, N.A., Babon, J.J., Gack, M.U., and Nicholson, S.E. (2013). Crystal structure of the TRIM25 B30.2 (PRYSPRY) domain: a key component of antiviral signalling. Biochem J 456, 231-240.

Deen, G.F., Broutet, N., Xu, W., Knust, B., Sesay, F.R., McDonald, S.L.R., Ervin, E., Marrinan, J.E., Gaillard, P., Habib, N., et al. (2017). Ebola RNA Persistence in Semen of Ebola Virus Disease Survivors - Final Report. N Engl J Med 377, 1428-1437.

Demaison, C., Parsley, K., Brouns, G., Scherr, M., Battmer, K., Kinnon, C., Grez, M., and Thrasher, A.J. (2002). High-level transduction and gene expression in hematopoietic repopulating cells using a human immunodeficiency [correction of imunodeficiency] virus type 1-based lentiviral vector containing an internal spleen focus forming virus promoter. Hum Gene Ther 13, 803-813.

Dutta, M., Robertson, S.J., Okumura, A., Scott, D.P., Chang, J., Weiss, J.M., Sturdevant, G.L., Feldmann, F., Haddock, E., Chiramel, A.I., et al. (2017). A Systems Approach Reveals MAVS Signaling in Myeloid Cells as Critical for Resistance to Ebola Virus in Murine Models of Infection. Cell Rep 18, 816-829. 
1051 Escudero-Pérez, B. and Muñoz-Fontela, C. (2019). Role of Type I Interferons on Filovirus

1052

1053

1054

Pathogenesis. Vaccines (Basel) Feb 20;7(1):22.

1055

Ficarelli, M., Wilson, H., Galão, R.P., Mazzon, M., Antzin-Anduetza, I., Marsh, M., Neil, S.J.D.,

1056

1057

1058

Swanson, C.M. (2019). KHNYN is essential for the zinc finger antiviral protein (ZAP) to restrict HIV-1 containing clustered CpG dinucleotides. Elife Jul 9;8:e46767.

1059

Fletcher, A.J., Mallery, D.L., Watkinson, R.E., Dickson, C.F., and James, L.C. (2015). Sequential ubiquitination and deubiquitination enzymes synchronize the dual sensor and effector functions of TRIM21. Proc Natl Acad Sci U S A 112, 10014-10019.

1061

1062

Fros, J.J., Dietrich, I., Alshaikhahmed, K., Passchier, T.C., Evans, D.J., and Simmonds, P.

1063 (2017). CpG and UpA dinucleotides in both coding and non-coding regions of echovirus 7 inhibit replication initiation post-entry. Elife 6.

1065

1066

Gack, M.U., Albrecht, R.A., Urano, T., Inn, K.S., Huang, I.C., Carnero, E., Farzan, M., Inoue, S., Jung, J.U., and Garcia-Sastre, A. (2009). Influenza A virus NS1 targets the ubiquitin ligase

1068 TRIM25 to evade recognition by the host viral RNA sensor RIG-I. Cell Host Microbe 5, 4391069449.

1070 Gack, M.U., Shin, Y.C., Joo, C.H., Urano, T., Liang, C., Sun, L., Takeuchi, O., Akira, S., Chen, Z., 1071 Inoue, S., et al. (2007). TRIM25 RING-finger E3 ubiquitin ligase is essential for RIG-I-mediated

1072

1073

1074 antiviral activity. Nature 446, 916-920.

1075

Gallois-Montbrun, S., Kramer, B., Swanson, C.M., Byers, H., Lynham, S., Ward, M., and Malim, M.H. (2007). Antiviral protein APOBEC3G localizes to ribonucleoprotein complexes

1076

1077

1078 found in P bodies and stress granules. J Virol 81, 2165-2178.

Gao, G., Guo, X., and Goff, S.P. (2002). Inhibition of retroviral RNA production by ZAP, a CCCH-type zinc finger protein. Science 297, 1703-1706.

1080

1081

Geisbert, T.W., Hensley, L.E., Larsen, T., Young, H.A., Reed, D.S., Geisbert, J.B., Scott, D.P., Kagan, E., Jahrling, P.B., and Davis, K.J. (2003a). Pathogenesis of Ebola hemorrhagic fever in cynomolgus macaques: evidence that dendritic cells are early and sustained targets of infection. Am J Pathol 163, 2347-2370.

1084

1085

1086

Geisbert, T.W., Young, H.A., Jahrling, P.B., Davis, K.J., Larsen, T., Kagan, E., and Hensley, L.E. 1087

1088 (2003b). Pathogenesis of Ebola hemorrhagic fever in primate models: evidence that hemorrhage is not a direct effect of virus-induced cytolysis of endothelial cells. Am J Pathol 1089 163, 2371-2382.

1090

1091

Goodier, J.L., Pereira, G.C., Cheung, L.E., Rose, R.J., and Kazazian, H.H., Jr. (2015). The Broad-

1092 Spectrum Antiviral Protein ZAP Restricts Human Retrotransposition. PLoS Genet 11, 1093 e1005252.

1094

1095

1096

1097

Hayakawa, S., Shiratori, S., Yamato, H., Kameyama, T., Kitatsuji, C., Kashigi, F., Goto, S., Kameoka, S., Fujikura, D., Yamada, T., et al. (2011). ZAPS is a potent stimulator of signaling mediated by the RNA helicase RIG-I during antiviral responses. Nat Immunol 12, 37-44. 
1098

1099

1100

1101

1102

1103

1104

1105

1106

1107

1108

1109

1110

1111

1112

1113

1114

1115

1116

1117

1118

1119

1120

1121

1122

1123

1124

1125

1126

1127

1128

1129

1130

1131

1132

1133

1134

1135

1136

1137

1138

1139

1140

1141

1142

1143
Hoenen, T., Shabman, R.S., Groseth, A., Herwig, A., Weber, M., Schudt, G., Dolnik, O., Basler, C.F., Becker, S., and Feldmann, H. (2012). Inclusion bodies are a site of ebolavirus replication. J Virol 86, 11779-11788.

Huang, I.C., Bailey, C.C., Weyer, J.L., Radoshitzky, S.R., Becker, M.M., Chiang, J.J., Brass, A.L., Ahmed, A.A., Chi, X., Dong, L., et al. (2011). Distinct patterns of IFITM-mediated restriction of filoviruses, SARS coronavirus, and influenza A virus. PLoS Pathog 7, e1001258.

James, L.C. (2014). Intracellular antibody immunity and the cytosolic Fc receptor TRIM21. Curr Top Microbiol Immunol 382, 51-66.

Kaletsky, R.L., Francica, J.R., Agrawal-Gamse, C., and Bates, P. (2009). Tetherin-mediated restriction of filovirus budding is antagonized by the Ebola glycoprotein. Proc Natl Acad Sci U S A 106, 2886-2891.

Kane, M., Zang, T.M., Rihn, S.J., Zhang, F., Kueck, T., Alim, M., Schoggins, J., Rice, C.M., Wilson, S.J., and Bieniasz, P.D. (2016). Identification of Interferon-Stimulated Genes with Antiretroviral Activity. Cell Host Microbe 20, 392-405.

Kerns, J.A., Emerman, M., and Malik, H.S. (2008). Positive selection and increased antiviral activity associated with the PARP-containing isoform of human zinc-finger antiviral protein. PLoS Genet 4, e21.

Kirchdoerfer, R.N., Abelson, D.M., Li, S., Wood, M.R., and Saphire, E.O. (2015). Assembly of the Ebola Virus Nucleoprotein from a Chaperoned VP35 Complex. Cell Rep 12, 140-149.

Kruse, T., Biedenkopf, N., Hertz, E.P.T., Dietzel, E., Stalmann, G., Lopez-Mendez, B., Davey, N.E., Nilsson, J., and Becker, S. (2018). The Ebola Virus Nucleoprotein Recruits the Host PP2A-B56 Phosphatase to Activate Transcriptional Support Activity of VP30. Mol Cell 69, 136-145 e136.

Kuroda, M., Halfmann, P.J., Hill-Batorski, L., Ozawa, M., Lopes, T.J.S., Neumann, G., Schoggins, J.W., Rice, C.M., Kawaoka, Y. (2020). Identification of interferon-stimulated genes that attenuate EBOV infection. Nat Commun Jun 11;11(1)2953.

Leroy, E.M., Kumulungui, B., Pourrut, X., Rouquet, P., Hassanin, A., Yaba, P., Delicat, A., Paweska, J.T., Gonzalez, J.P., and Swanepoel, R. (2005). Fruit bats as reservoirs of Ebola virus. Nature 438, 575-576.

Li, M.M., Lau, Z., Cheung, P., Aguilar, E.G., Schneider, W.M., Bozzacco, L., Molina, H., Buehler, E., Takaoka, A., Rice, C.M., et al. (2017). TRIM25 Enhances the Antiviral Action of Zinc-Finger Antiviral Protein (ZAP). PLoS Pathog 13, e1006145.

Liu, Y., Gordesky-Gold, B., Leney-Greene, M., Weinbren, N.L., Tudor, M., and Cherry, S. (2018). Inflammation-Induced, STING-Dependent Autophagy Restricts Zika Virus Infection in the Drosophila Brain. Cell Host Microbe 24, 57-68 e53. 
1144 Long, J., Wright, E., Molesti, E., Temperton, N., and Barclay, W. (2015). Antiviral therapies entry. F1000Res 4, 30.

Loo, Y.M., and Gale, M., Jr. (2011). Immune signaling by RIG-I-like receptors. Immunity 34, 680-692.

Lopez, L.A., Yang, S.J., Hauser, H., Exline, C.M., Haworth, K.G., Oldenburg, J., and Cannon, independent manner that does not require tetherin surface removal. J Virol 84, 7243-7255. Jul 17;14(1):74-84.

Martin-Serrano, J., Zang, T., and Bieniasz, P.D. (2001). HIV-1 and Ebola virus encode small medicine 7, 1313-1319.

McCarthy, S.D.S., Majchrzak-Kita, B., Racine, T., Kozlowski, H.N., Baker, D.P., Hoenen, T., Effective Inhibitors of Ebola Virus. PLoS Negl Trop Dis Jan 11;10(1):e0004364.

McNab, F., Mayer-Barber, K., Sher, A., Wack, A., and O'Garra, A. (2015). Type I interferons in infectious disease. Nat Rev Immunol 15, 87-103.

Messaoudi, I., Amarasinghe, G.K., and Basler, C.F. (2015). Filovirus pathogenesis and immune evasion: insights from Ebola virus and Marburg virus. Nat Rev Microbiol 13, 663676.

Meyerson, N.R., Zhou, L., Guo, Y.R., Zhao, C., Tao, Y.J., Krug, R.M., and Sawyer, S.L. (2017). Nuclear TRIM25 Specifically Targets Influenza Virus Ribonucleoproteins to Block the Onset 1190 of RNA Chain Elongation. Cell Host Microbe 22, 627-638 e627. 
1191 Moncorge, O., Long, J.S., Cauldwell, A.V., Zhou, H., Lycett, S.J., and Barclay, W.S. (2013).

1192

1193

1194

Investigation of influenza virus polymerase activity in pig cells. J Virol 87, 384-394.

1195

Moncorge, O., Mura, M., and Barclay, W.S. (2010). Evidence for avian and human host cell

1196

1197

1198

1199

factors that affect the activity of influenza virus polymerase. J Virol 84, 9978-9986.

Muhlberger, E. (2007). Filovirus replication and transcription. Future Virol 2, 205-215.

1200

Muller, S., Moller, P., Bick, M.J., Wurr, S., Becker, S., Gunther, S., and Kummerer, B.M.

1201 (2007). Inhibition of filovirus replication by the zinc finger antiviral protein. J Virol 81, 23912400.

1202

1203

Neil, S.J., Zang, T., and Bieniasz, P.D. (2008). Tetherin inhibits retrovirus release and is antagonized by HIV-1 Vpu. Nature 451, 425-430.

1205

1206

1207

1208

Noda, T., Hagiwara, K., Sagara, H., and Kawaoka, Y. (2010). Characterization of the Ebola virus nucleoprotein-RNA complex. J Gen Virol 91, 1478-1483.

Noda, T., Sagara, H., Suzuki, E., Takada, A., Kida, H., and Kawaoka, Y. (2002). Ebola virus VP40 drives the formation of virus-like filamentous particles along with GP. J Virol 76, 4855-

1211

1212

1213 4865 .

Odon, V., Fros, J.J., Goonawardane, N., Dietrich, I., Ibrahim, A., Alshaikhahmed, K., Nguyen, D., Simmonds, P. (2019). The role of ZAP and OAS3/RNAse L pathways in the attenuation of an RNA virus with elevated frequencies of $\mathrm{CpG}$ and UpA dinucleotides. Nucleic Acids Res 5;47(15):8061-8083.

Okamoto, M., Kouwaki, T., Fukushima, Y., and Oshiumi, H. (2017). Regulation of RIG-I Activation by K63-Linked Polyubiquitination. Front Immunol 8, 1942.

Okumura, A., Pitha, P.M., and Harty, R.N. (2008). ISG15 inhibits Ebola VP40 VLP budding in an L-domain-dependent manner by blocking Nedd4 ligase activity. Proc Natl Acad Sci U S A 105, 3974-3979.

Pertel, T., Hausmann, S., Morger, D., Zuger, S., Guerra, J., Lascano, J., Reinhard, C., Santoni, capsid lattice. Nature 472, 361-365.

Pleschka, S., Jaskunas, R., Engelhardt, O.G., Zurcher, T., Palese, P., and Garcia-Sastre, A. (1996). A plasmid-based reverse genetics system for influenza A virus. J Virol 70, 4188-4192.

Prins, K.C., Cardenas, W.B., and Basler, C.F. (2009). Ebola virus protein VP35 impairs the function of interferon regulatory factor-activating kinases IKKepsilon and TBK-1. J Virol 83, 1234 3069-3077. 
1236

1237

1238

1239

1240

1241

1242

1243

1244

1245

1246

1247

1248

1249

1250

1251

1252

1253

1254

1255

1256

1257

1258

1259

1260

1261

1262

1263

1264

1265

1266

1267

1268

1269

1270

1271

1272

1273

1274

1275

1276

1277

1278

1279

1280

1281
Sanchez, J.G., Chiang, J.J., Sparrer, K.M.J., Alam, S.L., Chi, M., Roganowicz, M.D., Sankaran, B., Gack, M.U., and Pornillos, O. (2016). Mechanism of TRIM25 Catalytic Activation in the Antiviral RIG-I Pathway. Cell Rep 16, 1315-1325.

Sanchez, J.G., Okreglicka, K., Chandrasekaran, V., Welker, J.M., Sundquist, W.I., and Pornillos, O. (2014). The tripartite motif coiled-coil is an elongated antiparallel hairpin dimer. Proc Natl Acad Sci U S A 111, 2494-2499.

Sanchez, J.G., Sparrer, K.M.J., Chiang, C., Reis, R.A., Chiang, J.J., Zurenski, M.A., Wan, Y., Gack, M.U., and Pornillos, O. (2018). TRIM25 Binds RNA to Modulate Cellular Anti-viral Defense. J Mol Biol 430, 5280-5293.

Schneider, W.M., Chevillotte, M.D., and Rice, C.M. (2014). Interferon-stimulated genes: a complex web of host defenses. Annu Rev Immunol 32, 513-545.

Schoggins, J.W., Wilson, S.J., Panis, M., Murphy, M.Y., Jones, C.T., Bieniasz, P., and Rice, C.M. (2011). A diverse range of gene products are effectors of the type I interferon antiviral response. Nature 472, 481-485.

Shabman, R.S., Gulcicek, E.E., Stone, K.L., and Basler, C.F. (2011). The Ebola virus VP24 protein prevents hnRNP C1/C2 binding to karyopherin alpha1 and partially alters its nuclear import. J Infect Dis 204 Suppl 3, S904-910.

Su, Z., Wu, C., Shi, L., Luthra, P., Pintilie, G.D., Johnson, B., Porter, J.R., Ge, P., Chen, M., Liu, G., et al. (2018). Electron Cryo-microscopy Structure of Ebola Virus Nucleoprotein Reveals a Mechanism for Nucleocapsid-like Assembly. Cell 172, 966-978 e912.

Subissi, L., Keita, M., Mesfin, S., Rezza, G., Diallo, B., Van Gucht, S., Musa, E.O., Yoti, Z., Keita, S., Djingarey, M.H., et al. (2018). Ebola Virus Transmission Caused by Persistently Infected Survivors of the 2014-2016 Outbreak in West Africa. J Infect Dis.

Takata, M.A., Goncalves-Carneiro, D., Zang, T.M., Soll, S.J., York, A., Blanco-Melo, D., and Bieniasz, P.D. (2017). CG dinucleotide suppression enables antiviral defence targeting nonself RNA. Nature 550, 124-127.

Thorson, A.E., Deen, G.F., Bernstein, K.T., Liu, W.J., Yamba, F., Habib, N., Sesay, F.R., Gaillard, P., Massaquoi, T.A., McDonald, S.L.R., et al. (2021). Persistence of Ebola virus in semen among Ebola virus disease survivors in Sierra Leone: A cohort study of frequency, duration, and risk factors. PLoS Med. Feb 10;18(2):e1003273.

Tomar, D., and Singh, R. (2015). TRIM family proteins: emerging class of RING E3 ligases as regulator of NF-kappaB pathway. Biol Cell 107, 22-40.

Treier, M., Staszewski, L.M., and Bohmann, D. (1994). Ubiquitin-dependent c-Jun degradation in vivo is mediated by the delta domain. Cell 78, 787-798. 
1282 Tscherne, D.M., and Garcia-Sastre, A. (2011). An enzymatic assay for detection of viral entry.

Vetter, P., Fischer, W.A., $2^{\text {nd }}$, Schibler, M., Jacobs, M., Bausch, D.G., and Kaiser, L. (2016). 1286 Ebola Virus Shedding and Transmission: Review of Current Evidence. J Infect Dis 214, S1771287 S184.

1288 Wan, W., Kolesnikova, L., Clarke, M., Koehler, A., Noda, T., Becker, S., and Briggs, J.A.G. 1289 (2017). Structure and assembly of the Ebola virus nucleocapsid. Nature 551, 394-397.

Watt, A., Moukambi, F., Banadyga, L., Groseth, A., Callison, J., Herwig, A., Ebihara, H., Feldmann, H., and Hoenen, T. (2014). A novel life cycle modeling system for Ebola virus shows a genome length-dependent role of VP24 in virus infectivity. J Virol 88, 10511-10524.

1294

Zhang, A.P., Bornholdt, Z.A., Liu, T., Abelson, D.M., Lee, D.E., Li, S., Woods, V.L., Jr., and 1296 Saphire, E.O. (2012). The ebola virus interferon antagonist VP24 directly binds STAT1 and has a novel, pyramidal fold. PLoS Pathog 8, e1002550. MAVS-mediated antiviral signaling through interaction with ATG5 and repressing ROS production. PLoS Pathog 8, e1003086.

1304 


\section{Figure Legends}

1310 Figure 1. Human ISG-expression screening identifies novel candidates with antiviral activity against 1311 EBOV trVLP.

1312 (A) EBOV trVLP normalized reporter activity on HEK293T- and U87-MG-stably expressing TIM1

1313 transfected with EBOV RNP proteins and pre-treated with increasing amounts of IFN-I 24 hours prior

1314 infection ( $\mathrm{p} 1$ target cells, blue). Supernatants from $\mathrm{p} 1$ cells were harvested $24 \mathrm{hpi}$, and used to infect

1315 HEK293T-TIM1 cells and reporter activities measured 24 hours later (p2 target cells, red).

1316 (B) HEK293T-TIM1 cells were pre-treated with IFN-I (1000U/ml) prior to transduction with BlaVP40-

1317 EBOV-GP virus-like particles. 24 hours later, viral particle entry was measured as percentage of cells 1318 presenting cleavage of CCF2-AM dye by flow cytometry.

1319 (C) Relative quantification of intracellular viral RNA levels on HEK293T-TIM1 (grey) and U87-MG-

1320 TIM1 (blue) p1 target cells pre-treated with IFN-I, and infected with EBOV trVLPs as in (A). Random 1321 hexamer primers were used to generate cDNAs and RT-qPCR analysis was performed using qPCR 1322 primers/probe sets targeting the 5'-trailer region of the trVLP 4cis minigenome (vRNA and cRNA, left 1323 panel), VP40 RNA (vRNA, cRNA and mRNA, right panel) or gapdh as endogenous control. Data 1324 presented as fold change compared to control (no IFN) based on $\Delta \Delta$ Ct values.

1325 (D) Relative quantification of viral transcripts present on supernatants from (C). cDNA synthesis 1326 performed as above and RT-qPCR performed with primers/probe set targeting EBOV VP40 RNA. 1327 Data shown as fold change compared to control (no IFN) based on absolute copy numbers.

1328 (E) Results of the arrayed human ISG screen. HEK293T-TIM1 target cells ( $p 1$ ) were pre-transfected 1329 with plasmids expressing individual ISGs together with EBOV RNP components and Firefly 1330 transfection control, and infected with EBOV trVLPs 24 hours later. Supernatants from p1 cells were 1331 harvested 24 hpi and used to infect p2 target cells pre-transfected solely with vRNP components and 1332 pFluc. EBOV trVLP reporter activities for p1 (blue dots) and p2 target cells (red dots) were measured 1333 as in (A). Each dot represents one ISG. Infectivity measured for each ISG-expressing well was 1334 normalized to the activity of Fluc control within the well, and values are represented as percentage of 1335 the screen plate average, which is indicated as log of $100 \%$.

1336 (F) Confirmatory assays for selected top candidate inhibitory ISGs. EBOV-trVLP infection was 1337 performed on HEK293T-TIM1 cells as in the primary screen. Normalized reporter activities for p1 
1338 (upper panels) and p2 target cells (lower panels) are represented as percentage of EBOV trVLP 1339 replication on cells transfected with GFP (white bars).

1340 (G) Relative quantification of intracellular (left and middle panels) and supernatant (right panel) viral 1341 RNA levels on HEK293T-TIM1 target cells ( 1 1) transfected with EBOV RNP components and the top 1342 inhibitory ISG candidates and infected as before. cDNA synthesis and RT-qPCR analysis performed 1343 as in (C) and (D).

1344 All the represented EBOV trVLP Rluc reporter activities are normalized to control Fluc values 1345 obtained in the same lysates. Universal Type I IFN- $\alpha$ was used to pre-treat cells in panels (A-D). * $p$ > $13460.05,{ }^{* \star} p>0.01$ and ${ }^{* \star *} p>0.001$ as determined by two-tailed paired t-test. All error bars represent \pm 1347 SEM of at least three independent experiments.

1349 Figure 2. TRIM25 is required for type-I IFN-mediated restriction of EBOV trVLP replication.

1350 (A) EBOV trVLP normalized reporter activity on HEK293T-TIM1 cells transfected with EBOV RNP 1351 proteins and either GFP (grey) or TRIM25 (blue) prior to infection with increasing amounts of EBOV 1352 trVLPs ( $\mathrm{p} 1$ target cells, left panel). Supernatants from $\mathrm{p} 1 \mathrm{cells}$ were harvested $24 \mathrm{hpi}$ and used to 1353 infect p2 target cells (right panel), and reporter activities measured 24 hours later.

1354 (B) HEK293T-TIM1 cells were transfected with plasmids expressing either GFP (grey) or TRIM25 1355 (blue), and transduced with BlaVP40-EBOV-GP virus like particles 24 hours later. Viral particle entry 1356 was determined 24 hours post-transduction by measuring the percentage of cells with cleaved CCF21357 AM dye by flow cytometry.

1358 (C) Quantification of viral RNA transcripts present on cell lysates (left panel) and supernatants (right 1359 panel) of HEK293T-TIM1 cells transfected and infected as in (A). Strand-specific reverse transcription 1360 primers were used on total RNA extracted from cells to generate cDNAs for minigenomic RNA 1361 (vRNA), complementary RNA (cRNA), and mRNA, which were subsequently analysed by RT-qPCR.

1362 Random hexamer primers were used to generate cDNAs from total viral RNA extracted from 1363 supernatants, and qPCR analysis performed using primers/probe sets targeting 5 ' trailer region of the 1364 4cis genome or VP40 RNA.

1365 (D) U87-MG- and HEK293T-based CRISPR cells lines were treated with increasing amounts of IFN-I, 1366 and lysed 24 hours later for analysis. Protein levels of HSP90 and TRIM25 were determined by 1367 western blot on LacZ CRISPR control cells and corresponding TRIM25 CRISPR KO cell lines. 
1368 (E) EBOV trVLP reporter activities on U87-MG LacZ CRISPR-TIM1 (grey) and U87-MG TRIM25 1369 CRISPR KO-TIM1 (blue) target cells (p1) transfected with EBOV RNP proteins, and pre-treated with 1370 increasing amounts of IFN-I prior to infection.

1371 (F) Relative quantification of intracellular and supernatant trVLP RNA levels on U87-MG LacZ 1372 CRISPR-TIM1 (grey) and U87-MG TRIM25 CRISPR KO-TIM1 cells (blue) from (E). Random hexamer 1373 primers were used to generate cDNAs and RT-qPCR analysis was performed using primers/probe 1374 sets targeting trVLP 4cis genome trailer region (VRNA and CRNA, left panel), or VP40 RNA 1375 (intracellular vRNA, cRNA and mRNA, middle panel; minigenomic RNA in the supernatant, right 1376 panel). Data shown as fold change compared to control (no IFN) based on absolute copy numbers.

1377 (G) EBOV trVLP reporter activities on U87-MG LacZ CRISPR-TIM1 (solid lines) and U87-MG TRIM25 1378 CRISPR KO-TIM1 (dashed lines) target cells transfected with EBOV RNP proteins and pre-treated 1379 with increasing amounts of IFN- $\alpha 2 a$ (blue) or IFN-B1b (red) prior to infection.

1380 (H) U87-MG LacZ CRISPR (grey) and U87-MG TRIM25 CRISPR KO cells (blue) were treated with 1381 increasing amounts of IFN-I, and transduced the following day with a VSV-G pseudo-typed lentiviral 1382 vector expressing GFP (CSGW). The percentage of GFP-positive cells was determined 24 hours later 1383 by flow cytometry.

1384 (I) HEK293T LacZ CRISPR (grey) and HEK293T TRIM25 CRISPR KO (blue) were used as producer 1385 cells $(\mathrm{p} 0)$ of EBOV trVLPs and reporter activities measured 48 hours post-transfection. Supernatants 1386 from p0 cells were used to infect HEK293T-TIM1 target cells (p1), and reporter activities determined 138724 hours later.

1388 All the represented EBOV trVLP RLuc reporter activities are normalized to control FLuc values 1389 obtained in the same lysates. ${ }^{*} p>0.05,{ }^{* *} p>0.01$ and ${ }^{* * *} p>0.001$ as determined by two-tailed 1390 paired t-test. All error bars represent \pm SEM of at least three independent experiments.

1392 Figure 3. TRIM25 antiviral effect against EBOV trVLPs is independent of RIG-I and downstream pro1393 inflammatory signal transduction.

1394 (A, B, H) U87-MG- and/or HEK293T-based CRISPR cells lines were treated with increasing amounts 1395 of IFN-I, and lysed 24 hours later for protein analysis. Protein levels of HSP90 (A, B and H), RIG-I (A), 1396 FL-MAVS/mini-MAVS (B) and TBK1 (H) were determined by western blot on LacZ CRISPR control 1397 cells and corresponding CRISPR knock-out (KO) cells lines. 
1398 (C, I) HEK293T-based CRISPR cell lines depicted in the figures were transfected with plasmids 1399 expressing EBOV RNP proteins and TIM-1 together with either GFP (grey bars) or TRIM25 (blue 1400 bars), and later infected with a fixed amount of EBOV trVLPs. 24 hpi cells were lysed and trVLP 1401 reporter activities measured.

1402 (D) EBOV trVLP reporter activities on U87-MG LacZ CRISPR (grey) and U87-MG RIG-I CRISPR KO 1403 (blue) target cells ( $\mathrm{p} 1$ ), transfected with TIM-1 and EBOV RNP proteins, and pre-treated overnight 1404 with increasing amounts of IFN-I prior to infection. Luciferase activities measured 24 hours post1405 infection.

1406 (E) EBOV trVLP reporter activities on U87-MG LacZ CRISPR (grey), U87-MG FL-MAVS KO (blue) 1407 and FL-MAVS/miniMAVS CRISPR DKO (red) target cells (p1), transfected with TIM-1 and EBOV 1408 RNP proteins, and pre-treated overnight with increasing amounts of IFN-I prior to infection. Luciferase 1409 activities measured 24 hours post-infection.

1410 (F) Protein levels of HSP90 and MAVS determined by western blot lysates from HEK293T LacZ 1411 control cells, and HEK293T-MAVS DKO cells lines engineered to stably express CRISPR-resistant 1412 variants of both MAVS isoforms $\left(M^{2} A V S^{C R}\right)$, miniMAVS $\left(M 1 A^{C R}\right)$ or FL-MAVS $\left(M 142 A^{C R}\right)$.

1413 (G) HEK293T LacZ CRISPR and engineered HEK293T-MAVS DKO cell lines from (F) were co1414 transfected with plasmids expressing EBOV RNP components and TIM-1 together with either GFP 1415 (grey bars) or TRIM25 (blue bars), and later infected with EBOV trVLPs. Reporter activities were 1416 measured 24 hours later.

1417 (J) U87-MG LacZ CRISPR and U87-MG TBK1 CRISPR KO cells were transfected with RNP proteins 1418 and TIM-1, followed by a IFN-I pre-treatment prior to infection with a fixed amount of EBOV trVLPS. 1419 EBOV trVLP reporter activities in $\mathrm{p} 1$ were measured 24 hours after infection.

1420 (K) Fold activation of a firefly luciferase NF-kB reporter in the depicted HEK293T-based CRISPR cells 1421 lines transiently transfected with TRIM25 compared to control GFP vector. Cells were harvested 48 1422 hours post-transfection and FLuc reporter values normalised to control Renilla luciferase activity in the 1423 same lysates.

1424 All the represented EBOV trVLP Renilla reporter activities are normalized to control Firefly luciferase 1425 values obtained in the same lysates. ${ }^{*} p>0.05,{ }^{* *} p>0.01$ and ${ }^{* * *} p>0.001$ as determined by two1426 tailed paired t-test. All error bars represent \pm SEM of at least three independent experiments. 
1429 Figure 4. TRIM25 and ZAP are inter-dependent for their antiviral activity against EBOV trVLP.

1430 (A) EBOV trVLP normalized reporter activity on HEK293T-TIM1 cells transfected with EBOV RNP 1431 proteins and either GFP (grey) or ZAP-L (red) prior to infection with increasing amounts of EBOV 1432 trVLPs ( $\mathrm{p} 1$ target cells, left panel). Supernatants from $\mathrm{p} 1$ cells were harvested and used to infect $\mathrm{p} 2$ 1433 target cells (right panel), and reporter activities measured 24 hours later.

1434 (B) HEK293T- and U87-MG-based CRISPR cells lines were treated with increasing amounts of IFN-I, 1435 and lysed 24 hours later for analysis. Protein levels of HSP90 and ZAP were determined by western 1436 blot on LacZ CRISPR control cells and corresponding ZAP CRISPR KO cell lines.

1437 (C) EBOV trVLP reporter activities on U87-MG LacZ CRISPR-TIM1 (grey) and U87-MG ZAP CRISPR 1438 KO-TIM1 (red) target cells ( $\mathrm{p} 1)$, transfect with RNP proteins and pre-treated with increasing amounts 1439 of IFN-I prior to infection. Reporter activities measured 24 hours after infection.

1440 (D) Quantification of intracellular and supernatant viral RNA levels on U87-MG LacZ CRISPR-TIM1 1441 (grey) and U87-MG ZAP CRISPR KO-TIM1 target cells (red) that were transfected with EBOV RNP 1442 proteins and pre-treated with IFN-I, prior to infection with EBOV trVLPs as in (C). Random hexamer 1443 primers were used to generate cDNAs and RT-qPCR analysis was performed using primers/probe 1444 sets targeting either the trailer region of the viral genome (vRNA and cRNA, left panel), or VP40 RNA 1445 (intracellular vRNA, cRNA and mRNA, middle panel; minigenomic RNA in the supernatant, right 1446 panel). Data presented as fold change compared to control (no IFN) based on absolute copy 1447 numbers.

1448 (E) EBOV trVLP normalized reporter activities on HEK293T LacZ CRISPR, HEK293T TRIM25 1449 CRISPR KO and HEK293T ZAP CRISPR KO cells stably expressing TIM1, that were transfected with 1450 EBOV RNP plasmids together with GFP (grey), ZAP L (red) or TRIM25 (blue), prior to infection with a 1451 fixed amount of EBOV trVLPs ( $\mathrm{p} 1$ target cells). Supernatants from $\mathrm{p} 1$ were then harvested and used 1452 to infect HEK293T-TIM1 cells (p2 target cells).

1453 (F) Relative quantification of EBOV L-Polymerase RNA transcripts on cell lysates of HEK293T LacZ 1454 CRISPR-TIM1 and HEK293T TRIM25 CRISPR KO-TIM1 cells transfected EBOV RNP plasmids in 1455 combination with either with GFP (grey) or ZAP-L (red), and infected with a fixed amount of EBOV 1456 trVLPs. Random hexamer primers were used to generate cDNAs from total RNA, and RT-qPCR 1457 analysis performed using a primers/probe sets targeting EBOV L-polymerase and gapdh. Data 
1458 normalized to L-polymerase RNA levels on HEK293T LacZ CRISPR-TIM1 cells transfected with GFP 1459 based on $\Delta \Delta \mathrm{Ct}$ values.

1460 (G) EBOV trVLP normalized reporter activity on p2 target cells. HEK293T-TIM1 p1 cells were 1461 transfected with EBOV RNP proteins, and either GFP (grey) or ZAP-L (red) prior to infection with 1462 increasing amounts of wild-type EBOV trVLPs (trVLPwt, solid lines) or a variant with no CpG 1463 dinucleotides on the Renilla ORF of the 4cis genome (CpG low, dashed lines). Supernatants from $\mathrm{p} 1$ 1464 were harvested and used to infect HEK293T-TIM1 p2 target cells.

1465 (H) Quantification of viral RNA transcripts present intracellularly (upper and middle panels) and in 1466 supernatants (lower panel) of 293T-TIM1 cells transfected as in (G), and infected with a fixed amount 1467 of EBOV trVLP WT or CpG low. Random hexamer primers were used to generate cDNAs from total 1468 RNA and RT-qPCR analysis was performed as in (D).

1469 (I) EBOV trVLP normalized reporter activity on HEK293T-TIM1 p2 target cells. HEK293T LacZ 1470 CRISPR-TIM1 (grey) and HEK293T ZAP CRISPR KO-TIM1 cells (red) were transfected with EBOV 1471 RNP proteins and pre-treated with increasing amounts of IFN-I prior to infection with wild-type EBOV 1472 trVLPs (solid lines) or CpG Low EBOV trVLP (dashed lines). Supernatants from p1 were harvested 1473 and used to infect HEK293T-TIM1 p2 target cells. Reporter activities measured 24 hours post1474 infection.

1475 All the represented EBOV trVLP Renilla reporter activities are normalized to control Firefly luciferase 1476 values obtained in the same lysates. $P>0.05,{ }^{* *} p>0.01$ and ${ }^{* * *} p>0.001$ as determined by two1477 tailed paired t-test. All error bars represent \pm SEM of at least three independent experiments.

1479 Figure 5. TRIM25 interacts with EBOV NP and promotes its ubiquitination.

1480 (A) Lysates of HEK293T-TIM1 cells transfected either with GFP or TRIM25, in combination with 1481 EBOV NP and/or EBOV VP35, were immunoprecipitated with an anti-TRIM25 antibody. Cellular 1482 lysates and pull-downs were analysed by western blot for HSP90, TRIM25, EBOV NP and VP35.

1483 (B) Panels show representative fields for the localization of EBOV NP and endogenous TRIM25 on 1484 HEK293T-TIM1 cells left untreated (Null), or transfected with EBOV NP protein alone, or in 1485 combination either with VP35 or all remaining RNP proteins (VP35, VP30 and L). Cells were stained 1486 with anti-TRIM25 (red) and anti-NP (green) antibodies, as well as with DAPI (blue). White arrows 1487 point to the localization of TRIM25 intracellular aggregates. 
1488 (C) Schematic representation of functional domains within TRIM25 (upper panel). Lysates of 1489 HEK293T-TIM1 cells transfected with EBOV NP in combination with GFP, TRIM25 or mutants 1490 thereof, were immunoprecipitated with an anti-TRIM25 antibody. Input and pull-down samples were 1491 blotted for HSP90, TRIM25 and EBOV NP (lower panel). (*) indicates the detected heavy-chains (HC) 1492 from the antibody used in the pull-down.

1493 (D) EBOV trVLP normalized reporter activity on HEK293T-TIM1 cells transfected with EBOV RNP 1494 proteins in combination with GFP (grey), TRIM25 wild-type (blue), TRIM25 $\Delta$ RING (red) or TRIM25 $1495 \triangle S P R Y$ (orange) mutants, prior to infection with increasing amounts of EBOV trVLPs (p1 target cells). 1496 EBOV trVLP Rluc reporter activities were measure $24 \mathrm{hpi}$ and normalized to control Fluc values 1497 obtained in the same lysates. EBOV trVLP Renilla reporter activities are normalized to control Firefly 1498 luciferase values obtained in the same lysates. ${ }^{*} p>0.05,{ }^{* *} p>0.01$ and ${ }^{* * *} p>0.001$ as determined 1499 by two-tailed paired t-test. All error bars represent \pm SEM of at least three independent experiments.

1500 (E) HEK293T-TIM1 cells were transfected either with GFP or TRIM25, in combination with EBOV NP 1501 and/or a plasmid expressing a HA-tagged Ubiquitin (HA-Ub). Lysates from these cells were 1502 immunoprecipitated with an anti-HA antibody (left panels) or an anti-NP antibody (right panels). 1503 Cellular lysates and pull-down samples were analysed by western blot for HSP90, TRIM25, EBOV NP 1504 and $\mathrm{HA}$ (ubiquitin).

1505 (F) Lysates from HEK293T cells co-transfected with EBOV NP and YFP or TRIM25 were 1506 immunoprecipitated with an anti-NP antibody, and pulled-down fractions treated with USP2 1507 deubiquitinase enzyme. Cellular lysates and pull-downs were analysed by western blot for HSP90, 1508 TRIM25 and EBOV NP.

1510 Figure 6. Determinants of TRIM25 antiviral activity and NP interaction

1511 (A) Upper Panel: schematic representation of TRIM25 with the localization of the RING dimerization 1512 mutants (light blue), E3-Ligase catalytic mutants (pink), Bbox2 \& coiled-coil mutants (orange) and 1513 SPRY-domain and RNA-binding mutants (light green) generated on a TRIM25 CRISPR-resistant 1514 background. Lower Panel: EBOV trVLP normalized reporter activity on HEK293T TRIM25 CRISPR 1515 KO-TIM1 cells transfected with EBOV RNP proteins in combination with GFP (grey), CRISPR1516 resistant (CR) TRIM25 wild-type (dark blue), or mutants thereof (see upper panel), prior to infection 1517 with EBOV trVLPs (p1 target cells). EBOV trVLP Rluc reporter activities were measure 24 hpi and 
1518 normalized to control Fluc values obtained in the same lysates. All error bars represent \pm SEM of four

1519 independent experiments. ${ }^{*} p>0.05,{ }^{* *} p>0.01$ and ${ }^{* * *} p>0.001$ as determined by Oneway-ANOVA.

1520 Statistics represented above graphic bars were calculated as multiple comparisons to TRIM25 wild-

1521 type, while the statistics within graphic bars are represented in function of multiple comparison to 1522 YFP.

1523 (B) HEK293T TRIM25 CRISPR KO cells were transfected with plasmids expressing the EBOV RNP 1524 proteins together with YFP, CRISPR-resistant TRIM25 or mutants thereof. Cell lysates were analysed 152548 hours later by western blot for the expression of HSP90, TRIM25 and EBOV NP.

1526 (C) Lysates of HEK293T cells transfected with EBOV NP in combination with either YFP or CRISPR1527 resistant TRIM25 (or mutants thereof) were immunoprecipitated with a rabbit anti-TRIM25 antibody. 1528 Cellular lysates and pull-down samples were analysed by western blot for HSP90, TRIM25 and EBOV 1529 NP.

1531 Figure 7. TRIM25 and ZAP promote the dissociation of EBOV trVLP genomic RNA from the viral 1532 ribonucleoprotein.

1533 (A) Typical confocal microscopy fields from HEK293T LacZ CRISPR-TIM1 (left panels) or HEK293T 1534 NPC1 CRIPSR KO-TIM1 cells (right panels) left untreated (Null) or infected with EBOV trVLPs 1535 concentrated on a $20 \%$ sucrose-cushion. Cells were stained 4 to 6 hours post-infection with anti1536 TRIM25 (red), anti-EBOV NP (green) and DAPI (blue). White arrows show localization of TRIM25 1537 intracellular aggregates.

1538 (B) Relative quantification of intracellular RNA levels (grey) and NP-associated RNA (blue) on 1539 HEK293T LacZ CRISPR-TIM1 and HEK293T NPC1 CRISPR KO-TIM1 cells transfected with GFP, 1540 TRIM25 or ZAP-L prior to infection with EBOV trVLPs. 3 hours post-infection cells were UV cross1541 linked, and EBOV NP from incoming virions was immunoprecipitated from lysates with an anti-NP 1542 antibody. Following proteinase K treatment, pulled-down RNA was extracted with Qiazol / chloroform, 1543 and random hexamer primers were used to generate cDNAs, and RT-qPCR analysis performed using 1544 a primers/probe set targeting EBOV VP40 RNA. Values are presented as percentage of absolute 1545 RNA copy numbers on cells transfected with GFP.

1546 (C) HEK293T LacZ CRISPR, HEK293T ZAP CRISPR KO and HEK293T TRIM25 CRISPR KO cells 1547 stably expressing TIM1 were transfected with GFP, TRIM25 or ZAP-L as depicted in the panels, and 
1548 later infected with EBOV trVLPs. Relative quantification of intracellular viral RNA levels (grey) and 1549 NP-associated RNA (coloured bars) were determined as in (B).

1550 (D) HEK293T-TIM1 cells were transfected with GFP, wild-type TRIM25 or mutants thereof prior to 1551 infection with EBOV trVLPs. Relative quantification of intracellular viral RNA levels (grey) and NP1552 associated RNA (blue) were determined as in (B).

1553 (E) HEK293T TRIM25 CRISPR KO-TIM1 cells were transfected with GFP (grey), or CRISPR-resistant 1554 versions of TRIM25 (wild-type, dark blue; or mutants thereof, as depicted in the figure, light blue) prior 1555 to infection with EBOV trVLPs. Relative quantification of NP-associated RNA was determined as in 1556 (B).

1557 (F) Prior to infection with EBOV trVLPs, HEK293T LacZ CRISPR-TIM1 cells were transfected with 1558 GFP or TRIM25 and either treated with $250 \mu \mathrm{M}$ of T705 (Favipiravir), or the equivalent volume of the 1559 diluent (DMSO). Relative quantification of intracellular viral RNA levels (grey) and NP-associated RNA 1560 (coloured bars) were determined as in (B). Values are presented as percentage of absolute RNA copy 1561 numbers on cells transfected with GFP.

1562 (G) Relative quantification of ZAP-associated RNA on HEK293T LacZ CRISPR-TIM1 and HEK293T 1563 TRIM25 CRISPR KO-TIM1 cells transfected with GFP (grey) or ZAP-L (red) prior to infection with 1564 EBOV trVLPs. 3 hours post-infection cells were UV cross-linked, and ZAP was immunoprecipitated 1565 from lysates. RNA extraction, cDNA synthesis and RT-qPCR analysis were performed as in (B). 1566 Values were normalized to the respective inputs and are presented relative to absolute RNA copy 1567 numbers on cells transfected with GFP.

1568 (H) HEK293T LacZ CRISPR, HEK293T TRIM25 CRISPR KO and HEK293T ZAP CRISPR KO cells 1569 stably expressing TIM1 were either untreated or pre-treated with $1000 \mathrm{U} / \mathrm{ml}$ of IFN-I prior to infection 1570 with EBOV trVLPs. Relative quantification of intracellular viral RNA levels (grey) and NP-associated 1571 RNA (coloured bars) were determined as in (B). Values are presented as percentage of absolute RNA 1572 copy numbers on cells non-treated with IFN.

1573 (I) HEK293T LacZ CRISPR, HEK293T TRIM25 CRISPR and HEK293T ZAP CRISPR KO cells stably 1574 expressing TIM1 were pre-treated overnight with increasing concentrations of IFN-I prior to infection 1575 with EBOV nanoluciferase trVLPs. EBOV trVLP nanoluc reporter activities were measured 48 hpi and 1576 data is shown as a percentage of untreated for each cell line individually. 
bioRxiv preprint doi: https://doi.org/10.1101/2021.05.23.445113; this version posted May 24, 2021. The copyright holder for this preprint (which

was not certified by peer review) is the author/funder, who has granted bioRxiv a license to display the preprint in perpetuity. It is made available under aCC-BY-NC-ND 4.0 International license.

1577 (J). Proposed model for the mechanism associated with the antiviral activities of TRIM25 and ZAP

1578 against EBOV trVLP. EBOV viral particle enters the cells by macropinocytosis, followed by NPC1-

1579 dependent fusion with the cellular endosomal membrane. Once in the cytoplasm, TRIM25 is recruited

1580 to the viral particle through an interaction with EBOV NP protein, leading to the ubiquitination of both

1581 viral target and TRIM25 itself. This results in the displacement of the viral RNA genome from the

1582 VRNP, followed by its recognition by ZAP in a way dependent of the genome's CpG content and

1583 subsequent impact in the transcription and replication of EBOV trVLP.

1584

1585

1586 


\section{Supplemental Figure Legends}

1588 Supplemental Figure S1 (related to Figure 1). EBOV trVLP assay and characterization of top 1589 candidate inhibitory ISGs.

1590 (A) Upper panels: Graphical representations of the Ebola virus genome, and of the tetra-cistronic 1591 minigenome (4cis) encoding Renilla luciferase (R/uc) used in the transcription- and replication1592 competent (trVLP) assay. Lower panel: Schematic representation of the EBOV trVLP assay. Plasmids 1593 expressing ISGs of interest were co-transfected with viral RNP proteins into p1 target cells.

1594 Alternatively, p1 target cells were pre-treated with IFN-I prior infection with EBOV trVLPs (detailed 1595 description on Methods).

1596 (B) U87-MG-Tim1 cells were transfected with plasmids expressing EBOV's RNP components and 1597 pre-treated with increasing amounts of Universal type-I IFN- $\alpha$, IFN- $\alpha 2 a$ or IFN-B1a, 16-24 hours prior 1598 to EBOV trVLP infection. Reporter activities were measured 24 hours later.

1599 (C) U87-MG-TIM1 and HEK293T-TIM1 cells were transfected with plasmids expressing EBOV NP, 1600 VP35, VP30 and a HA-tagged version of L-polymerase, before being treated with increasing amounts 1601 of IFN-I prior to EBOV trVLP infection as in Figure 1A. Cells were lysed 24 hours post-transfection 1602 and lysates analysed by western blot for the expression of the EBOV RNP proteins and HSP90.

1603 (D) ISG Screen Validation. Normal distribution of EBOV trVLP Rluc values in the presence of 1604 individually over-expressed ISGs on p1 (left panel, blue dots) and p2 (right panel, red dots) target 1605 cells, normalized to Fluc levels on the same well. The number (n) of ISGs within standard deviation 1606 (s.d. or z score) ranges is shown in the boxes.

1607 (E) HEK293T-TIM1 cells were transfected with plasmids expressing the EBOV RNP proteins together 1608 with selected ISGs. Cells lysates were analysed 48 hours later by western blot as in (C).

1609 (F) HEK293T-TIM1 cells were transfected with individual ISGs and EBOV RNP-expressing plasmids 1610 as in (E), and tested for cellular viability 48 hours later using Cell-Titer Glo luminescence-based assay 1611 (Promega). As positive control for toxicity (red bar), cells were treated for $48 \mathrm{~h}$ with a concentration of 1612 MG132 $(25 \mu \mathrm{M})$ sufficient to reduce in 50 percent the ATP levels in the supernatant. Values are 1613 represented as percentage of luminescence obtained in control wells transfected with GFP (grey bar), 1614 and toxicity cut-off represented as a dashed line.

1615 (G) Fold activation of Firefly luciferase NF-kB, ISG56/IFIT1 or ISRE reporters (top, middle or bottom 1616 panels, respectively) in HEK293T cells transiently transfected with selected individual ISGs compared 
1617 to control GFP vector. Cells were harvested either 24 hours (blue) or 48 hours (grey) post1618 transfection.

1620 Supplemental Figure S2 (related to Figure 4). Overexpression of ZAP-L impacts on EBOV trVLP 1621 viral RNA levels

1622 (A) Quantification of viral RNA transcripts present intracellularly (left panel) and in supernatants (right 1623 panel) of HEK293T-TIM1 cells transfected as in Figure 4A, and infected with a fixed amount of EBOV 1624 trVLPs. Strand-specific reverse transcription primers were used on total RNA extracted from cells to 1625 generate cDNAs for minigenomic RNA (vRNA), complementary RNA (cRNA), and mRNA, followed by 1626 RT-qPCR analysis. Random hexamer primers were used to generate cDNAs from total RNA 1627 extracted from supernatants, and qPCR analysis performed using primers targeting the 5 ' trailer 1628 region of the 4cis minigenome or VP40 RNA.

1629 (B) EBOV trVLP reporter activities on U87-MG LacZ CRISPR-TIM1 (solid lines) and U87-MG ZAP 1630 CRISPR KO-TIM1 (dashed lines) target cells transfected with EBOV RNP proteins and pre-treated 1631 with increasing amounts of IFN- $\alpha 2 a$ (blue) or IFN-B1b (red) prior to infection.

1632 (C) HEK293T LacZ CRISPR (grey) and HEK293T ZAP CRISPR KO (red) were used as producer 1633 cells $(\mathrm{p} 0)$ for EBOV trVLPs, and reporter activities measured 48 hours post-transfection. Supernatants 1634 from p0 were used to infect HEK293T-TIM1 target cells (p1), and reporter activities determined 24 1635 hours later.

1636 (D) Influenza A minigenome assay was performed in HEK293T LacZ CRISPR (grey), HEK293T ZAP 1637 CRISPR KO (red) and HEK293T RIG-I CRISPR KO (blue) cells transfected with Influenza polymerase 1638 components (NP, PB1, PB2 and PA) and increasing amounts of TRIM25. Normalized Fluc values are 1639 presented as percentage relative to a GFP control in each cell line.

1640 (E) HEK293T LacZ CRISPR, and HEK293T TRIM25 CRISPR KO cells were transfected with 1641 plasmids expressing the EBOV NP, VP35, VP30 proteins and a HA-tagged L Polymerase together 1642 with either pcDNA4 or ZAP-L. Cells lysates were analysed 48 hours later by western blot for the 1643 expression of HSP90, TRIM25, ZAP and the EBOV RNP complex proteins.

1644 (F) Relative quantification of intracellular viral RNA transcripts on cell lysates of HEK293T LacZ 1645 CRISPR-TIM1 and HEK293T TRIM25 CRISPR KO-TIM1 cells transfected EBOV RNP plasmids in 1646 combination with either with GFP (grey) or ZAP-L (red), and infected with a fixed amount of EBOV 
1647 trVLPs. Random hexamer primers were used to generate cDNAs from total RNA, and RT-qPCR

1648 analysis performed using a primers/probe sets targeting VP40 (mRNA,cRNA and vRNA, left), Trailer

1649 (cRNA and vRNA, right) and gapdh. Data normalized to HEK293T LacZ CRISPR-TIM1 cells 1650 transfected with GFP based on $\Delta \Delta \mathrm{Ct}$ values.

1651 (G) Graphical representation of the ratio between observed and expected CpG dinucleotide 1652 frequencies in the full-length EBOV genomic RNA (grey), in the wild-type trVLP 4cis genome (dark 1653 blue) and in the trVLP genomic variant with no CpG dinucleotides in the Renilla reporter sequence 1654 (CpG low, light blue).

1655 (H) Graphical representation of $\mathrm{CpG}$ dinucleotides localization on full-length EBOV genome (upper 1656 panel), on EBOV trVLP 4cis genome (middle panel) and on a 4cis genome with no CpG on the 1657 Renilla ORF (lower panel). CpG dinucleotides present on intergenic regions are represented in blue, 1658 while the ones present on viral ORFs are represented in red. In yellow are represented the CpG 1659 dinucleotides present on the Renilla reporter gene.

1660 (I) U87-MG LacZ CRISPR and U87-MG KHNYN CRISPR KO cells were transfected with RNP 1661 proteins and TIM-1, followed by a IFN-I pre-treatment prior to infection with a fixed amount of EBOV 1662 trVLPs. EBOV trVLP reporter activities in p1 were measured 24 hours after infection.

1663 (J) Relative quantification of intracellular viral RNA levels on cellular lysates from (I). Random 1664 hexamer primers were used to generate cDNAs and RT-qPCR analysis was performed using qPCR 1665 primers/probe sets targeting the VP40 RNA (vRNA, cRNA and mRNA, left panel) or the 5'-trailer 1666 region of the trVLP 4cis minigenome (VRNA and cRNA, right panel). Data presented as fold change 1667 compared to control (no IFN) based on absolute copy numbers.

1668

1669 Supplemental Figure S3 (related to Figure 5). TRIM25-mediated ubiquitination of EBOV NP is 1670 independent of ZAP and MAVS

1671 (A) Lysates of HEK293T-TIM1 cells transfected either with GFP or TRIM25, in combination with 1672 EBOV NP and/or EBOV VP35 were immunoprecipitated with an anti-NP antibody. Cellular lysates 1673 and pull-downs were analysed by western blot for HSP90, TRIM25, EBOV NP and VP35.

1674 (B) Lysates of HEK293T-TIM1 cells transfected either with EBOV NP and/or TRIM25 were left 1675 untreated (NT), or treated with RNase A prior to immunoprecipitation with an anti-TRIM25 antibody. 1676 Cellular lysates and pull-downs were analysed by western blot for HSP90, TRIM25 and EBOV NP. 
1677 (C) Lysates of HEK293T LacZ CRISPR and HEK293T ZAP CRISPR KO cells transfected either with 1678 GFP or TRIM25 and/or EBOV NP were immunoprecipitated with anti-TRIM25 antibody. Cellular 1679 lysates and pull-down samples were analysed by western blot for HSP90, TRIM25, EBOV NP and 1680 ZAP.

1681 (D) HEK293T-TIM1 cells were transfected either with GFP, TRIM25 wild-type or TRIM25 $\Delta$ RING 1682 mutant, in combination with EBOV NP and/or a plasmid expressing a HA-tagged Ubiquitin (HA-Ub). 1683 Lysates from these cells were immunoprecipitated 48 hours later with an anti-HA antibody. Cellular 1684 lysates and pull-down samples were analysed by western blot for HSP90, TRIM25, NP and HA 1685 (ubiquitin).

1686 (E) HEK293T LacZ CRISPR and HEK293T ZAP CRISPR KO cells were transfected either with GFP 1687 or TRIM25, in combination with EBOV NP and/or Ub-HA. Lysates from these cells were 1688 immunoprecipitated 48 hours later with an anti-HA antibody. Cellular lysates and pull-down samples 1689 were analysed by western blot as in (D).

1690 (F) HEK293T LacZ control and HEK293T FL-MAVS/miniMAVS CRISPR DKO cells were transfected 1691 either with GFP or TRIM25 in combination with EBOV NP and/or HA-Ub. Lysates were 1692 immunoprecipitated with anti-HA antibody and analysed by western blotting as in (D).

1693 (G) HEK293T LacZ CRISPR control and HEK293T TRIM25 CRISPR KO cells were infected with a 1694 fixed volume of EBOV trVLPs concentrated on a $20 \%$ sucrose-cushion. Cell were lysed at the 1695 depicted time points after infection and lysates analysed by western blot for HSP90 and EBOV NP.

1697 Supplemental Figure S4 (related to Figure 7). EBOV trVLP replication is dependent on the entry 1698 factor NPC1 and it is sensitive to transcription inhibitor T705 (Favipiravir)

1699 (A) Cellular lysates from HEK293T LacZ CRISPR-TIM1, HEK293T NPC1 CRISPR KO-TIM1 and 1700 HEK293T NPC1 CRISPR KO-TIM1 cells with restored expression of NPC1 (+NPC1) were analysed 1701 by western blot for HSP90 and NPC1.

1702 (B) The cells lines used in (A) were transduced either with BlaVP40-EBOV-GP or BlaVP40-VSV-G 1703 virus-like particles, and 24 hours later the percentages of cells presenting cleavage of CCF2-AM dye 1704 were determined by flow cytometry as readout for viral particle entry. 
1705 (C) EBOV trVLP normalized reporter activity on the upper mentioned cell lines (p1) transfected with 1706 EBOV RNP proteins and infected the following day with a fixed amount of EBOV trVLPs. Reporter 1707 activities were measured 24 hours later.

1708 (D) Quantification of intracellular viral RNA levels on HEK293T-TIM1 target cells 3 and 24 hours post1709 infection with a fixed amount of EBOV trVLPs. Prior to infection the cells were transfected with EBOV 1710 RNP expressing plasmids together with GFP (grey), TRIM25 (blue) or ZAP-L (red). Strand-specific 1711 reverse transcription primers were used on total RNA extracted from cells to generate cDNAs for 1712 minigenomic RNA (vRNA), complementary RNA (cRNA), and mRNA, followed by RT-qPCR analysis.

1713 (E) Relative quantification of NP-associated RNA on HEK293T LacZ CRISPR-TIM1 cells transfected 1714 with GFP (grey), TRIM25 (blue) or ZAP-L (red) prior to infection with wild-type or CpG low EBOV 1715 trVLPs. 3 hours post-infection cells were UV cross-linked, and EBOV NP from incoming virions was 1716 immunoprecipitated from lysates with an anti-NP antibody. Following proteinase K treatment, pulled1717 down RNAs were extracted with Qiazol / chloroform, random hexamer primers used to generate 1718 cDNAs, and RT-qPCR analysis performed using a primers/probe set targeting EBOV VP40 RNA. 1719 Values are presented as percentage of absolute RNA copy numbers on cells transfected with GFP.

1720 (F) HEK293T LacZ CRISPR, HEK293T ZAP CRISPR KO and HEK293T TRIM25 CRISPR KO cells 1721 stably expressing TIM1 were transfected with GFP (grey), TRIM25 (blue) or ZAP-L (red) as depicted 1722 in the panels, and later infected with wild-type (solid bars) or CpG low (striped bars) EBOV trVLPs. 1723 Relative quantification of NP-associated RNA was determined as in (E).

1724 (G) EBOV trVLP reporter activities on HEK293T-TIM1 target cells (p1), transfect with RNP proteins 1725 and pre-treated overnight with increasing amounts of T-705 (Favipiravir) prior to infection. Reporter 1726 activities measured 24 hours after infection.

1727 (H) Relative quantification of intracellular viral RNA levels on HEK293T-TIM1 p1 target cells pre1728 treated with increasing amounts of T-705 compound and infected with EBOV trVLPs as in $(G)$. 1729 Random hexamer primers were used to generate cDNAs and RT-qPCR analysis was performed 1730 using qPCR primers/probe sets targeting the VP40 mRNA or gapdh as endogenous control. Data 1731 presented as fold change compared to control (no T-705) based on $\Delta \Delta \mathrm{Ct}$ values.

1732 (I) Graphical representation of CpG dinucleotides localization on a monocistronic genome containing 1733 a Renilla reporter gene flanked by the 5'-leader and 3'-trailer regions of EBOV genome (upper panel), 1734 and its Low-CpG variant (bottom panel) in which all CpGs in the Renilla ORF were silently mutated. 
$1735 \mathrm{CpG}$ dinucleotides present on the trailer and leader regions are represented in blue, while in yellow

1736 are represented the CpG dinucleotides present on the Renilla reporter gene.

1737 (J) Normalized reporter activity of the monocistronic genomes on HEK293T-TIM1 target transfected 1738 with EBOV RNP proteins, and either GFP (grey) or ZAP-L (red) prior to infection with increasing

1739 amounts of wild-type monocistronic VLPs (WT, solid lines) or a variant with no CpG dinucleotides on

1740 the Renilla ORF (CpG low, striped lines).

1741 (K) HEK293T LacZ CRISPR-TIM1 cells were transfected with GFP (grey) or ZAP-L (red) and later 1742 infected with wild-type (solid bars) or CpG low (striped bars) monocistronic VLPs. Relative 1743 quantification of ZAP-associated RNA was determined as in (E).

1744 (L) HEK293T LacZ CRISPR and HEK293T NPC1 CRISPR stably expressing TIM1 were infected with 1745 either WT or $\triangle$ GP EBOV nanoluciferase trVLPs. EBOV trVLP nanoluc reporter activities were 1746 measured 48 hpi.

1747 (M) HEK293T TRIM25 CRISPR KO cells were transfected with TIM1 and either a CRISPR-resistant 1748 version of TRIM25 or YFP before infection with WT or $\triangle$ GP EBOV nanoluciferase trVLPs. EBOV $1749 \operatorname{trVLP}$ nanoluc reporter activities were measured $48 \mathrm{hpi}$. 
Figure 1

bioRxiv preprint doi: https://doi.org/10.1101/2021.05.23.445113; this version posted May 24, 2021. The copyright holder for this preprint (which A was not certified by peer review) is the aythor/funder, whothas granted bioRxiv a license to display the preprint in perpetuity. It is made
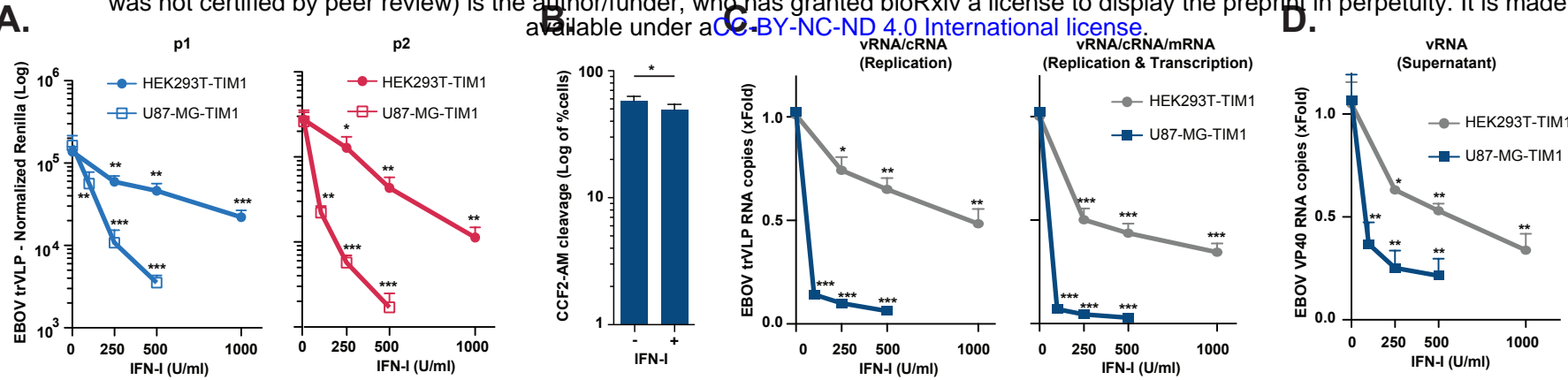

E.

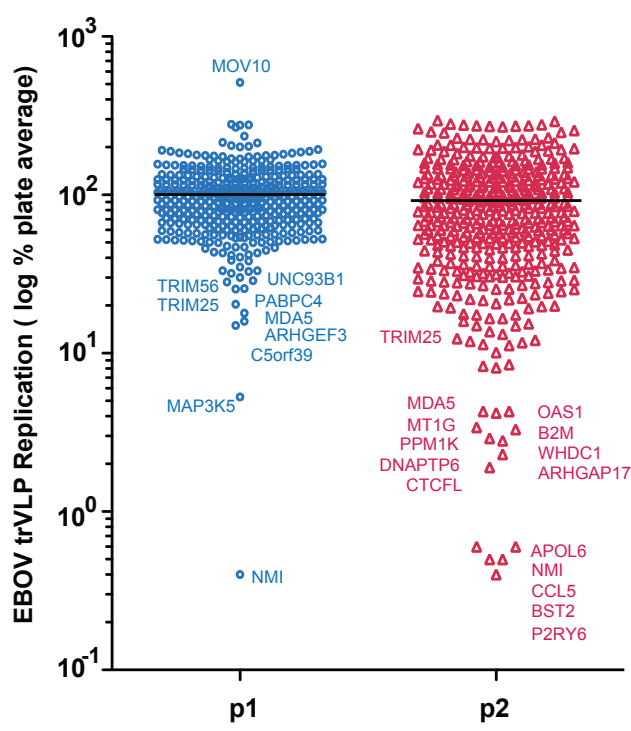

F.
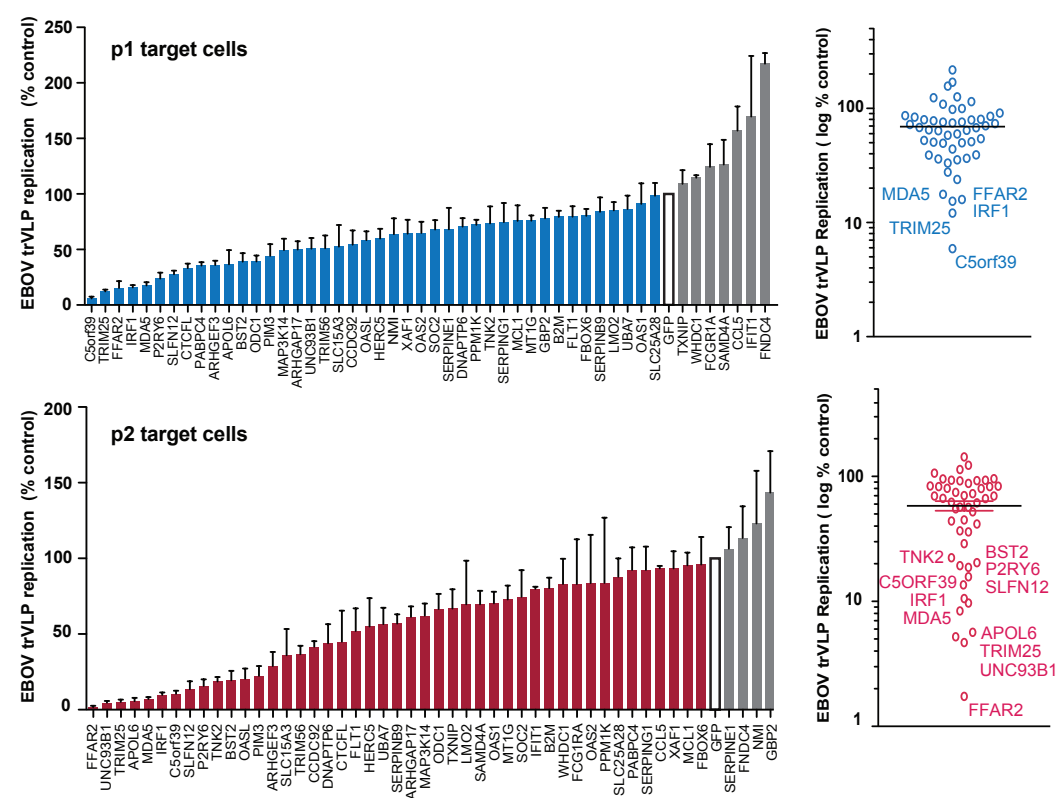

G.

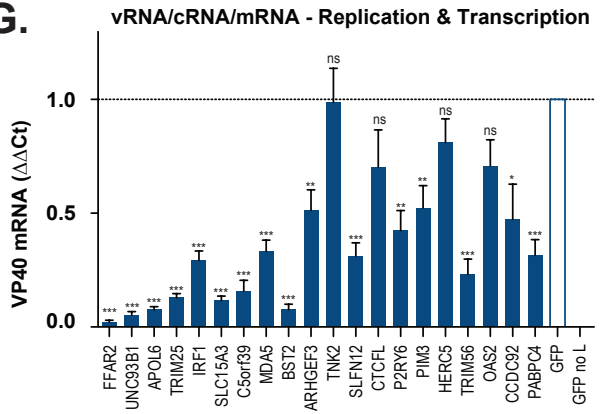

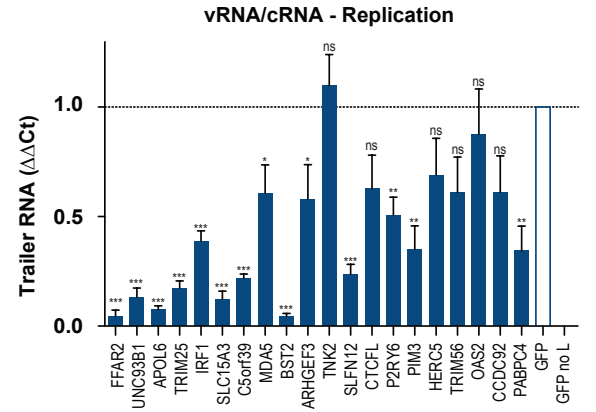

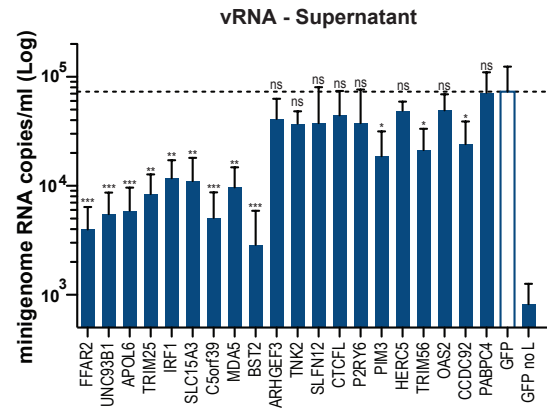


Figure 2 2 pionxiv preprint doi: https://doi.org/10.1101/2021.05.23.445113; this version posted May 24, 2021. The copyright holder for this preprint (which was not certified by peer review) is the author/funder, who has granted bioRxiv a license to display the preprint in perpetuity. It is made

A.

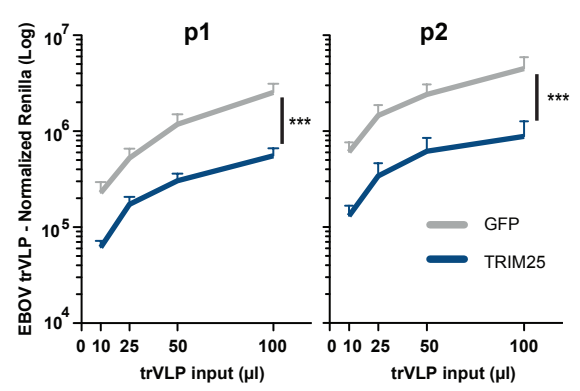

D.

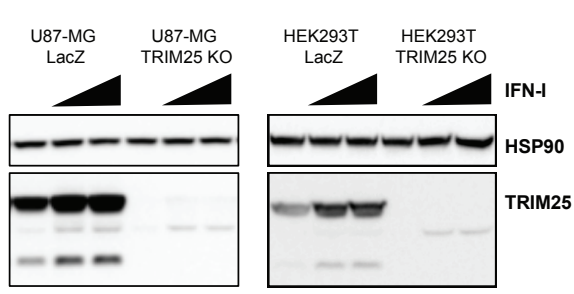

G.

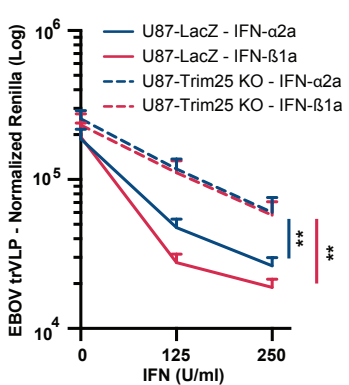

B.

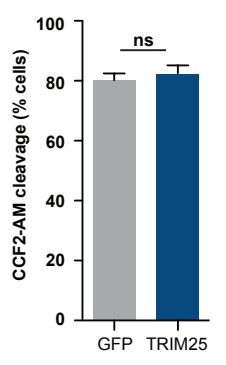

E.

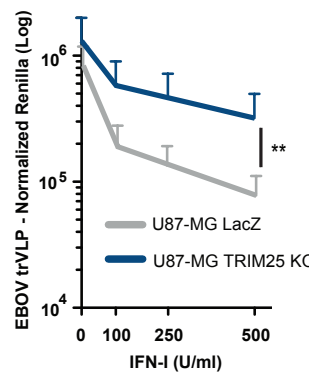

H.

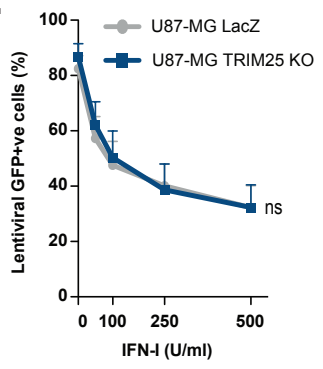

C.
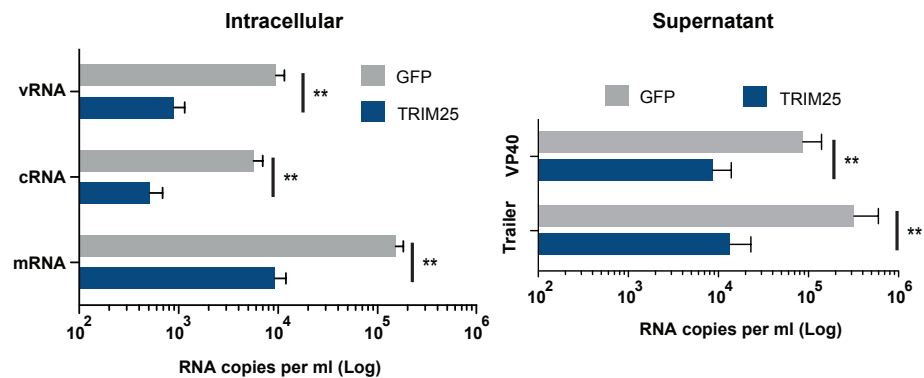

F.
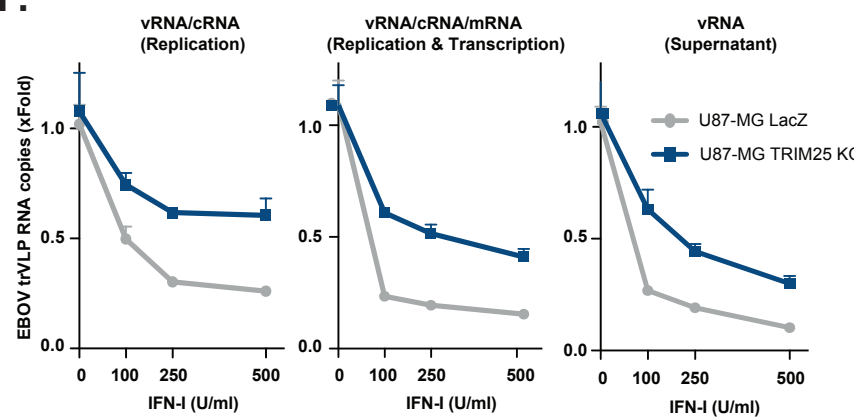

I.

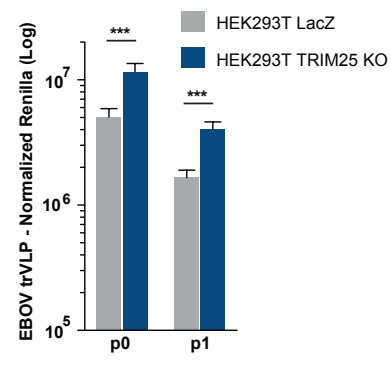


bioRxiv preprint doi: https://doi.org/10.1101/2021.05.23.445113; this version posted May 24, 2021. The copyright holder for this preprint (which was not certified by peer review) is the author/funder, who has granted bioRxiv a license to display the preprint in perpetuity. It is made available under aCC-BY-NC-ND 4.0 International license.

Figure 3

A.

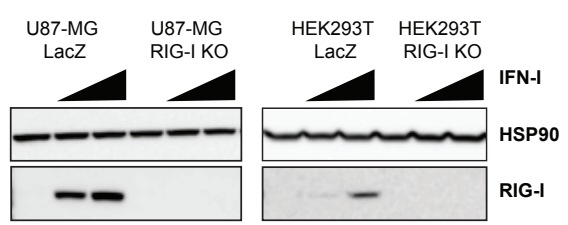

D.

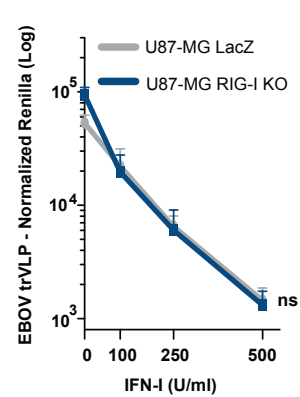

E.

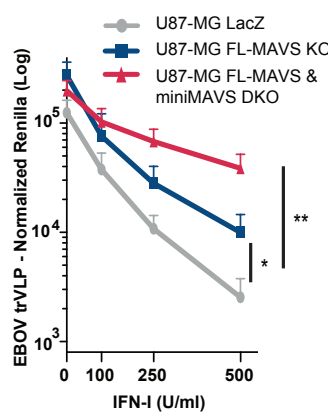

B.

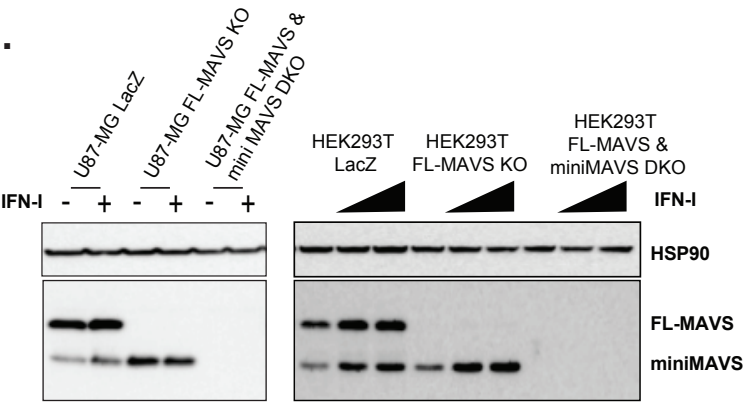

F.

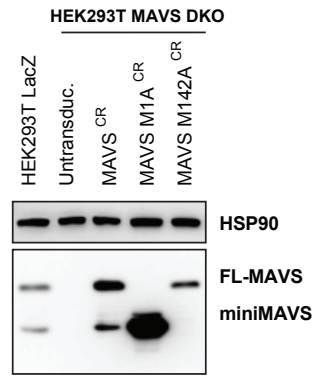

G.
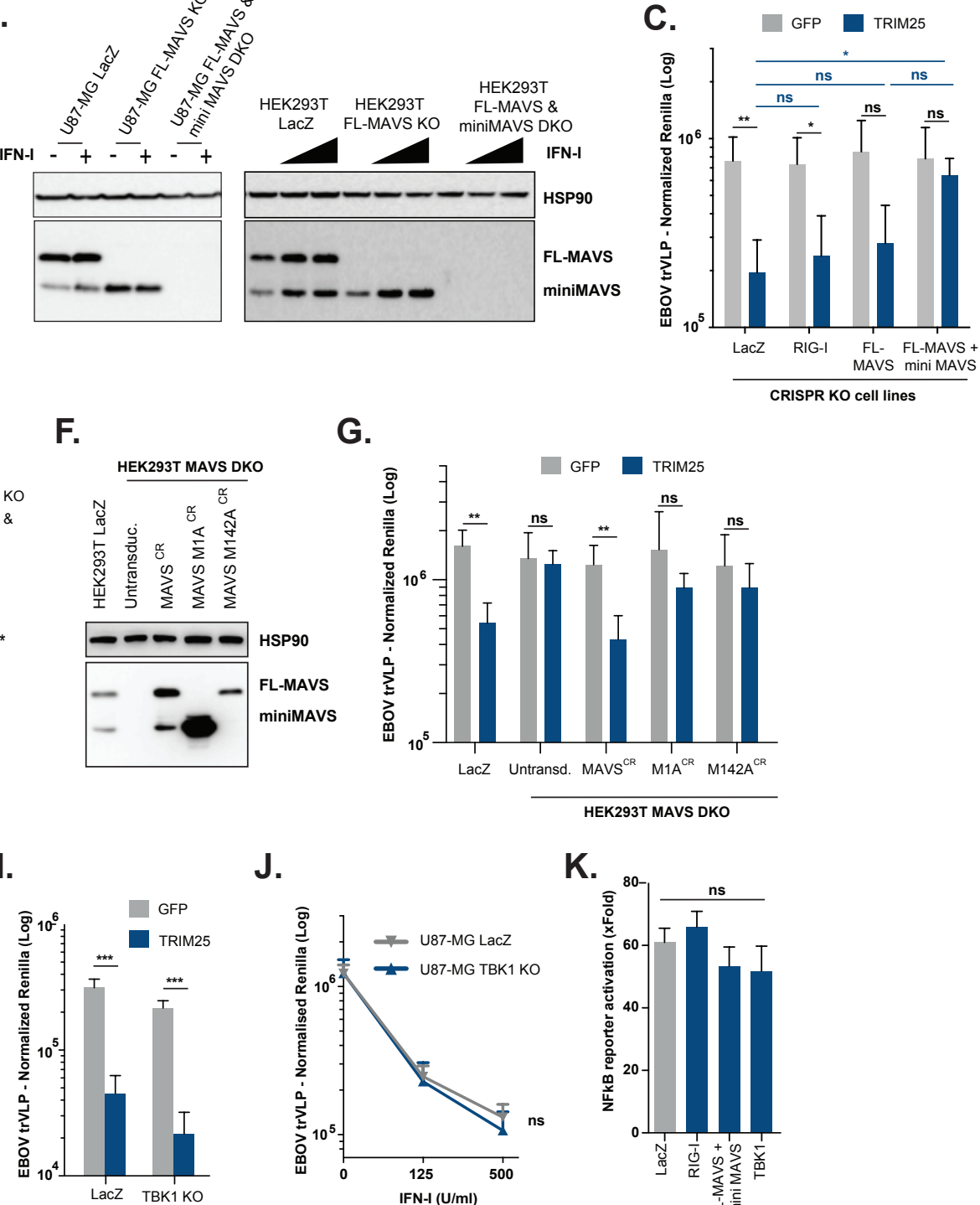

J.

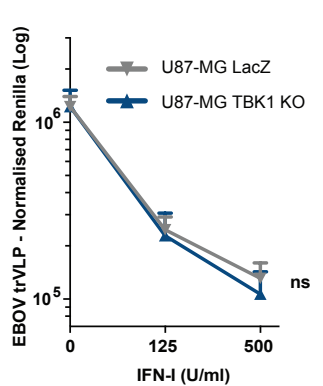

K.

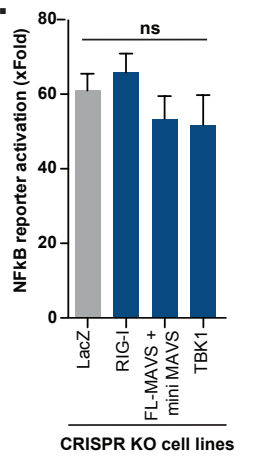

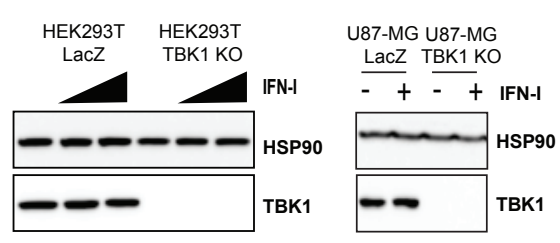

I.

H. 
Figure 4

bioRxiv preprint doi: https://doi.org/10.1101/2021.05.23.445113; this version posted May 24, 2021. The copyright holder for this preprint (which was not certified by peer review) is the author/funder, who has granted bioRxiv a license to display the preprint in perpetuity. It is made

A.

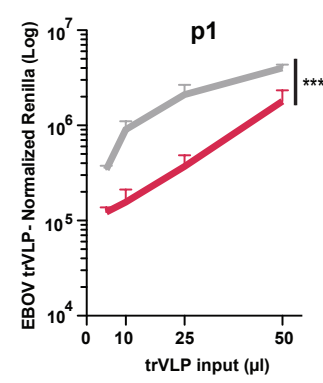

D.
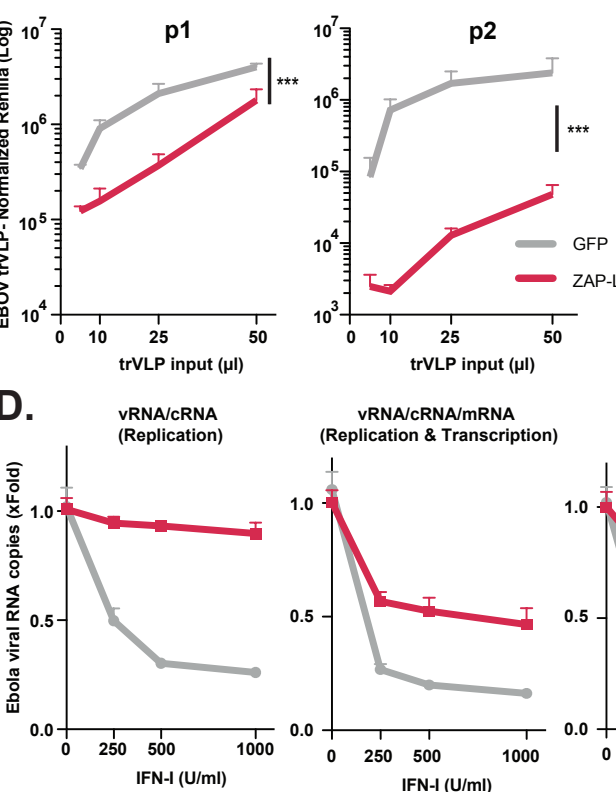

B.

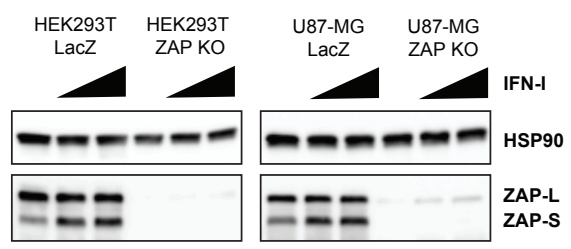

\begin{abstract}
ion)
\end{abstract} (Replication \& Transcription)
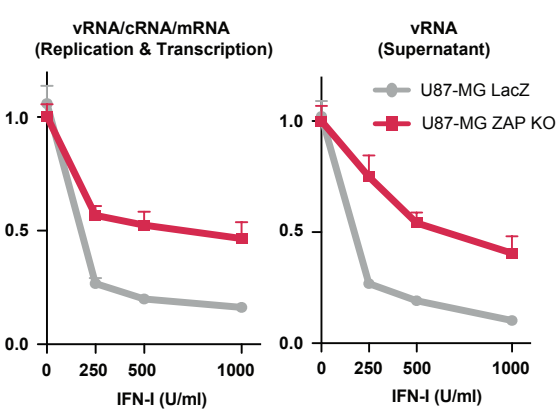

E.
C.

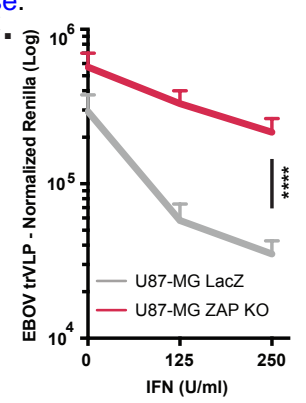

F.

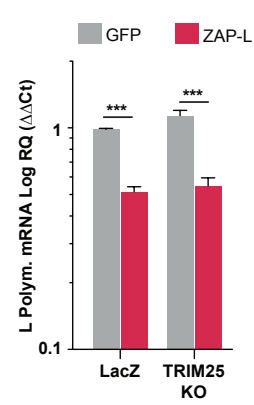

G.

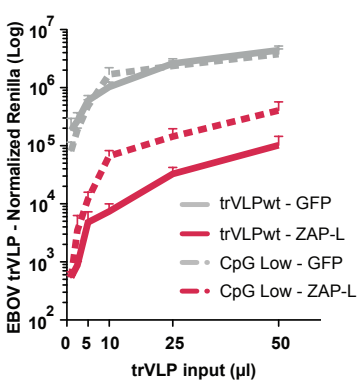

I.

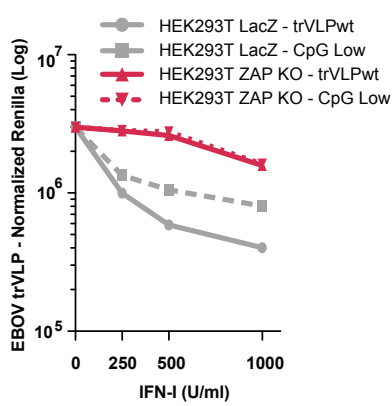

H.

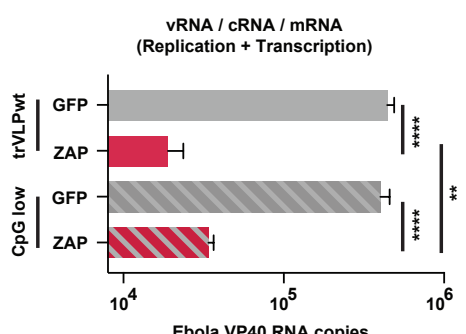

Ebola VP40 RNA copies
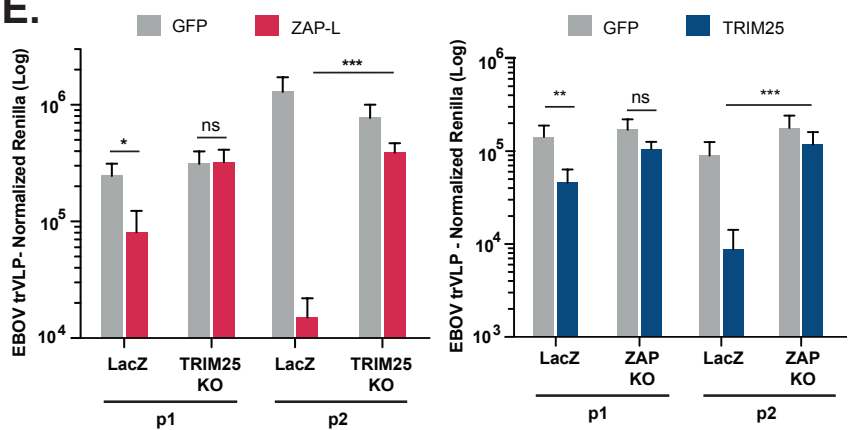
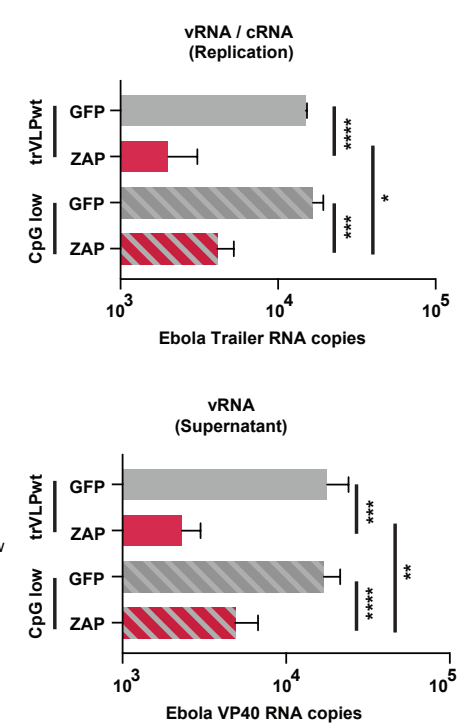
A.
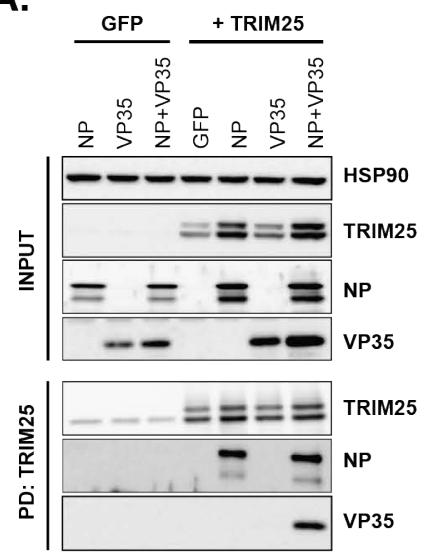

D.

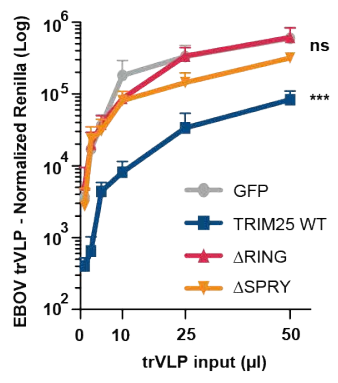

B.
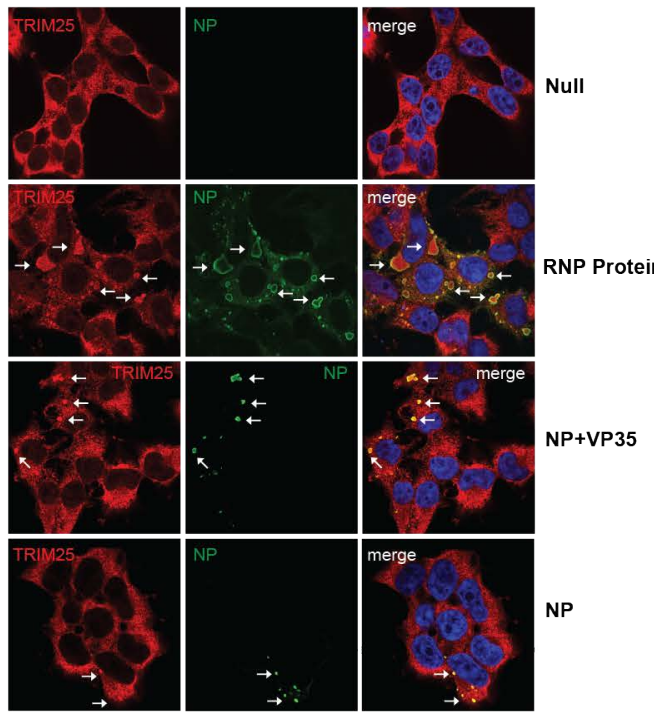

RNP Proteins

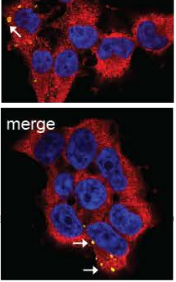

NP

E.
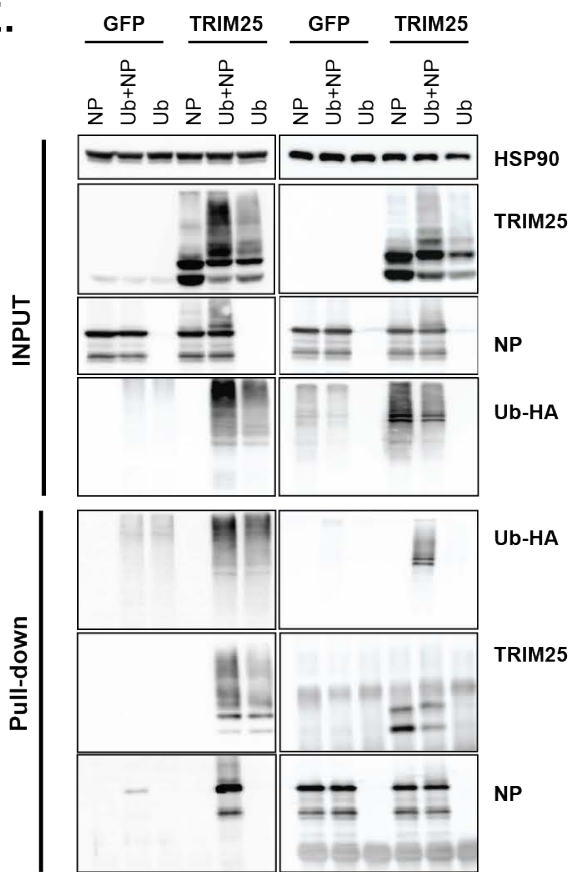

PD: Ub-HA

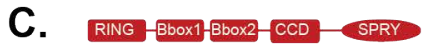

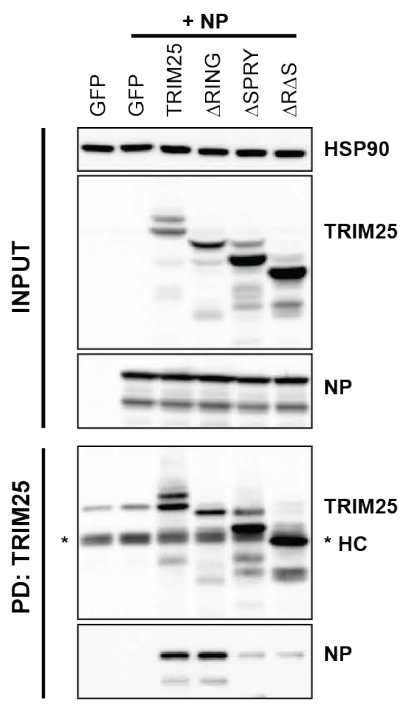

F.

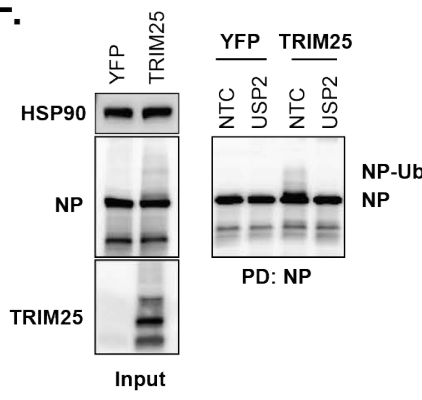


Figure 6

bioRxiv preprint doi: https://doi.org/10.1101/2021.05.23.445113; this version posted May 24, 2021. The copyright holder for this preprint (which

A. was not certified by peer review) is the author/fumer, who has granted bioRxiv a license to display the preprint in perpetuity. It is made

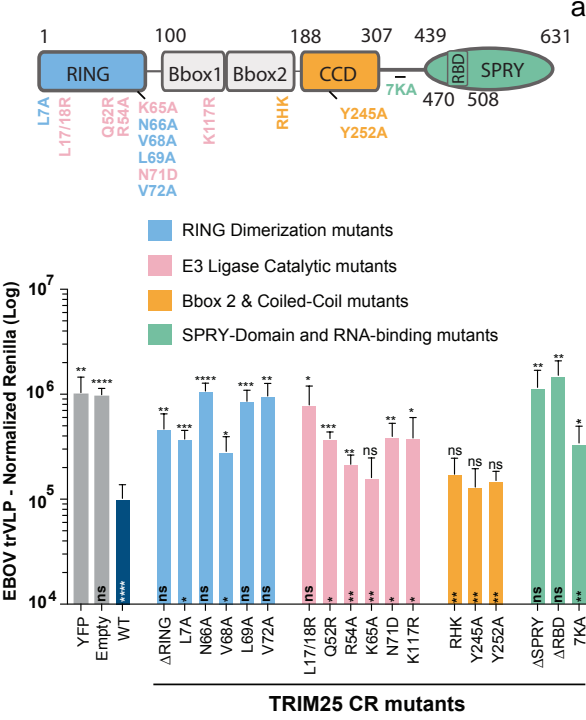
vailable under aCC-BY-NC-ND 4.0 International license.

RING Dimerization

mutants

E3 Ligase catalytic

SPRY-domain, Coiled-coil and

NA-binding mutants
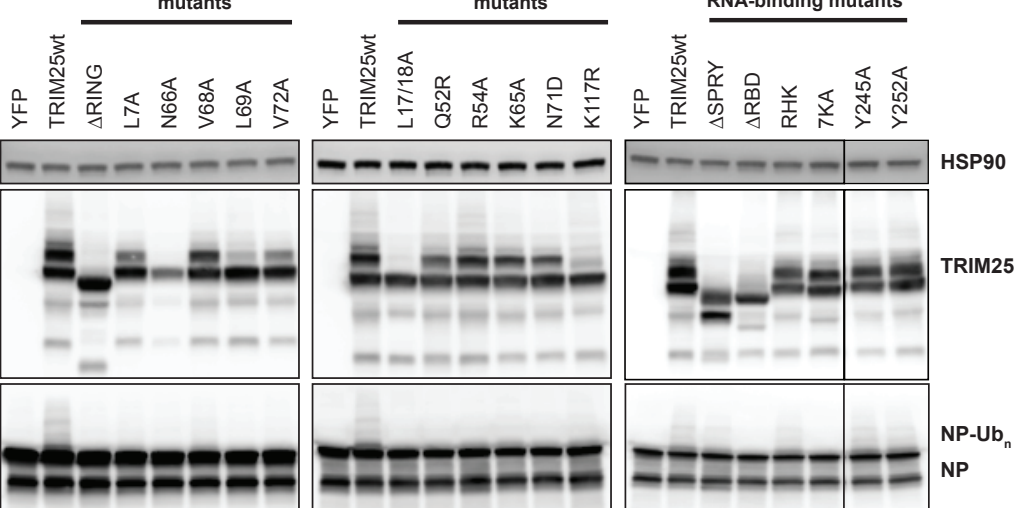

C.
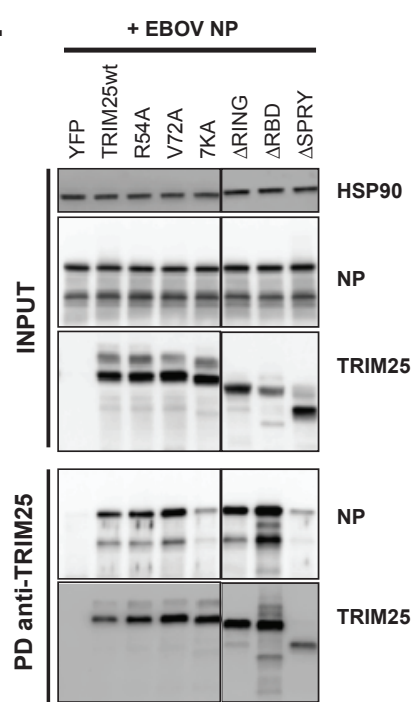

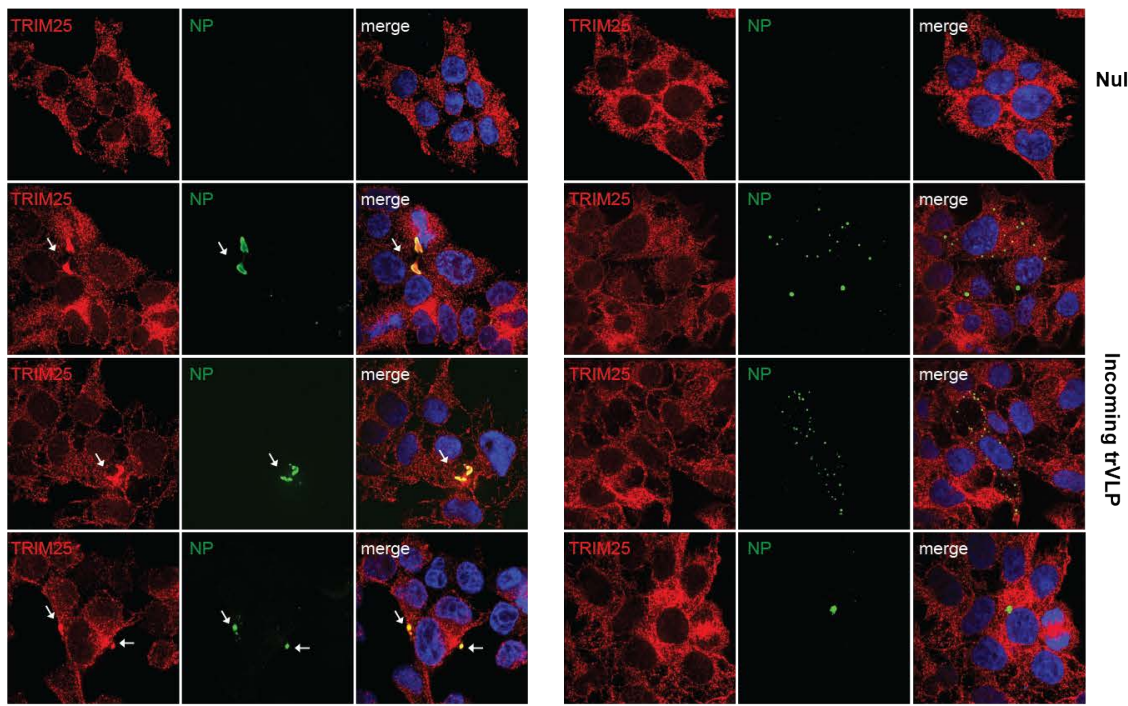

B.

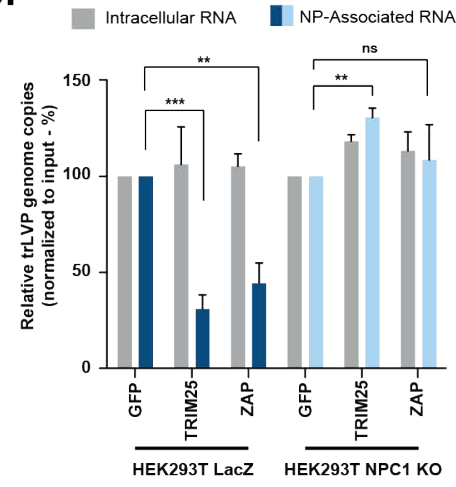

E.

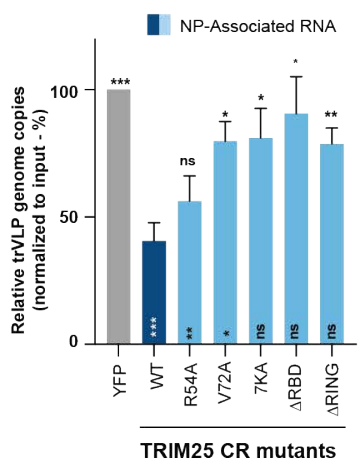

H.

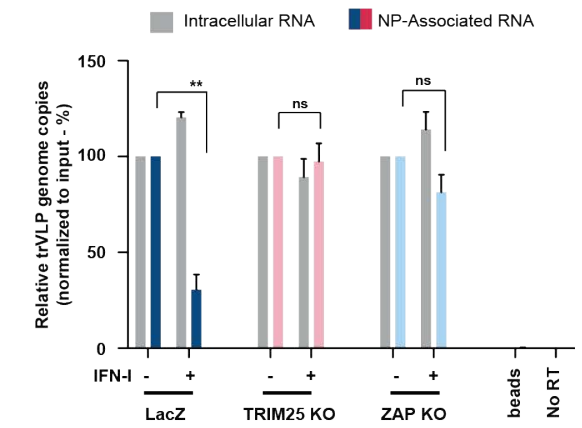

C.

F.
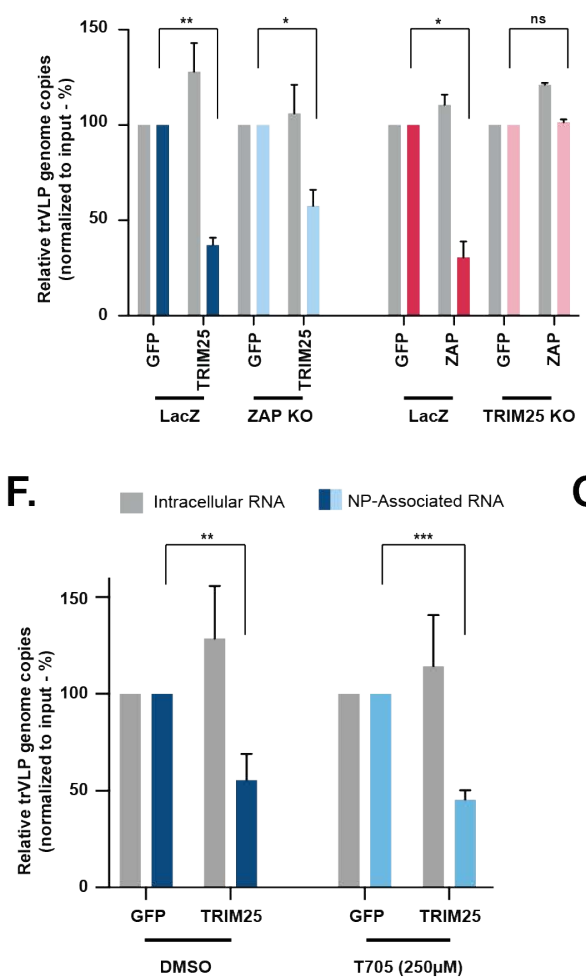

I.

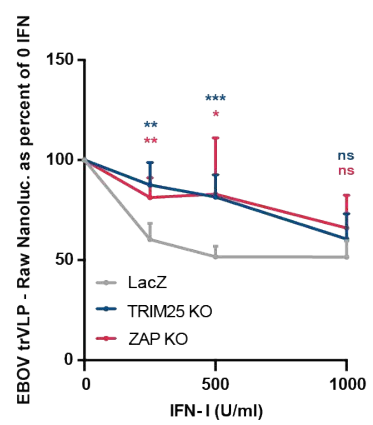

D.

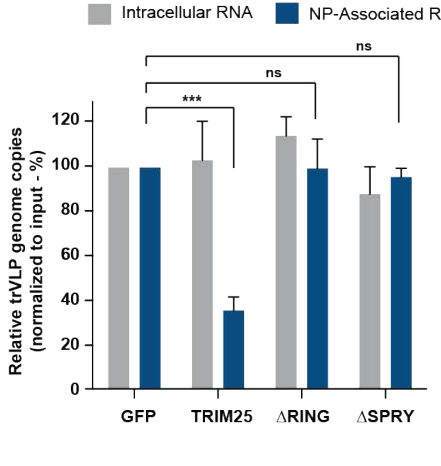

G.

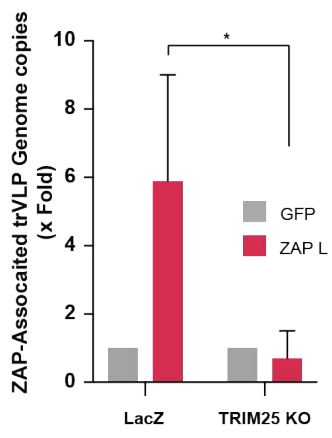

J.

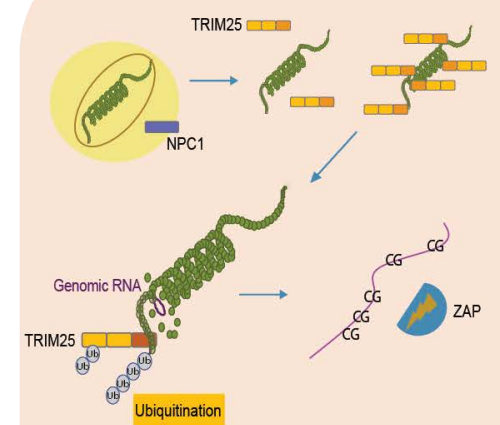




\section{Figure S2 (related to Figure 4)}

bioRxiv preprint doi: https://doi.org/10.1101/2021.05.23.445113; this version posted May 24, 2021. The copyright holder for this preprint (which

A. was not certified by peer review) is the author/funder, who has granted bioRxiv a license to display the preprint in perpetuity. It is made
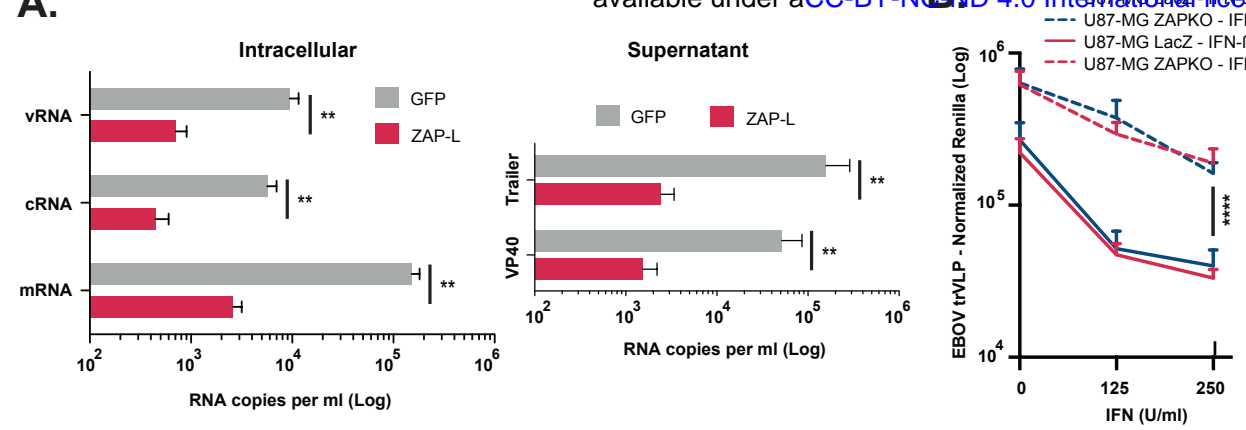

D.

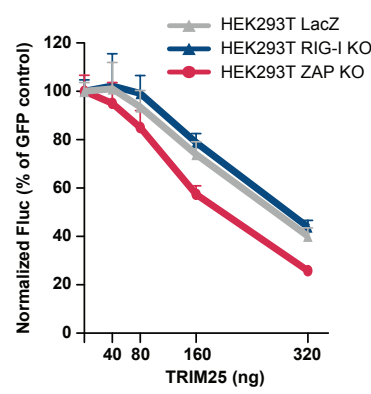

E.

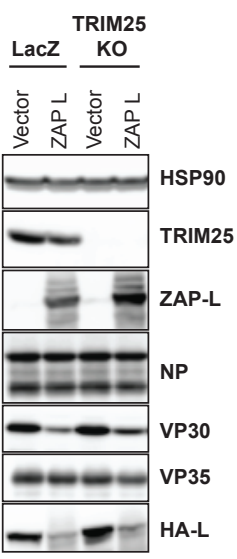

F.

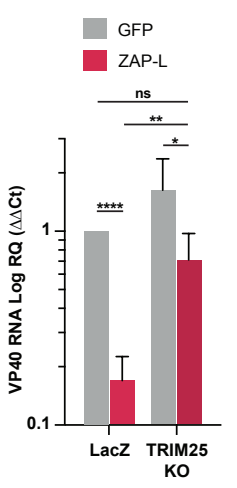

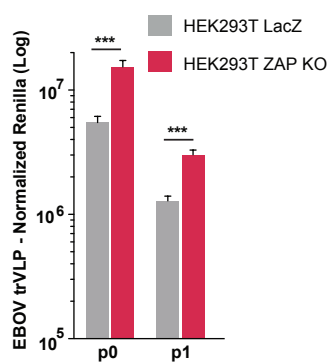

G.
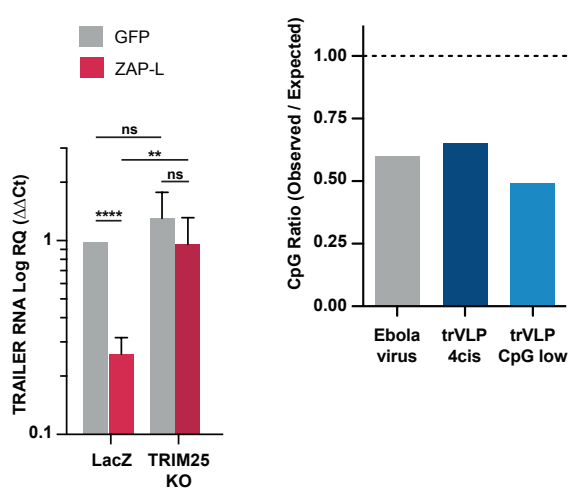

H.

Full length Ebola Virus vRNA ( $n=483 \mathrm{CpG})$

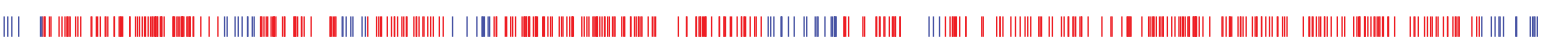
$\vdash \quad \mathrm{NP} \quad-\mathrm{VP} 35-\mathrm{VP} 40-\mathrm{GP} / \mathrm{sGP}-\mathrm{VP30}-\mathrm{VP} 24-$

Ebola trVLP vRNA $(\mathrm{n}=233 \mathrm{CpG})$

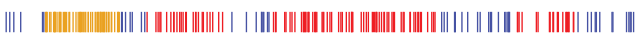

—Renilla_VP40 — GP $\longrightarrow$ VP24 -

Ebola low CpG trVLP vRNA ( $\mathrm{n}=172 \mathrm{CpG})$

| || | | || || || || || || || || || || | | | | || || || || || || || || || || || || || || || || || || || || | | | | | | | | || || || || || | ||

—Renilla_VP40 — GP $\longrightarrow$ VP24 -

I.

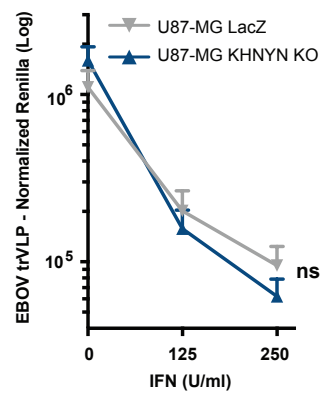

J.
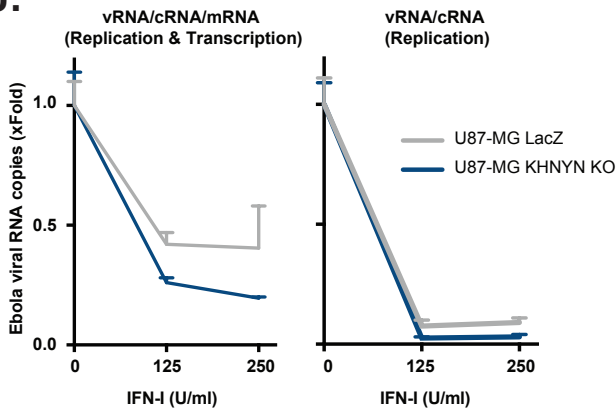

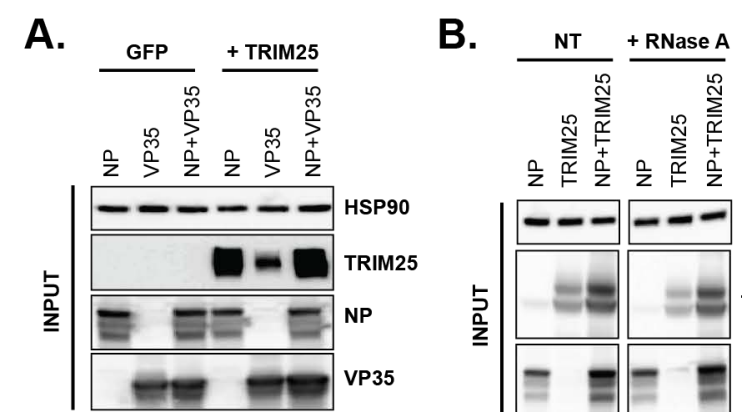

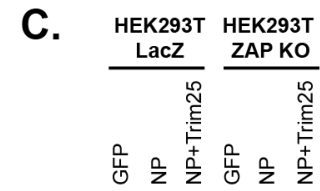
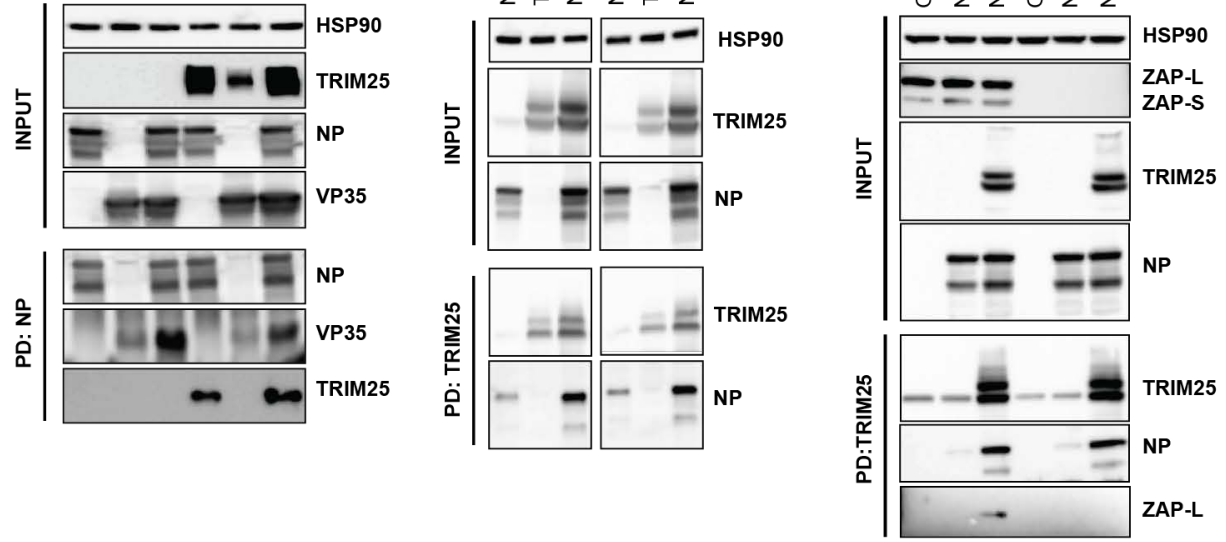

D

E. HЕK293T LacZ HEK293T ZAP KO

F. GFP TRIM25 GFP TRIM25

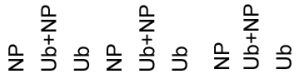

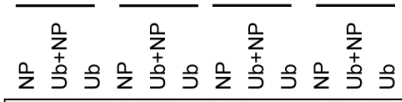
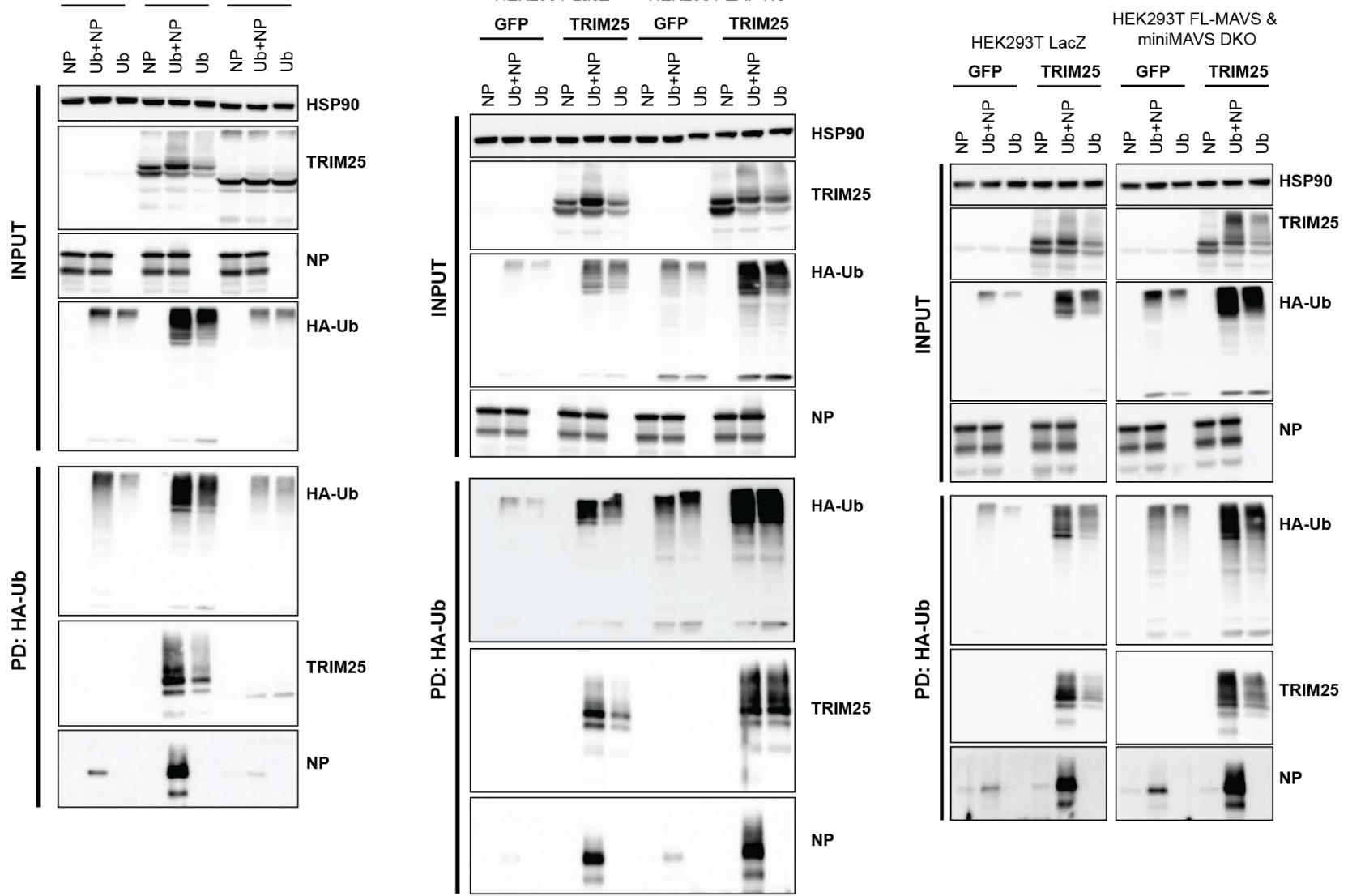

G.

\begin{tabular}{|c|c|}
\hline $\begin{array}{l}\text { HEK293T } \\
\text { LacZ-TIM1 }\end{array}$ & $\begin{array}{c}\text { HEK293T } \\
\text { TRIM25 KO-TIM1 }\end{array}$ \\
\hline $0-\infty 0$ 우 & $0-m 0$ 우 \\
\hline - - - & $-\infty-\infty$ \\
\hline-- & $-\infty-7$ \\
\hline
\end{tabular}


FioRxiv preprint doi: https://doi.org/10,1101/2021.05.23.445113; this version posted May 24, 2021. The copyright holder for this preprint (which Figur available under aCC-BY-NC-ND 4.0 International license.

A. $\stackrel{\bar{\Sigma}}{\bar{\Sigma}}$ B.

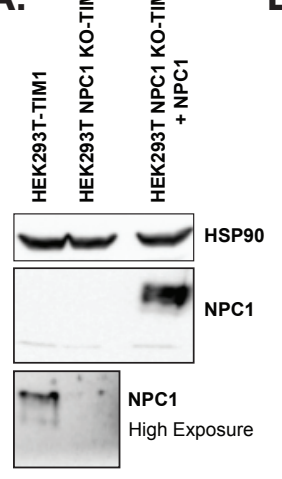

E.

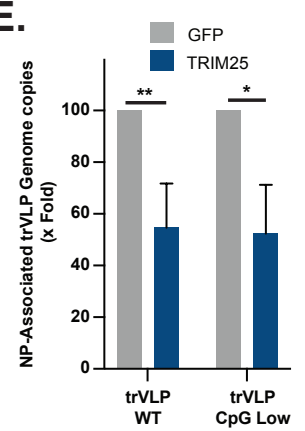

G.

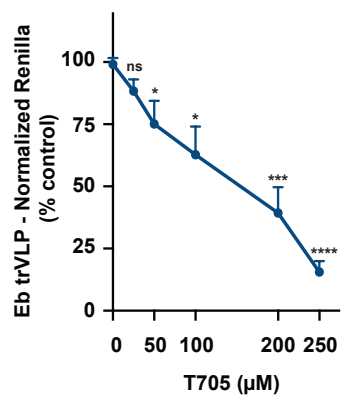

C.

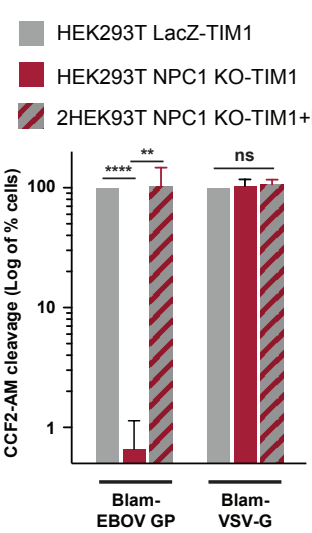

HEK293T LacZ-TIM1 D.

HEK293T NPC1 KO-TIM1 $\checkmark$ HEK293T NPC1 KO-TIM1+NPC1
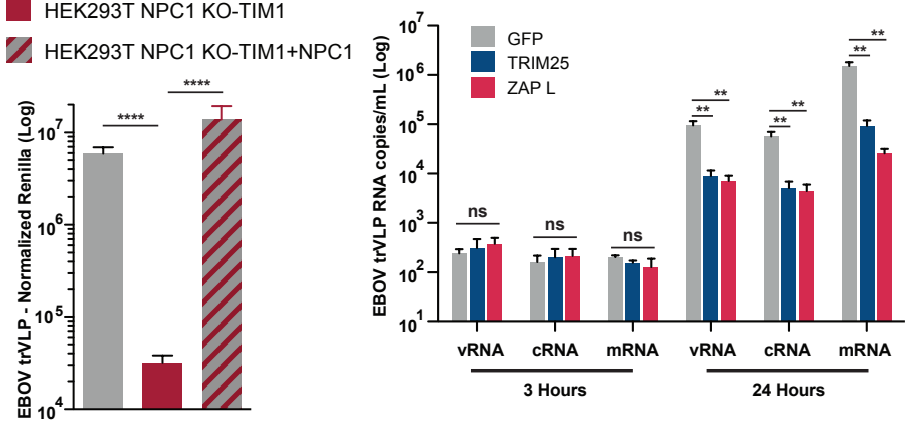

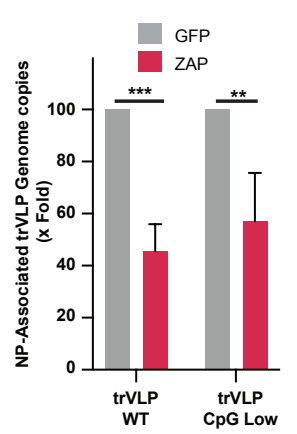

F. TrVLP wt-GFP CPG Low-GeP

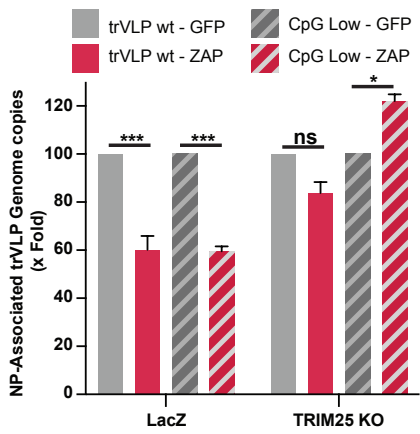

I.

Monocistronic Genome ( $\mathrm{n}=80 \mathrm{CpG})$

|||| |||||||||||||||||||| | ||

$\longmapsto$ Renilla—

Monocistronic low CpG Genome ( $n=19 \mathrm{CpG})$

|||| | | | | || | | |

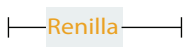

J.

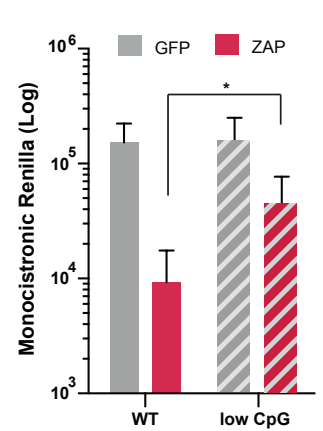

K.

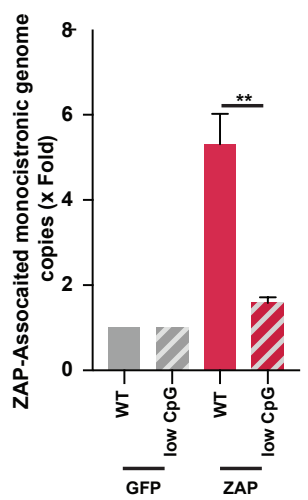

L.

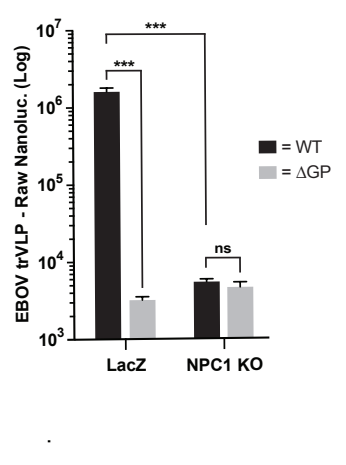

M.

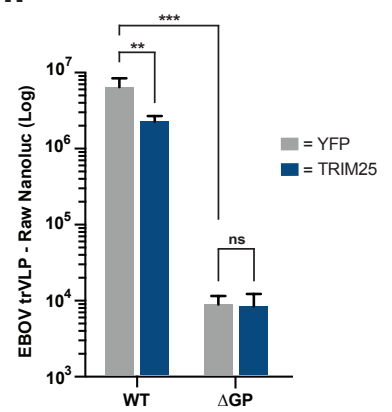


bioRxiv preprint doi: https://doi.org/10.1101/2021.05.23.445113; this version posted May 24, 2021. The copyright holder for this preprint (which was not certified by peer review) is the author/funder, who has granted bioRxiv a license to display the preprint in perpetuity. It is made

Supplemental Table 1

Large Scale ISG Screen: EboV trVLP in HEK293T cells - p1 and p2 values (Page 1 of 4)

\begin{tabular}{|c|c|c|c|c|c|c|c|c|c|}
\hline Gene & $\begin{array}{c}\text { P2 } \\
\text { Replication } \\
\text { (\% control) }\end{array}$ & $\begin{array}{c}\text { Z } \\
\text { score }\end{array}$ & $\begin{array}{c}\text { P1 } \\
\text { Replication } \\
\text { (\% control) }\end{array}$ & $\begin{array}{c}\text { Z } \\
\text { score }\end{array}$ & Gene & $\begin{array}{c}\text { P2 } \\
\text { Replication } \\
\text { (\% control) }\end{array}$ & $\begin{array}{c}\text { Z } \\
\text { score }\end{array}$ & $\begin{array}{c}\text { P1 } \\
\text { Replication } \\
\text { (\% control) }\end{array}$ & $\begin{array}{c}\text { Z } \\
\text { score }\end{array}$ \\
\hline P2RY6 & 0.4 & -1.24 & 41.5 & -1.23 & MCOLN & 28.0 & -0.89 & 40.4 & -1.25 \\
\hline BST2/THN & 0.5 & -1.24 & 91.8 & -0.18 & ZNF313 & 28.1 & -0.89 & 53.5 & -0.98 \\
\hline CCL5 & 0.5 & -1.24 & 106.0 & 0.11 & PDGFRL & 28.3 & -0.89 & 100.0 & -0.01 \\
\hline NMI & 0.6 & -1.24 & 0.4 & -2.08 & PNPT1 & 28.7 & -0.88 & 103.6 & 0.06 \\
\hline APOL6 & 0.6 & -1.24 & 188.5 & 1.83 & PHF15 & 28.7 & -0.88 & 119.2 & 0.39 \\
\hline ARHGAP17 & 1.9 & -1.22 & 57.9 & -0.88 & GBP5 & 28.9 & -0.88 & 116.9 & 0.34 \\
\hline WHDC1 & 2.3 & -1.21 & 32.0 & -1.42 & JAK2 & 29.6 & -0.87 & 96.8 & -0.08 \\
\hline B2M & 2.8 & -1.21 & 108.2 & 0.16 & ATF3 & 30.3 & -0.86 & 116.4 & 0.33 \\
\hline OAS1 & 2.9 & -1.21 & 76.4 & -0.50 & C10orf10 & 30.5 & -0.86 & 41.8 & -1.22 \\
\hline CTCFL & 3.3 & -1.20 & 55.6 & -0.93 & AIM2 & 30.5 & -0.86 & 70.3 & -0.63 \\
\hline DNAPTP6 & 3.4 & -1.20 & 58.4 & -0.88 & CCL19 & 30.6 & -0.86 & 78.0 & -0.47 \\
\hline PPM1K & 4.2 & -1.19 & 35.0 & -1.36 & RAB27A & 30.9 & -0.86 & 58.7 & -0.87 \\
\hline MT1G & 4.3 & -1.19 & 57.1 & -0.90 & IFI35 & 31.1 & -0.85 & 174.6 & 1.54 \\
\hline IFIH1 / MDA5 & 4.3 & -1.19 & 17.9 & -1.72 & FBX06 & 31.4 & -0.85 & 52.3 & -1.00 \\
\hline FNDC4 & 8.1 & -1.14 & 142.9 & 0.88 & UNC93B1 & 31.9 & -0.84 & 28.2 & -1.50 \\
\hline C5orf39 & 8.3 & -1.14 & 15.0 & -1.78 & HLA-E & 32.1 & -0.84 & 66.7 & -0.70 \\
\hline SOCS2 & 8.5 & -1.14 & 77.3 & -0.48 & GTPBP2 & 32.5 & -0.84 & 184.2 & 1.74 \\
\hline FCGR1A & 10.1 & -1.12 & 148.1 & 0.99 & GLRX & 32.8 & -0.83 & 60.9 & -0.82 \\
\hline MCL1 & 11.2 & -1.10 & 124.4 & 0.50 & CX3CL1 & 33.1 & -0.83 & 212.9 & 2.33 \\
\hline ARHGEF3 & 11.4 & -1.10 & 15.9 & -1.76 & TAP2 & 33.2 & -0.83 & 145.1 & 0.92 \\
\hline FLT1 & 11.7 & -1.10 & 67.9 & -0.68 & XAF1 & 33.4 & -0.82 & 55.0 & -0.95 \\
\hline MAP3K14 & 11.9 & -1.09 & 63.6 & -0.77 & WARS & 33.7 & -0.82 & 112.2 & 0.24 \\
\hline OASL & 12.1 & -1.09 & 123.2 & 0.47 & IFNGR1 & 34.1 & -0.82 & 51.7 & -1.01 \\
\hline TNK2 & 12.4 & -1.09 & 165.0 & 1.34 & SLC25A28 & 34.5 & -0.81 & 105.1 & 0.10 \\
\hline GBP2 & 13.2 & -1.08 & 74.2 & -0.55 & VIPERIN & 34.7 & -0.81 & 98.2 & -0.05 \\
\hline GALNT2 & 13.7 & -1.07 & 133.9 & 0.69 & ZBP1 & 34.9 & -0.81 & 54.1 & -0.96 \\
\hline FFAR2 & 14.9 & -1.06 & 43.0 & -1.20 & MYD88 & 35.4 & -0.80 & 46.4 & -1.12 \\
\hline CCDC92 & 15.0 & -1.06 & 79.8 & -0.43 & CASP7 & 35.5 & -0.80 & 71.3 & -0.61 \\
\hline LMO2 & 15.4 & -1.05 & 80.7 & -0.41 & NDC80 & 35.6 & -0.80 & 66.9 & -0.70 \\
\hline SLC15A3 & 16.0 & -1.04 & 174.0 & 1.53 & MAFF & 36.0 & -0.79 & 97.5 & -0.06 \\
\hline HERC5 & 16.6 & -1.04 & 77.1 & -0.49 & АРОВЕСЗА & 36.5 & -0.79 & 56.2 & -0.92 \\
\hline TXNIP & 16.6 & -1.03 & 80.5 & -0.42 & ZNF385B & 36.6 & -0.78 & 61.2 & -0.82 \\
\hline UBA7 & 17.5 & -1.02 & 55.8 & -0.93 & DEFB1 & 37.1 & -0.78 & 80.9 & -0.41 \\
\hline PIM3 & 17.5 & -1.02 & 87.6 & -0.27 & XRN & 37.1 & -0.78 & 88.0 & -0.26 \\
\hline TRIM25 & 17.7 & -1.02 & 25.4 & -1.56 & SAMD4A & 38.3 & -0.76 & 62.5 & -0.79 \\
\hline TRIM56 & 19.2 & -1.00 & 25.6 & -1.56 & SMAD3 & 38.7 & -0.76 & 80.5 & -0.42 \\
\hline SLFN12 & 19.4 & -1.00 & 56.1 & -0.92 & STAT2 & 39.9 & -0.74 & 105.0 & 0.09 \\
\hline STEAP4 & 19.8 & -1.00 & 86.3 & -0.30 & PUS1 & 39.9 & -0.74 & 120.3 & 0.41 \\
\hline CXCL10 & 19.8 & -0.99 & 90.5 & -0.21 & IFIT3 & 40.9 & -0.73 & 92.5 & -0.17 \\
\hline MAB21L2 & 19.9 & -0.99 & 130.6 & 0.62 & C15orf48 & 41.2 & -0.73 & 63.9 & -0.76 \\
\hline FAM46C & 20.6 & -0.99 & 38.6 & -1.29 & IFITM1 & 41.3 & -0.73 & 109.3 & 0.18 \\
\hline MX2 & 21.6 & -0.97 & 49.9 & -1.05 & GK & 41.4 & -0.72 & 67.8 & -0.68 \\
\hline GBP1 & 21.8 & -0.97 & 78.6 & -0.46 & SAT1 & 42.4 & -0.71 & 93.9 & -0.14 \\
\hline PABPC4 & 22.0 & -0.97 & 20.4 & -1.67 & KIAA0082 & 42.5 & -0.71 & 50.9 & -1.03 \\
\hline SERPINE1 & 22.3 & -0.96 & 52.2 & -1.00 & TNFRSF10A & 43.7 & -0.70 & 177.3 & 1.59 \\
\hline SERPING1 & 23.2 & -0.95 & 68.0 & -0.68 & TNFAIP3 & 44.3 & -0.69 & 182.0 & 1.69 \\
\hline C5orf27 & 23.5 & -0.95 & 81.9 & -0.39 & IL28RA & 44.4 & -0.69 & 80.4 & -0.42 \\
\hline SERPINB9 & 23.8 & -0.94 & 155.3 & 1.14 & NFIL3 & 45.0 & -0.68 & 78.1 & -0.47 \\
\hline IRF1 & 24.0 & -0.94 & 33.2 & -1.40 & RARRES3 & 45.1 & -0.68 & 97.0 & -0.07 \\
\hline HCP5 & 24.5 & -0.94 & 110.4 & 0.21 & BIRC3 & 46.4 & -0.66 & 67.0 & -0.70 \\
\hline ODC1 & 24.6 & -0.93 & 151.4 & 1.06 & HEG1 & 46.5 & -0.66 & 74.1 & -0.55 \\
\hline TRIM14 & 24.7 & -0.93 & 65.9 & -0.72 & C9ofr19 & 46.5 & -0.66 & 85.1 & -0.32 \\
\hline CLEC4D & 25.3 & -0.93 & 68.9 & -0.66 & HSPA6 & 46.6 & -0.66 & 124.7 & 0.50 \\
\hline IFIT1 & 25.4 & -0.92 & 96.3 & -0.09 & USP18 & 47.4 & -0.65 & 52.6 & -1.00 \\
\hline CNP & 25.5 & -0.92 & 156.1 & 1.15 & DDX60 & 47.7 & -0.65 & 87.9 & -0.26 \\
\hline NCF1 & 26.8 & -0.91 & 92.8 & -0.16 & EPAS1 & 48.0 & -0.64 & 193.5 & 1.93 \\
\hline CD274 & 26.9 & -0.91 & 88.2 & -0.26 & SAMHD1 & 48.2 & -0.64 & 55.7 & -0.93 \\
\hline IFI27 & 27.5 & -0.90 & 95.5 & -0.10 & FAM125B & 48.4 & -0.64 & 60.8 & -0.82 \\
\hline CEACAM1 & 27.6 & -0.90 & 59.7 & -0.85 & STAP1 & 49.1 & -0.63 & 50.5 & -1.04 \\
\hline
\end{tabular}


bioRxiv preprint doi: https://doi.org/10.1101/2021.05.23.445113; this version posted May 24, 2021. The copyright holder for this preprint (which was not certified by peer review) is the author/funder, who has granted bioRxiv a license to display the preprint in perpetuity. It is made available under aCC-BY-NC-ND 4.0 International license.

Large Scale ISG Screen: EboV trVLP in HEK293T cells - p1 and p2 values (Page 2 of 4)

\begin{tabular}{|c|c|c|c|c|c|c|c|c|c|}
\hline Gene & $\begin{array}{c}\text { P2 } \\
\text { Replication } \\
\text { (\% control) }\end{array}$ & $\begin{array}{c}\text { Z } \\
\text { score }\end{array}$ & $\begin{array}{c}\text { P1 } \\
\text { Replication } \\
\text { (\% control) }\end{array}$ & $\begin{array}{c}\text { Z } \\
\text { score }\end{array}$ & Gene & $\begin{array}{c}\text { P2 } \\
\text { Replication } \\
\text { (\% control) }\end{array}$ & $\begin{array}{c}\text { Z } \\
\text { score }\end{array}$ & $\begin{array}{c}\text { P1 } \\
\text { Replication } \\
\text { (\% control) }\end{array}$ & $\begin{array}{c}\text { Z } \\
\text { score }\end{array}$ \\
\hline DYNLT1 & 49.5 & -0.62 & 77.0 & -0.49 & ISG20 & 68.1 & -0.39 & 44.7 & -1.16 \\
\hline SSBP3 & 49.5 & -0.62 & 51.2 & -1.03 & TRAFD1 & 68.1 & -0.39 & 126.7 & 0.54 \\
\hline RBM43 & 49.7 & -0.62 & 75.9 & -0.51 & MX1 & 68.2 & -0.39 & 72.0 & -0.59 \\
\hline AKT3 & 49.8 & -0.62 & 109.0 & 0.18 & HLA-F & 68.4 & -0.39 & 125.4 & 0.52 \\
\hline ANGPTL1 & 50.5 & -0.61 & 97.3 & -0.07 & TAP1 & 68.6 & -0.38 & 98.8 & -0.04 \\
\hline FAM70A & 50.7 & -0.61 & 75.8 & -0.51 & LGALS3 & 69.9 & -0.37 & 85.9 & -0.30 \\
\hline UPP2 & 50.7 & -0.61 & 50.0 & -1.05 & HLA-C & 70.2 & -0.36 & 123.5 & 0.48 \\
\hline SIRPA & 51.0 & -0.60 & 38.2 & -1.29 & CASP1 & 70.4 & -0.36 & 43.4 & -1.19 \\
\hline CCND3 & 52.1 & -0.59 & 163.9 & 1.32 & RPL22 & 70.8 & -0.35 & 116.2 & 0.33 \\
\hline RNF19B & 52.2 & -0.59 & 82.5 & -0.37 & APOL3 & 71.2 & -0.35 & 75.3 & -0.52 \\
\hline MTHFD2L & 52.5 & -0.59 & 73.4 & -0.56 & PSCD1 & 72.4 & -0.34 & 67.5 & -0.69 \\
\hline EIF3EIP & 53.2 & -0.58 & 147.1 & 0.97 & SCO2 & 72.6 & -0.33 & 166.5 & 1.37 \\
\hline THBD & 53.3 & -0.57 & 201.1 & 2.09 & TRIM38 & 73.4 & -0.32 & 116.5 & 0.33 \\
\hline NT5C3 & 53.5 & -0.57 & 84.5 & -0.33 & IFI44 & 75.2 & -0.30 & 79.5 & -0.44 \\
\hline PSMB8 & 53.6 & -0.57 & 80.4 & -0.42 & IFI44L & 75.7 & -0.29 & 30.0 & -1.47 \\
\hline MS4A4A & 54.0 & -0.57 & 52.2 & -1.00 & AXUD1 & 75.9 & -0.29 & 90.9 & -0.20 \\
\hline SECTM1 & 54.0 & -0.57 & 45.8 & -1.14 & MAFF & 76.4 & -0.28 & 102.4 & 0.04 \\
\hline ABLIM3 & 54.5 & -0.56 & 53.7 & -0.97 & ARNTL & 76.6 & -0.28 & 154.5 & 1.12 \\
\hline FAM46A & 54.9 & -0.55 & 52.3 & -1.00 & TLR3 & 76.9 & -0.28 & 106.4 & 0.12 \\
\hline RTP4 & 55.1 & -0.55 & 87.1 & -0.28 & CXCL9 & 77.0 & -0.28 & 85.2 & -0.32 \\
\hline СМАН & 55.2 & -0.55 & 115.0 & 0.30 & C9orf91 & 77.0 & -0.28 & 120.6 & 0.42 \\
\hline MT1M & 55.9 & -0.54 & 148.2 & 0.99 & IFI16 & 77.7 & -0.27 & 94.9 & -0.12 \\
\hline Socs1 & 56.6 & -0.53 & 108.5 & 0.17 & PSMB9 & 77.7 & -0.27 & 126.0 & 0.53 \\
\hline DDX58 & 57.1 & -0.53 & 33.2 & -1.40 & IFITM3 & 78.3 & -0.26 & 64.8 & -0.74 \\
\hline BAG1 & 57.2 & -0.53 & 122.4 & 0.45 & ALDH1A1 & 78.9 & -0.25 & 69.4 & -0.65 \\
\hline UNC84B & 57.3 & -0.52 & 96.8 & -0.08 & ERLIN1 & 79.2 & -0.25 & 72.9 & -0.57 \\
\hline C19orf66 & 57.4 & -0.52 & 96.9 & -0.08 & CCL8 & 79.3 & -0.25 & 51.3 & -1.02 \\
\hline B4GALT5 & 57.9 & -0.52 & 104.5 & 0.08 & INDO & 79.8 & -0.24 & 88.7 & -0.25 \\
\hline SPTLC2 & 58.1 & -0.51 & 88.3 & -0.25 & RNASE4 & 80.1 & -0.24 & 161.0 & 1.26 \\
\hline BUB1 & 58.6 & -0.51 & 74.2 & -0.55 & AGPAT9 & 80.2 & -0.24 & 69.0 & -0.66 \\
\hline MOV10 & 59.1 & -0.50 & 513.4 & 8.58 & DCP1A & 82.3 & -0.21 & 108.3 & 0.16 \\
\hline SAMD9L & 59.4 & -0.50 & 66.9 & -0.70 & HERC 6 & 82.5 & -0.21 & 124.0 & 0.49 \\
\hline TMEM51 & 60.0 & -0.49 & 104.9 & 0.09 & IL17RB & 82.9 & -0.20 & 152.4 & 1.08 \\
\hline VAMP5 & 60.2 & -0.49 & 65.5 & -0.73 & JUNB & 84.0 & -0.19 & 115.9 & 0.32 \\
\hline BLZF1 & 60.2 & -0.49 & 109.1 & 0.18 & N4BP1 & 84.5 & -0.18 & 59.3 & -0.86 \\
\hline PRKD2 & 60.4 & -0.49 & 150.6 & 1.04 & EPSTI1 & 84.6 & -0.18 & 90.3 & -0.21 \\
\hline CHMP5 & 60.6 & -0.48 & 126.8 & 0.55 & TGFB1 & 85.1 & -0.18 & 126.1 & 0.53 \\
\hline DDX3X & 60.6 & -0.48 & 59.7 & -0.85 & SAA1 & 85.1 & -0.18 & 204.6 & 2.16 \\
\hline TMEM49 & 60.9 & -0.48 & 118.1 & 0.36 & PFKFB3 & 85.6 & -0.17 & 137.3 & 0.76 \\
\hline SP110 & 61.2 & -0.48 & 131.9 & 0.65 & C2orf31 & 85.9 & -0.17 & 125.1 & 0.51 \\
\hline CCNA1 & 62.6 & -0.46 & 128.5 & 0.58 & РCTK3 & 86.5 & -0.16 & 113.5 & 0.27 \\
\hline IRF9 & 62.9 & -0.46 & 90.5 & -0.21 & PARP12 & 86.7 & -0.16 & 103.0 & 0.05 \\
\hline PARP10 & 63.6 & -0.45 & 98.6 & -0.04 & STARD5 & 87.4 & -0.15 & 115.0 & 0.30 \\
\hline SLC1A1 & 63.7 & -0.45 & 51.9 & -1.01 & FER1L3 & 87.5 & -0.15 & 69.5 & -0.65 \\
\hline ANKRD22 & 64.0 & -0.44 & 110.6 & 0.21 & ISG15 & 87.6 & -0.14 & 135.4 & 0.72 \\
\hline C4orf32 & 64.0 & -0.44 & 91.9 & -0.18 & MT1L & 87.7 & -0.14 & 84.7 & -0.33 \\
\hline BCL3 & 64.0 & -0.44 & 128.9 & 0.59 & IFI6 & 87.9 & -0.14 & 47.4 & -1.10 \\
\hline MAFF & 64.1 & -0.44 & 64.8 & -0.74 & IFITM2 & 88.1 & -0.14 & 86.1 & -0.30 \\
\hline C4orf33 & 64.4 & -0.44 & 76.6 & -0.50 & PMAIP1 & 88.5 & -0.13 & 61.8 & -0.81 \\
\hline C1S & 64.5 & -0.43 & 50.3 & -1.04 & NOS2A & 89.7 & -0.12 & 76.5 & -0.50 \\
\hline APOL2 & 64.6 & -0.43 & 87.8 & -0.26 & PLEKHA4 & 90.0 & -0.11 & 83.1 & -0.36 \\
\hline TRIM21 & 65.5 & -0.42 & 56.4 & -0.92 & STAT3 & 90.7 & -0.11 & 61.9 & -0.80 \\
\hline HESX1 & 65.9 & -0.42 & 97.7 & -0.06 & EIF2AK2 & 91.0 & -0.10 & 67.4 & -0.69 \\
\hline SNN & 66.7 & -0.41 & 57.6 & -0.89 & ELF1 & 91.5 & -0.10 & 32.8 & -1.41 \\
\hline LIPA & 66.7 & -0.41 & 107.0 & 0.13 & PBEF1 & 92.3 & -0.09 & 127.7 & 0.56 \\
\hline LAMP3 & 67.1 & -0.40 & 107.0 & 0.13 & RIPK2 & 92.6 & -0.08 & 28.7 & -1.49 \\
\hline CCDC109B & 67.2 & -0.40 & 51.7 & -1.02 & DUSP5 & 93.1 & -0.08 & 142.8 & 0.88 \\
\hline OPTN & 67.8 & -0.39 & 77.9 & -0.47 & CSDA & 93.8 & -0.07 & 164.4 & 1.33 \\
\hline DDIT4 & 68.0 & -0.39 & 130.1 & 0.61 & OGFR & 94.1 & -0.06 & 106.3 & 0.12 \\
\hline
\end{tabular}


bioRxiv preprint doi: https://doi.org/10.1101/2021.05.23.445113; this version posted May 24, 2021. The copyright holder for this preprint (which was not certified by peer review) is the author/funder, who has granted bioRxiv a license to display the preprint in perpetuity. It is made

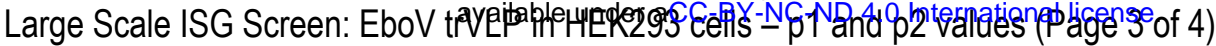

\begin{tabular}{|c|c|c|c|c|c|c|c|c|c|}
\hline Gene & $\begin{array}{c}\text { P2 } \\
\text { Replication } \\
\text { ( } \% \text { control) }\end{array}$ & $\begin{array}{c}\text { Z } \\
\text { score }\end{array}$ & $\begin{array}{c}\text { P1 } \\
\text { Replication } \\
\text { (\% control) }\end{array}$ & $\begin{array}{c}\text { Z } \\
\text { score }\end{array}$ & Gene & $\begin{array}{c}\text { P2 } \\
\text { Replication } \\
\text { (\% control) }\end{array}$ & $\begin{array}{c}\text { Z } \\
\text { score }\end{array}$ & $\begin{array}{c}\text { P1 } \\
\text { Replication } \\
\text { (\% control) }\end{array}$ & $\begin{array}{c}\text { Z } \\
\text { score }\end{array}$ \\
\hline EXT1 & 94.2 & -0.06 & 99.2 & -0.03 & SLC25A30 & 128.3 & 0.37 & 157.1 & 1.18 \\
\hline RBM25 & 95.1 & -0.05 & 77.9 & -0.47 & S100A8 & 128.4 & 0.37 & 96.7 & -0.08 \\
\hline BCL2L14 & 95.1 & -0.05 & 60.0 & -0.84 & SP100 & 129.2 & 0.38 & 82.8 & -0.37 \\
\hline PRAME & 95.9 & -0.04 & 177.4 & 1.60 & CRY1 & 130.9 & 0.40 & 115.4 & 0.31 \\
\hline GEM & 95.9 & -0.04 & 80.8 & -0.41 & ATP10D & 131.8 & 0.41 & 102.7 & 0.04 \\
\hline BTN3A3 & 96.1 & -0.04 & 106.2 & 0.12 & IL1RN & 132.0 & 0.41 & 175.7 & 1.56 \\
\hline TBX3 & 96.4 & -0.03 & 168.5 & 1.41 & IFI30 & 132.5 & 0.42 & 107.7 & 0.15 \\
\hline MICB & 98.2 & -0.01 & 63.5 & -0.77 & APOBEC3G & 132.8 & 0.42 & 68.1 & -0.67 \\
\hline GPX2 & 98.9 & 0.00 & 114.8 & 0.30 & TDRD7 & 132.9 & 0.42 & 123.3 & 0.47 \\
\hline CD74 & 100.2 & 0.01 & 130.0 & 0.61 & PTMA & 133.0 & 0.42 & 99.1 & -0.03 \\
\hline STAT1 & 101.6 & 0.03 & 115.6 & 0.31 & LINCR & 134.5 & 0.44 & 83.8 & -0.35 \\
\hline RNF24 & 102.2 & 0.04 & 91.1 & -0.20 & MT1F & 134.6 & 0.44 & 49.9 & -1.05 \\
\hline GZMB & 102.2 & 0.04 & 75.8 & -0.51 & GCA & 134.7 & 0.45 & 98.5 & -0.04 \\
\hline CYP1B1 & 102.4 & 0.04 & 202.7 & 2.12 & CD163 & 136.0 & 0.46 & 174.2 & 1.53 \\
\hline LEPR & 102.4 & 0.04 & 116.0 & 0.32 & CPT1A & 136.6 & 0.47 & 161.5 & 1.27 \\
\hline ADAMDEC1 & 103.3 & 0.05 & 101.6 & 0.02 & TCF7L2 & 136.7 & 0.47 & 138.7 & 0.79 \\
\hline NPAS2 & 103.6 & 0.06 & 133.9 & 0.69 & SLC16A1 & 137.5 & 0.48 & 46.8 & -1.12 \\
\hline ADFP & 104.0 & 0.06 & 103.1 & 0.05 & PMM2 & 139.5 & 0.51 & 103.8 & 0.07 \\
\hline ANKFY1 & 104.0 & 0.06 & 92.6 & -0.17 & MAFB & 139.6 & 0.51 & 214.0 & 2.36 \\
\hline ABTB2 & 104.7 & 0.07 & 144.1 & 0.90 & THOC4 & 140.0 & 0.51 & 105.6 & 0.10 \\
\hline CD69 & 105.2 & 0.08 & 108.9 & 0.17 & HES4 & 140.8 & 0.52 & 149.2 & 1.01 \\
\hline ZNF295 & 106.3 & 0.09 & 115.1 & 0.30 & TIMP1 & 143.6 & 0.56 & 76.6 & -0.50 \\
\hline AQP9 & 106.6 & 0.09 & 51.1 & -1.03 & IRF7 & 143.7 & 0.56 & 186.1 & 1.78 \\
\hline NCOA3 & 107.0 & 0.10 & 104.8 & 0.09 & TAGAP & 143.7 & 0.56 & 153.9 & 1.11 \\
\hline CCDC75 & 107.9 & 0.11 & 88.5 & -0.25 & LGMN & 145.4 & 0.58 & 113.9 & 0.28 \\
\hline RGS1 & 108.4 & 0.12 & 183.2 & 1.72 & PADI2 & 146.2 & 0.59 & 278.6 & 3.70 \\
\hline FKBP5 & 108.8 & 0.12 & 78.9 & -0.45 & BLVRA & 146.5 & 0.59 & 86.8 & -0.29 \\
\hline FLJ39739 & 108.8 & 0.12 & 104.5 & 0.08 & SQLE & 146.9 & 0.60 & 118.5 & 0.37 \\
\hline CXCL11 & 109.6 & 0.13 & 85.0 & -0.32 & NOD2 & 147.4 & 0.61 & 169.5 & 1.43 \\
\hline CLEC2B & 109.7 & 0.13 & 142.8 & 0.88 & GBP3 & 148.4 & 0.62 & 145.5 & 0.93 \\
\hline PXK & 110.1 & 0.14 & 68.8 & -0.66 & MKX & 148.7 & 0.62 & 69.7 & -0.64 \\
\hline CCL2 & 111.2 & 0.15 & 43.0 & -1.19 & COMMD3 & 149.6 & 0.63 & 64.9 & -0.74 \\
\hline IRF2 & 111.4 & 0.15 & 145.1 & 0.93 & BATF2 & 150.7 & 0.65 & 109.8 & 0.19 \\
\hline TLK2 & 112.3 & 0.16 & 92.1 & -0.17 & DHX58 & 153.6 & 0.68 & 100.6 & 0.00 \\
\hline APOL1 & 112.5 & 0.17 & 70.4 & -0.63 & GCH1 & 154.0 & 0.69 & 57.1 & -0.90 \\
\hline GAK & 112.8 & 0.17 & 121.8 & 0.44 & CDKN1A & 154.2 & 0.69 & 153.5 & 1.10 \\
\hline PCTK2 & 113.3 & 0.18 & 95.6 & -0.10 & ENPP1 & 154.9 & 0.70 & 106.5 & 0.12 \\
\hline ZNF107 & 113.5 & 0.18 & 103.5 & 0.06 & IL1R & 155.1 & 0.70 & 46.7 & -1.12 \\
\hline MARCK & 114.2 & 0.19 & 276.4 & 3.65 & UBE2L6 & 155.3 & 0.70 & 86.3 & -0.29 \\
\hline CEBPD & 115.1 & 0.20 & 116.2 & 0.33 & PFKFB3 & 155.7 & 0.71 & 275.7 & 3.64 \\
\hline TYMP & 115.7 & 0.21 & 96.6 & -0.08 & RBCK1 & 158.7 & 0.75 & 140.3 & 0.83 \\
\hline CES1 & 115.9 & 0.21 & 130.3 & 0.62 & HSH2D & 158.8 & 0.75 & 178.5 & 1.62 \\
\hline KIAA1618 & 116.4 & 0.22 & 134.5 & 0.70 & RIPK2 & 159.8 & 0.76 & 79.2 & -0.44 \\
\hline TREX1 & 116.4 & 0.22 & 99.7 & -0.02 & NAPA & 160.1 & 0.76 & 75.3 & -0.53 \\
\hline G6PC & 116.9 & 0.22 & 133.4 & 0.68 & CFB & 161.7 & 0.78 & 107.0 & 0.13 \\
\hline IMPA2 & 117.4 & 0.23 & 97.7 & -0.06 & CLEC4A & 162.0 & 0.79 & 109.9 & 0.19 \\
\hline DDX60 & 117.5 & 0.23 & 78.6 & -0.46 & IFIT5 & 162.7 & 0.80 & 106.0 & 0.11 \\
\hline C22orf28 & 119.4 & 0.25 & 98.5 & -0.04 & FNDC3B & 163.2 & 0.80 & 103.6 & 0.06 \\
\hline ABCA9 & 120.2 & 0.26 & 154.0 & 1.11 & KIAA0082 & 164.0 & 0.81 & 64.6 & -0.75 \\
\hline MT1H & 120.9 & 0.27 & 153.7 & 1.10 & CD38 & 167.2 & 0.85 & 77.4 & -0.48 \\
\hline SPSB1 & 121.0 & 0.27 & 120.4 & 0.41 & HK2 & 167.7 & 0.86 & 149.8 & 1.02 \\
\hline SCARB2 & 121.0 & 0.27 & 57.4 & -0.90 & ETV6 & 168.2 & 0.87 & 97.4 & -0.07 \\
\hline PPM1K & 122.1 & 0.29 & 63.1 & -0.78 & LY6E & 168.4 & 0.87 & 66.6 & -0.71 \\
\hline MAP3K5 & 122.7 & 0.29 & 5.3 & -1.98 & TFEC & 170.4 & 0.89 & 98.1 & -0.05 \\
\hline CRP & 124.0 & 0.31 & 98.4 & -0.04 & SLFN5 & 170.5 & 0.89 & 64.6 & -0.75 \\
\hline IRF2 & 124.9 & 0.32 & 59.8 & -0.85 & LAP3 & 172.5 & 0.92 & 110.1 & 0.20 \\
\hline RGL-1 & 125.8 & 0.33 & 153.1 & 1.09 & NRN1 & 172.7 & 0.92 & 91.3 & -0.19 \\
\hline GMPR & 126.4 & 0.34 & 93.6 & -0.14 & ZNF107 & 174.4 & 0.94 & 86.4 & -0.29 \\
\hline CCL4 & 127.4 & 0.35 & 72.7 & -0.58 & PDK1 & 174.5 & 0.94 & 94.9 & -0.12 \\
\hline
\end{tabular}


bioRxiv preprint doi: https://doi.org/10.1101/2021.05.23.445113; this version posted May 24, 2021. The copyright holder for this preprint (which was not certified by peer review) is the author/funder, who has granted bioRxiv a license to display the preprint in perpetuity. It is made

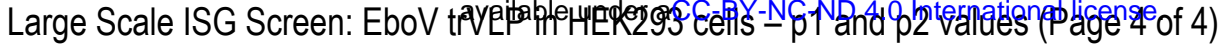

\begin{tabular}{|c|c|c|c|c|c|c|c|c|c|}
\hline Gene & $\begin{array}{c}\text { P2 } \\
\text { Replication } \\
\text { (\% control) }\end{array}$ & $\begin{array}{c}\text { Z } \\
\text { score }\end{array}$ & $\begin{array}{c}\text { P1 } \\
\text { Replication } \\
\text { (\% control) }\end{array}$ & $\begin{array}{c}\text { Z } \\
\text { score }\end{array}$ & Gene & $\begin{array}{c}\text { P2 } \\
\text { Replication } \\
\text { (\% control) }\end{array}$ & $\begin{array}{c}\text { Z } \\
\text { score }\end{array}$ & $\begin{array}{c}\text { P1 } \\
\text { Replication } \\
\text { ( } \% \text { control) }\end{array}$ & $\begin{array}{c}\mathbf{Z} \\
\text { score }\end{array}$ \\
\hline LGALS9 & 175.7 & 0.96 & 166.6 & 1.37 & LRG1 & 246.4 & 1.85 & 132.9 & 0.67 \\
\hline IL6ST & 176.3 & 0.97 & 106.9 & 0.13 & TLR7 & 248.7 & 1.88 & 63.9 & -0.76 \\
\hline RASGEF1B & 179.1 & 1.00 & 72.8 & -0.58 & ADAR & 250.4 & 1.90 & 180.5 & 1.66 \\
\hline RASSF4 & 183.0 & 1.05 & 118.3 & 0.37 & TNFSF10 & 255.5 & 1.96 & 99.2 & -0.03 \\
\hline DTX3L & 188.2 & 1.12 & 110.6 & 0.21 & CD80 & 262.4 & 2.05 & 63.1 & -0.78 \\
\hline CCR1 & 189.7 & 1.13 & 70.7 & -0.62 & ARG2 & 269.5 & 2.14 & 132.9 & 0.67 \\
\hline CREB3L3 & 192.2 & 1.17 & 152.9 & 1.09 & TRIM34 & 271.6 & 2.16 & 103.1 & 0.05 \\
\hline LOC400759 & 193.2 & 1.18 & 85.1 & -0.32 & HPSE & 273.0 & 2.18 & 109.3 & 0.18 \\
\hline IL15 & 193.6 & 1.18 & 55.3 & -0.94 & ZC3HAV1 & 273.6 & 2.19 & 70.7 & -0.62 \\
\hline NUP50 & 196.4 & 1.22 & 87.3 & -0.27 & PML & 277.0 & 2.23 & 267.3 & 3.46 \\
\hline IGFBP2 & 197.3 & 1.23 & 141.9 & 0.86 & PI4K2B & 278.1 & 2.24 & 99.9 & -0.01 \\
\hline GJA4 & 198.1 & 1.24 & 104.7 & 0.09 & MASTL & 280.4 & 2.27 & 161.7 & 1.27 \\
\hline HLA-G & 198.5 & 1.25 & 82.1 & -0.38 & FLJ23556 & 291.6 & 2.41 & 99.0 & -0.03 \\
\hline FUT4 & 199.1 & 1.25 & 234.5 & 2.78 & PAK3 & 295.7 & 2.46 & 59.2 & -0.86 \\
\hline PNRC1 & 200.1 & 1.27 & 80.6 & -0.41 & TNFSF13B & 306.0 & 2.59 & 90.3 & -0.21 \\
\hline LAMP3 & 206.0 & 1.34 & 143.4 & 0.89 & ULK4 & 312.9 & 2.68 & 90.2 & -0.21 \\
\hline EHD4 & 206.6 & 1.35 & 77.7 & -0.47 & MSR1 & 317.5 & 2.74 & 124.4 & 0.50 \\
\hline SIGLEC1 & 206.9 & 1.35 & 177.7 & 1.60 & TNFAIP6 & 323.0 & 2.81 & 127.8 & 0.57 \\
\hline C6orf150 & 213.1 & 1.43 & 142.6 & 0.87 & MAX & 331.3 & 2.91 & 146.1 & 0.95 \\
\hline FAM134B & 217.7 & 1.49 & 94.5 & -0.12 & KIAA0040 & 345.5 & 3.09 & 121.8 & 0.44 \\
\hline PLSCR1 & 221.2 & 1.53 & 63.1 & -0.78 & OAS3 & 371.0 & 3.41 & 148.0 & 0.99 \\
\hline GBP4 & 223.4 & 1.56 & 92.3 & -0.17 & IFIT2 & 406.4 & 3.85 & 103.0 & 0.05 \\
\hline ADM & 223.6 & 1.56 & 124.9 & 0.51 & AHNAK2 & 408.6 & 3.88 & 125.6 & 0.52 \\
\hline VEGFC & 224.7 & 1.57 & 134.0 & 0.69 & TRIM5 & 410.9 & 3.91 & 80.4 & -0.42 \\
\hline ETV7 & 225.2 & 1.58 & 80.0 & -0.43 & OAS2 & 433.0 & 4.19 & 104.0 & 0.07 \\
\hline AMPH & 228.5 & 1.62 & 190.9 & 1.88 & CD9 & 491.6 & 4.92 & 188.2 & 1.82 \\
\hline IL15RA & 229.8 & 1.64 & 135.0 & 0.72 & & & & & \\
\hline
\end{tabular}


bioRxiv preprint doi: https://doi.org/10.1101/2021.05.23.445113; this version posted May 24, 2021. The copyright holder for this preprint (which was not certified by peer review) is the author/funder, who has granted bioRxiv a license to display the preprint in perpetuity. It is made available under aCC-BY-NC-ND 4.0 International license.

\begin{tabular}{|l|l|}
\hline \multicolumn{2}{|l|}{ Table S2 - CRISPR Guides } \\
\hline LacZ Guide & 5'- CGA TTA AGT TGG GTA ACG CC -3' \\
\hline TRIM25 CRISPR Guide & 5'- GAG CCG GTC ACC ACT CCG TG -3' \\
\hline ZAP CRISPR Guide & 5'- ACT TCC ATC TGC CTT ACC GG -3' \\
\hline RIG-I CRISPR Guide & 5'- GGG TCT TCC GGA TAT AAT CC -3' \\
\hline MAVS CRISPR Guide & 5'- ATT GCG GCA GAT ATA CTT AT -3' \\
\hline $\begin{array}{l}\text { MAVS \& miniMAVS } \\
\text { CRISPR Guide 7 }\end{array}$ & 5'- TCT GGG GCT GAG CGT CTG CA -3' \\
\hline TBK1 CRISPR Guide & 5'- AGA GCA CTT CTA ATC ATC TG -3' \\
\hline NPC1 CRISPR Guides & $\begin{array}{l}\text { 5'- GCT CAC AAA ACA GGT TCA GT -3', } \\
\text { 5'- ACA GTC GTC TTG CTG TCG AG -3' }\end{array}$ \\
\hline KHNYN CRISPR Guides & 5'-GGG GGT GAG CGT CCT TCC GA-3' \\
\hline
\end{tabular}

2

\begin{tabular}{|l|l|}
\hline Table S3 - Primers used for cloning \\
\hline EcoRI_Kz_TRIM25wt_Fwd & GCGCGAATTCGCCACCATGGCAGAGCTGTGCCCCCTGG \\
\hline TRIM25_BRING_FwdEcoRI & GCGCGAATTCGCCACCATGCGCGCCGTCTACCAGGCGCGACCGC \\
\hline TRIM25_SPRY_Rev Xhol & CGCGCGCTCGAGAATTTTAATGTAATACTCCAGGAGCTC \\
\hline TRIM25wt_Rev_Xhol & CGCGCGCTCGAGCTACTTGGGGGAGCAGATGG \\
\hline TRIM25wt_CR_Fwd & GAGCCGGTGACAACACCTTGCGGCCACAA \\
\hline TRIM25wt_CR_Rev & TTGTGGCCGCAAGGTGTTGTCACCGGCTC \\
\hline TRIM25_CR_L7A_Fwd & GCGCGAATTCGCCACCATGGCAGAGCTGTGCCCCGCGGCCGAGGAGCT \\
\hline TRIM25_CR_L17/18R_Fwd & GCTGTCGTGCTCCATCTGCCGGCGACCCTTCAAGGAGCCGGTC \\
\hline TRIM25_CR_L17/18R_Rev & GACCGGCTCCTTGAAGGGTCGCCGGCAGATGGAGCACGACAGC \\
\hline TRIM25_CR_Q52R_Fwd & CGCCATACCTGTGCCCGCGATGCCGCGCCGTCTACCAGG \\
\hline TRIM25_CR_Q52R_Rev & CCTGGTAGACGGCGCGGCATCGCGGGCACAGGTATGGCG \\
\hline TRIM25_CR_R54A_Fwd & CCATACCTGTGCCCGCAGTGCGCGGCCGTCTACCAGGCGCG \\
\hline TRIM25_CR_R54A_Rev & CGCGCCTGGTAGACGGCCGCGCACTGCGGGCACAGGTATGG \\
\hline TRIM25_CR_K65A_Fwd & GGCGCGACCGCAGCTGCACGCGAACACGGTGCTGTGCAACG \\
\hline TRIM25_CR_K65A_Rev & CGTTGCACAGCACCGTGTTCGCGTGCAGCTGCGGTCGCGCC \\
\hline TRIM25_CR_N66A_Fwd & CCGCAGCTGCACAAGGCCACGGTGCTGTGCAAC \\
\hline TRIM25_CR_N66A_Rev & GTTGCACAGCACCGTGGCCTTGTGCAGCTGCGG \\
\hline TRIM25_CR_V68A_Fwd & AGCTGCACAAGAACACGGCGCTGTGCAACGTGGTGG \\
\hline TRIM25_CR_V68A_Rev & CCACCACGTTGCACAGCGCCGTGTTCTTGTGCAGCT \\
\hline TRIM25_CR_L69A_Fwd & CTGCACAAGAACACGGTGGCGTGCAACGTGGTGGAGC \\
\hline TRIM25_CR_L69A_Rev & GCTCCACCACGTTGCACGCCACCGTGTTCTTGTGCAG \\
\hline TRIM25_CR_N71D_Fwd & AACACGGTGCTGTGCGACGTGGTGGAGCAGTTCCTG \\
\hline TRIM25_CR_N71D_Rev & CAGGAACTGCTCCACCACGTCGCACAGCACCGTGTT \\
\hline TRIM25_CR_V72A_Fwd & ACGGTGCTGTGCAACGCGGTGGAGCAGTTCCTGCA \\
\hline TRIM25_CR_V72A_Rev & TGCAGGAACTGCTCCACCGCGTTGCACAGCACCGT \\
\hline TRIM25_CR_K117R_Fwd & GAGGCCGCCGTGAGGACGTGCTTGGTGTGC \\
\hline TRIM25_CR_K117R_Rev & GCACACCAAGCACGTCCTCACGGCGGCCTC \\
\hline TRIM25_CR_Y245A_Fwd & GTGGAGCAGCTACAACAAGAAGCCACGGAAATGAAGGCTCTCT \\
\hline TRIM25_CR_Y245A_Rev & AGAGAGCCTTCATTTCCGTGGCTTCTTGTTGTAGCTGCTCCAC \\
\hline TRIM25_CR_Y252A_Fwd & ACGGAAATGAAGGCTCTCGCGGACGCCTCAGAGACCAC \\
\hline TRIM25_CR_Y252A_Rev & GTGGTCTCTGAGGCGTCCGCGAGAGCCTTCATTTCCGT \\
\hline TRIM25_CR_RHK_AAAFwd & CGACCTGGAGGCCACCCTGGCCGCAGCCCTAACTGTCATGTACAGTCAGATC \\
\hline TRIM25_CR_RHK_AAA Rev & GATCTGACTGTACATGACAGTTAGGGCTGCGGCCAGGGTGGCCTCCAGGTCG \\
\hline
\end{tabular}


bioRxiv preprint doi: https://doi.org/10.1101/2021.05.23.445113; this version posted May 24, 2021. The copyright holder for this preprint (which was not certified by peer review) is the author/funder, who has granted bioRxiv a license to display the preprint in perpetuity. It is made

\begin{tabular}{|c|c|}
\hline TRIM25_CR_ARBD_Fwd & 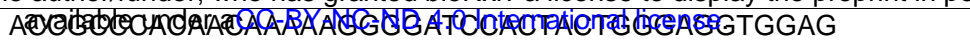 \\
\hline TRIM25_CR_ARBD_Fwd & GTAGTGGATCCCCTTTTTGTTGTGGGCGGTGTTGTAGTCCAG \\
\hline TRIM25_CR_7KA_Fwd 1 & CGCAGAGGAAGCGGCATCCGCGGCACCTCCCCCTGTCCCTGCCTTA \\
\hline TRIM25_CR_7KA_Fwd 2 & ACACGCCCTGTGGCGGCGGTCTCCGCAGAGGAAGCGGCATCC \\
\hline TRIM25_CR_7KA_Rev 1 & TGCCGCTTCCTCTGCGGAGACCGCCGCCACAGGGCGTGTGGATTTGTG \\
\hline TRIM25_CR_7KA_Rev 2 & AGGGACAGGGGGAGGTGCCGCGGATGCCGCTTCCTCTGCGGAG \\
\hline MAVS Not I Fwd & AAGCGCGGCCGCGCAGCAATGCCGTTTGCTGAAGACAAG \\
\hline MAVS CR Fwd & ATTCAGAGCAAGCACTGCAGACGCTCAGCC \\
\hline MAVS CR Rev & GGCTGAGCGTCTGCAGTGCTTGCTCTGAAT \\
\hline MAVS M1A Notl Fwd & AGGCGCGGCCGCGCAGCAGCGCCGTTTGCTGAAGACAAG \\
\hline MAVS M142A Fwd & AGGAGCCAAGTTACCCCGCGCCTGTCCAGGAGACCCAG \\
\hline MAVS M142A Rev & CTGGGTCTCCTGGACAGGCGCGGGGTAACTTGGCTCCT \\
\hline MAVS Rev Xhol & TGCTCTCGAGCTAGTGCAGACGCCGCC \\
\hline Xhol_TIM1_Fwd & AGACCTCGAGATCCCATAATGCATCTTCAAGTGGTCATCTTAAGC \\
\hline TIM1_Rev_Notl & ATGCGCGGCCGCTCATGGGCGTAAACTCTCAAAGAGCAC \\
\hline EcoRI_NPC1_Fwd & GAATTCGCCACCATGACCGCTCGCGGCCTGGCCC \\
\hline NPC1_Rev_Xhol & CGCGCTCGAGGGGGGCCTCCACATCCCGGCAGGC \\
\hline P4 cis vRNA Blpl F & GACCCGTTTAGAGGCCCCAA \\
\hline P4 cis low CpG TRAIL F & GGGTGCTGAAGAATGAGCAGTAAATTACCGTGCATAGTATCCTGATACTT \\
\hline P4 cis low CpG TRAIL R & AAGTATCAGGATACTATGCACGGTAATTTACTGCTCATTCTTCAGCACCC \\
\hline P4 cis vRNA Xmal R & TCGATCCCGGGTTAATACGACTCA \\
\hline
\end{tabular}

4

\section{Table S4 - Primers and probes used for cDNA synthesis and RT-qPCR}

\begin{tabular}{|l|l|}
\hline Trailer qPCR_F & 5'- CCA AAA CAC TAT TCC ATC TGA CAG GA -3' \\
\hline Trailer qPCR_R & 5'- TGC CGC AAT GAA TTT AAC GC -3' \\
\hline Trailer qPCR probe & 5'- ATG AGC CCA GAC CTT TCG TT -3' \\
\hline VP40 qPCR_F & 5'- AGT TGG ACT GGC GGA AGA AC -3' \\
\hline VP40 qPCR_R & 5'- CAG AGT CAA TCG GCT GGG TC -3' \\
\hline VP40 qPCR probe & 5'- AAG CCT GGT TTC CAA TTC GC -3' \\
\hline GAPDH Taqman Assay & Applied Biosystems (Cat\# Hs99999905_m1) \\
\hline OligodT & 5'- TTT TTT TTT TTT TTT T -3' \\
\hline L-Pol RNA qPCR F & 5'- CCT ACG AAC AAT GTC CGC -3' \\
\hline L-Pol RNA qPCR R & 5'- CTG CGG AAG GAC ATT TTG -3' \\
\hline L-Pol qPCR probe & 5'- TTG TTA GTG CAT GGC CGA AC -3' \\
\hline EBOV -vRNA RT & 5' CCT CTC TCC CTG CGT GAT AAT C -3' \\
\hline EBOV +CRNA RT & 5'- GCC TTC TGA TGA GCG TGG TC -3' \\
\hline
\end{tabular}

